\title{
Modelling the impacts of ammonia emissions reductions on North American air quality
}

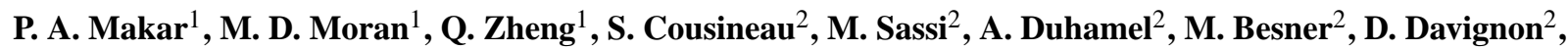 \\ L.-P. Crevier ${ }^{2}$, and V. S. Bouchet ${ }^{2}$ \\ ${ }^{1}$ Air Quality Research Division, Science and Technology Branch, Environment Canada, Toronto, Ontario, Canada \\ ${ }^{2}$ Air Quality Model Applications Section, Meteorological Service of Canada, Environment Canada, Montreal, \\ Quebec, Canada
}

Received: 19 December 2008 - Published in Atmos. Chem. Phys. Discuss.: 2 March 2009

Revised: 22 June 2009 - Accepted: 31 July 2009 - Published: 29 September 2009

\begin{abstract}
A unified regional air-quality modelling system (AURAMS) was used to investigate the effects of reductions in ammonia emissions on regional air quality, with a focus on particulate-matter formation. Three simulations of one-year duration were performed for a North American domain: (1) a base-case simulation using 2002 Canadian and US national emissions inventories augmented by a more detailed Canadian emissions inventory for agricultural ammonia; (2) a 30\% North-American-wide reduction in agricultural ammonia emissions; and (3) a 50\% reduction in Canadian beef-cattle ammonia emissions. The simulations show that a $30 \%$ continent-wide reduction in agricultural ammonia emissions lead to reductions in median hourly $\mathrm{PM}_{2.5}$ mass of $<1 \mu \mathrm{g} \mathrm{m}^{-3}$ on an annual basis. The atmospheric response to these emission reductions displays marked seasonal variations, and on even shorter time scales, the impacts of the emissions reductions are highly episodic: 95th-percentile hourly $\mathrm{PM}_{2.5}$ mass decreases can be up to a factor of six larger than the median values.

A key finding of the modelling work is the linkage between gas and aqueous chemistry and transport; reductions in ammonia emissions affect gaseous ammonia concentrations close to the emissions site, but substantial impacts on particulate matter and atmospheric deposition often occur at considerable distances downwind, with particle nitrate being the main vector of ammonia/um transport. Ammonia emissions reductions therefore have trans-boundary consequences downwind. Calculations of critical-load exceedances for sensitive ecosystems in Canada suggest that ammonia emission reductions will have a minimal impact on
\end{abstract}

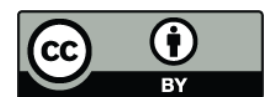

Correspondence to: P. A. Makar (paul.makar@ec.gc.ca) current ecosystem acidification within Canada, but may have a substantial impact on future ecosystem acidification. The $50 \%$ Canadian beef-cattle ammonia emissions reduction scenario was used to examine model sensitivity to uncertainties in the new Canadian agricultural ammonia emissions inventory, and the simulation results suggest that further work is needed to improve the emissions inventory for this particular sector. It should be noted that the model in its current form neglects coarse mode base cation chemistry, so the predicted effects of ammonia emissions reductions shown here should be considered upper limits.

\section{Introduction}

The chemistry describing the interactions of atmospheric ammonia $\left(\mathrm{NH}_{3}\right)$ with other atmospheric constituents has been well established through field and laboratory studies. While very high concentrations of ammonia gas are known to have health impacts (e.g., Stilg, 1994), its role in the creation of airborne particulate matter (PM) at lower concentrations is of interest due to the known effects of fine particulate matter on human health (cf. Schwarze et al., 2006).

The creation of airborne PM from ammonia is dependant on the presence of other precursor gases, primarily directlyemitted sulphur dioxide and nitrogen oxides $\left(\mathrm{SO}_{2}\right.$ and $\mathrm{NO}_{\mathrm{x}}$; Seinfeld and Pandis, 1998). $\mathrm{SO}_{2}$ may oxidize via gas-phase (Stockwell and Calvert, 1983) and/or aqueous-phase (Coste and Courtier, 1936; Junge and Ryan, 1958; Hermann et al., 2000, 2005) reactions, creating sulphuric acid gas or sulphuric acid ions in cloud or rain water, respectively. The vapour pressure of sulphuric acid gas is sufficiently low that almost all of the gas created will partition to the particle phase, either through condensation on existing particles or

Published by Copernicus Publications on behalf of the European Geosciences Union. 
nucleation of new particles. Sulphuric acid created in cloud and/or rainwater may be transferred to the particle phase upon droplet evaporation.

Ammonia affects aqueous-phase chemistry through the provision of a weak base; the hydrogen ion concentration will be inversely proportional to the ammonia partial pressure. Reductions in the hydrogen ion concentration due to excess ammonia will allow a greater aqueous uptake of $\mathrm{SO}_{2}$ in cloud water in the form of the bisulphite ion $\left(\mathrm{HSO}_{3}^{-}\right)$. The latter may be oxidized by hydrogen peroxide, ozone, organic peroxides, or catalytic oxygen reactions to bisulphate and sulphate ions, the ionic equilibrium products of sulphuric acid dissociation (Hermann et al., 2000, 2005). $\mathrm{H}_{2} \mathrm{O}_{2}$ is believed to be the dominant aqueous-phase oxidant of $\mathrm{HSO}_{3}^{-}$, but the strongly $\mathrm{pH}$-dependent oxidation by $\mathrm{O}_{3}$ becomes more important as $\mathrm{pH}$ increases or when $\mathrm{H}_{2} \mathrm{O}_{2}$ has been depleted (e.g., Fung et al., 1991). The relative contribution of these two oxidants to aqueous-phase sulphate formation is therefore influenced by $\mathrm{NH}_{3}$ levels. An additional process of importance for ammonia chemistry is the formation of gaseous nitric acid $\left(\mathrm{HNO}_{3}\right)$ through well-known " $\mathrm{NO}_{\mathrm{x}}$ termination" reactions (Seinfeld and Pandis, 1998); $\mathrm{HNO}_{3}$ may in turn participate in aqueous reactions with the ammonium ion, or in particle-phase chemistry.

Laboratory studies and related thermodynamics of highconcentration particle ammonium chemistry are well established (cf. D'Ans, 1913), and observations of ammonium, sulphate, and nitrate in PM have appeared in the literature over the past sixty years (cf. Robbins and Cadle, 1958; Fenn et al., 1963; Spurny and Heard, 1969; Heard and Wiffen, 1969; Gordon and Bryan, 1973; Anlauf et al., 1978; Brosset, 1978; Stelson et al., 1979; Tanner, 1983). The partitioning between different phases, including gases, may be predicted using fundamental thermodynamics theory (cf. Kusik and Meissner, 1978) in box models (e.g., Ansari and Pandis, 1999; Makar et al., 2003) or regional models such as AURAMS (Gong et al., 2006).

The concept of ammonia limitation has been used in the past (Blanchard et al., 1999), in order to better understand the aqueous and particulate chemistry of ammonia. By analogy to the $\mathrm{NO}_{\mathrm{x}}$ - and VOC-limit concept for ozone formation, which refer to environments in which changes in $\mathrm{NO}_{\mathrm{x}}$ or VOC emissions respectively have the greatest impact on changes in the ozone concentration, ammonia limitation refers to the thermodynamic conditions (a chemical regime) in which changes to ammonia emissions have a significant impact on particle mass. Specifically, an ammonialimited regime is one in which the total available ammonia (gaseous ammonia + aerosol phase ammonium) is insufficient to charge-balance difference the remaining other anions and cations (cf. Blanchard et al., 1999), with the result that small perturbations in the ammonia emissions may have a significant effect on particle mass. Ammonia-limited regimes are thus those in which:

$$
\begin{aligned}
& {\left[\mathrm{NH}_{3}(\mathrm{~g})\right]+\left[\mathrm{NH}_{4}^{+}(\mathrm{aq})\right]<\left\{2\left[\mathrm{Ca}^{2+}\right]+2\left[\mathrm{Mg}^{2+}\right]+\left[\mathrm{Na}^{+}\right]+\left[\mathrm{K}^{+}\right]\right.} \\
& \left.-2\left[\mathrm{SO}_{4}^{2-}(\mathrm{aq})\right]-\left[\mathrm{NO}_{3}^{-}(\mathrm{aq})\right]-\left[\mathrm{HNO}_{3}(\mathrm{~g})\right]-[\mathrm{HCl}(\mathrm{g})]-\left[\mathrm{Cl}^{-}(\mathrm{aq})\right]\right\}
\end{aligned}
$$

The above equation is appropriate for bulk chemistry in which all species are in a common mixture. The ionic species in the above equation refer to all forms of the species in particles and cloud water. In the ambient atmosphere, the situation is complicated by the size segregation of some of the cations and anions into different particle size modes in the overall particle size distribution. Calcium, magnesium, sodium and potassium base cations all typically have the greatest portion of their mass in the coarse mode (particle sizes greater than $2.5 \mu \mathrm{m}$ aerodynamic diameter), since their dominant sources are in soil dust, and sea- or road-salt. Most the sulphate mass is produced from sulphur dioxide oxidation by cloud water aqueous-phase reactions or gas-phase hydroxyl radical reaction, both of which create sulphuric acid. This, in turn forms particle sulphate with a mass peak in smaller particles (less than $2.5 \mu \mathrm{m}$ diameter) due to nucleation, condensation and cloud evaporation processes favouring the smaller sizes.

Equation (1) suggests that total ammonia will have little effect on particle formation if large amounts of calcium, magnesium, sodium or potassium are present. The size segregation of sulphate from these cations, however, suggests that a two equation definition would more closely describe the impact of ammonia in the ambient atmosphere:

$\left[\mathrm{NH}_{3}(\mathrm{~g})\right]+\left[\mathrm{NH}_{4}^{+}(\mathrm{aq})\right]<2\left[\mathrm{SO}_{4}^{2-}(\mathrm{aq})\right]$, and

$$
\begin{aligned}
& {\left[\mathrm{NH}_{3}(\mathrm{~g})\right]+\left[\mathrm{NH}_{4}^{+}(\mathrm{aq})\right]-2\left[\mathrm{SO}_{4}^{2-}(\mathrm{aq})\right]<} \\
& \left\{\left[\mathrm{NO}_{3}^{-}(\mathrm{aq})\right]+\left[\mathrm{HNO}_{3}(\mathrm{~g})\right]+[\mathrm{HCl}(\mathrm{g})]+\left[\mathrm{Cl}^{-}(\mathrm{aq})\right]\right. \\
& \left.-2\left[\mathrm{Ca}^{2+}\right]-2\left[\mathrm{Mg}^{2+}\right]-\left[\mathrm{Na}^{+}\right]-\left[\mathrm{K}^{+}\right]\right\}
\end{aligned}
$$

Equation (2a) describes a strongly ammonia-limited chemical regime, in which small perturbations in the gaseous ammonia concentration will likely result in changes to $\mathrm{PM}_{2.5}$ mass, due to the size separation of sulphate from coarse mode cations. Equation (2b) describes a weakly ammonialimited chemical regime, in which the excess total ammonia subsequent to sulphate charge-balancing is still less than that required to charge balance the remaining ions of the system. The advantage of this two-level definition of ammonialimitation is that it captures the potential impact of ammonia on fine mode particle growth due to the presence of sulphate in the smaller particle sizes. Chemical regimes for which for which (2b) is false are ammonia-saturated; ammonia emissions reductions would thus be less effective in reducing $\mathrm{PM}_{2.5}$ mass for these environments.

Comprehensive Eulerian regional models are useful tools for studying the potential impacts of ammonia emissions on atmospheric particle formation and deposition to sensitive 
ecosystems. The first generation of these models were designed to predict the gas-phase concentrations of acidifying gases, ozone,, other reactive gases, and wet and dry deposition of atmospheric acidic species (e.g., Chang et al., 1987; Venkatram and Karamchandani, 1988). Later work extended these models to include size-distributed PM (Binkowski and Shankar, 1995). Further developments within the last decade included the introduction of more detailed inorganic and organic particulate chemistry, and the introduction of sizeresolved and speciated PM (e.g., Binkowski and Roselle, 2003; Gong et al., 2006). More recently, these models have begun to be used to investigate the role of ammonia and other nitrogen compounds in atmospheric chemistry and deposition (Mathur and Dennis, 2003; Ying and Kleeman, 2006; Phillips et al., 2006; Luo et al., 2007; Quan and Zhang, 2008; Wang et al., 2008). Environmental impacts have been assessed through the calculation of exceedances of aciddeposition critical loads (defined below) in order to estimate the impact of deposition on sensitive ecosystems (Fowler et al., 1998; Dentener et al., 2006; Spranger et al., 2008; Fenn et al., 2008; Moran et al., 2008).

Past research has suggested that ammonia emissions controls may be one means of reducing the levels of ambient PM in the atmosphere, with some caveats. Using a box model, Ansari and Pandis (1998) showed that reductions in ammonia emissions were the most effective means of reducing total PM, with the caveat that the remaining particulate mass became more acidic. West et al. (1999) used ambient air data from Eastern US monitoring sites as inputs for box modelling; they concluded that $\mathrm{SO}_{2}$ emission controls might have to be accompanied by $\mathrm{NO}_{\mathrm{x}}$ and $\mathrm{NH}_{3}$ emissions controls to ensure that the former would not result in an increase in PM mass due to an increase in particulate nitrate Pinder et al. (2007) calculated the relative costs of ammonia emissions reductions versus other strategies in conjunction with regional modelling, and suggested that these reductions would be particularly cost effective and effective in the winter. Pinder et al. (2008) noted significant sensitivity of PM to $\mathrm{NH}_{3}$ emission magnitude near $\mathrm{NH}_{3}$ emission sources in the midwestern USA, with significant nitrogen deposition near those sources in the winter.

Of the few modelling studies that have investigated the impact of $\mathrm{NH}_{3}$ emissions reductions on ambient PM levels in North America, the focus has been on the Eastern USA for short periods of time (Pinder et al., 2007; Tsimpidi et al., 2007), with considering seasonal and annual scenarios for the Eastern USA. (Pinder et al., 2008). In this paper, we describe the application of a comprehensive regional air-quality model for the entire North American continent, to predict the likely effects of reductions in North American emissions of agricultural ammonia on the mass and composition of atmospheric PM, and on the amount of acid deposition to sensitive ecosystems. Three one-year simulations, a 2002 base case and two hypothetical $\mathrm{NH}_{3}$ emission scenarios, have been run and analyzed. The next section describes the study method- ology. Section 3 summarizes a performance evaluation for the 2002 base case, and Sect. 4 and 5 analyze the results of the two emission scenarios. Conclusions and recommendations for further study are provided in Sect. 6 .

\section{Methodology}

\subsection{Modelling system description}

AURAMS (A Unified Regional Air-quality Modelling System) consists of three main components: (a) a prognostic meteorological model, GEM (Global Environmental Multiscale model: Côté et al., 1998); (b) an emissions processing system, SMOKE (Sparse Matrix Operator Kernel Emissions: Houyoux et al., 2000; CEP, 2003); and (c) an off-line regional chemical transport model, the AURAMS Chemical Transport Model (CTM: Gong et al., 2006).

The GEM meteorological model is an integrated weather forecasting and data assimilation system that was designed to meet Canada's operational needs for both short- and medium-range weather forecasts. For the 2002 simulation, GEM version 3.2.0 with physics version 4.2 was run on the variable-resolution global horizontal grid centred on North America.

Files of gridded hourly emission fields (including ammonia) for input by the AURAMS CTM were prepared using version 2.2 of the SMOKE emissions processing system for four major emissions streams: on-road mobile sources; area and offroad-mobile sources, minor point sources; and major point sources. Emitted (i.e., "primary") PM from these sources is speciated within the AURAMS CTM based on composite speciation profiles for each emissions stream, but ammonium is assumed to be emitted as primary PM.

The multi-pollutant, regional AURAMS CTM was developed as a tool to study the formation of ozone, PM, and acid deposition in a single "unified" framework. The PM size distribution in this study was represented using 12 size bins ranging from 0.01 to $41 \mu \mathrm{m}$ in Stokes diameter and nine chemical components: sulphate $\left(\mathrm{p}-\mathrm{SO}_{4}\right)$; nitrate (p$\mathrm{NO}_{3}$ ); ammonium (p- $\mathrm{NH}_{4}$ ); elemental carbon (EC); primary organic matter (POM); secondary organic matter (SOM); crustal material (CM); sea salt; and particle-bound water. PM is assumed to be internally mixed in each size bin. Process representations in version 1.3.1b of the AURAMS CTM include emissions from surface and from elevated sources, horizontal and vertical advection, vertical diffusion, gas-phase, aqueous-phase, and inorganic heterogeneous chemistry, secondary organic particle formation, dry and wet deposition, and particle nucleation, condensation, coagulation, sedimentation, and activation (Gong et al., 2006). Up to 157 model species (gases and speciated particle size bins) may be selected as model output, although summary measures such as $\mathrm{PM}_{2.5}$ bulk mass are compared to observations here. 
AURAMS inorganic particle components are reported as the mass of sulphate, nitrate, and ammonium within each particle bin size, but within the model, the inorganic heterogeneous chemistry module (Makar et al., 2003) performs equilibrium calculations to determine the relative amounts of mass of ammonium sulphate $\left(\left(\mathrm{NH}_{4}\right)_{2} \mathrm{SO}_{4}(\mathrm{~s})\right)$, ammonium bisulphate $\left(\mathrm{NH}_{4} \mathrm{HSO}_{4}(\mathrm{~s})\right)$, letovicite $\left(\left(\mathrm{NH}_{4}\right)_{3} \mathrm{H}\left(\mathrm{SO}_{4}\right)_{2}(\mathrm{~s})\right)$, ammonium nitrate $\left(\mathrm{NH}_{4} \mathrm{NO}_{3}(\mathrm{~s})\right)$, and the ammonium $\left(\mathrm{NH}_{4}^{+}(\mathrm{aq})\right)$, sulphate $\left(\mathrm{SO}_{4}^{2-}(\mathrm{aq})\right)$, bisulphate $\left(\mathrm{HSO}_{4}^{-}(\mathrm{aq})\right)$, and nitrate ions $\left(\mathrm{NO}_{3}^{-}(\mathrm{aq})\right)$. The reported sulphate mass (p$\mathrm{SO}_{4}$ ) is thus the sum of sulphate mass from all particle components containing sulphate, with similar sums for the nitrate and ammonium mass.

The representation of dry deposition of ammonia gas within AURAMS follows Zhang et al. (2002); deposition is parameterized as a weighted combination of the deposition properties of ozone and $\mathrm{SO}_{2}$. Dry deposition of $\mathrm{p}-\mathrm{NH}_{4}$ is a function of particle size (Zhang et al., 2001). It should be noted that AURAMS does not include the possible "codeposition" of $\mathrm{SO}_{2}(\mathrm{~g})$ and $\mathrm{NH}_{3}(\mathrm{~g})$. Some researchers have found evidence of enhanced deposition of both gases when both are present at the same site (e.g., Neirynck et al., 2005; Van Hove et al., 1989; Adema et al., 1986). Others have found no effect (Erisman et al., 1994a, b), and Sutton et al. (1994) found enhanced emissions of ammonia gas from natural surfaces when ambient $\mathrm{NH}_{3}$ is present. More observational work on co-deposition is needed before parameterizations for this process may be reliably included in airquality models.

The time-invariant, vertically-varying chemical lateral boundary conditions used in AURAMS CTM are taken from a variety of sources. Latitudinally-dependent $\mathrm{O}_{3}$ boundary conditions were taken from a monthly-varying climatology (Logan, 1998). CO boundary conditions were derived from vertical profiles in Wang et al. (1999), with a simple latitudinal dependence of concentration peaking at $45^{\circ} \mathrm{N}$, in rough accord with satellite observations. Speciated particulate boundary conditions (including $\mathrm{p}-\mathrm{NH}_{4}$ ) were based on data collected at an elevated site on Whistler Mountain on the Canadian west coast (MacDonald et al, 2006), with a similar simple latitude dependence assumed as for CO. Seasonally-varying profiles of the concentrations of other reactive gases (including $\mathrm{NH}_{3}$ ) were taken taken from a set of "clean" chemical boundary conditions from simulations of the ADOM regional acid-deposition model (Scire et al., 1986; Fung et al., 1991).

\subsection{Model domain, grid discretization, and simulation period}

The GEM horizontal grid consisted of $353 \times 415$ grid points on a rotated latitude-longitude map projection with grid spacing of approximately $24 \mathrm{~km}\left(0.22^{\circ}\right)$ on the $270 \times 353$ uniform regional "core" grid. In the vertical 28 hybrid-coordinate levels reached from the Earth's surface to $10 \mathrm{hPa}$, with layer

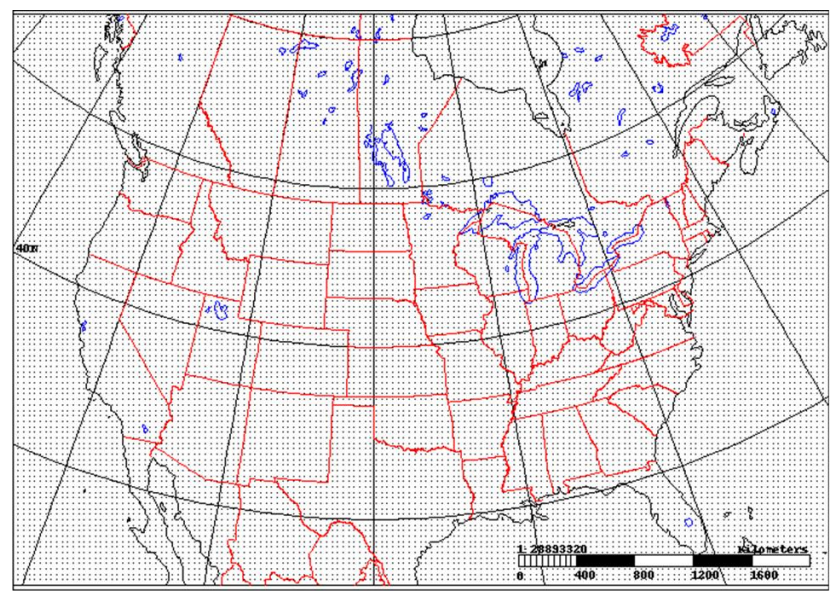

Fig. 1. AURAMS CTM North American 150×106 42-km domain.

thickness increasing monotonically with height. A time step of $450 \mathrm{~s}$ was used.

The uniform horizontal grid used for the AURAMS CTM was $150 \times 106$ in size and spanned the North American continent on a secant polar-stereographic projection true at $60^{\circ} \mathrm{N}$, with a horizontal grid spacing of $42 \mathrm{~km}$ (see Fig. 1). Twentyeight terrain-following vertical levels stretched telescopically from the Earth's surface to $29 \mathrm{~km}$, with the first three levels at $0,13.9$, and 55m AGL. An advective time step of $900 \mathrm{~s}$ was used, and AURAMS-predicted fields were output hourly. Both GEM and the AURAMS CTM were run for the 13month period from 1 December 2001 to 31 December 2002, where the first month was treated as a spin-up period for the AURAMS CTM. GEM was run from analyzed fields for 396 overlapping 30-hour segments starting $24 \mathrm{~h}$ apart, where the first six hours of each segment were treated as a "spin-up" period and were discarded. The remaining $24 \mathrm{~h}$ of consecutive simulations were then "stitched" together to create a complete set of meteorological fields with a 900 s timestep for input to the AURAMS CTM. The CTM itself was run in three segments, with a one-month spin-up for each segment, allowing an entire year's simulation to be run in parallel on multiple processors in order to reduce simulation "wall-clock" time.

\subsection{Description of emissions scenarios}

The hourly gridded anthropogenic emissions files for all of the emitted species required by AURAMS were generated using SMOKE v2.2 (http://www.smoke-model.org/ index.cfm) based on the 2002 Canadian (obtained from Environment Canada), 2002 US (obtained from US EPA), and 1999 Mexican (obtained from US EPA) national criteriaair-contaminant inventories. Biogenic emissions are calculated on-line in the AURAMS CTM using BEIS version 3.09 (Biogenic Emissions Inventory System;: CEP, 2003, and http://www.epa.gov/AMD/biogen.html). Biogenic emissions 

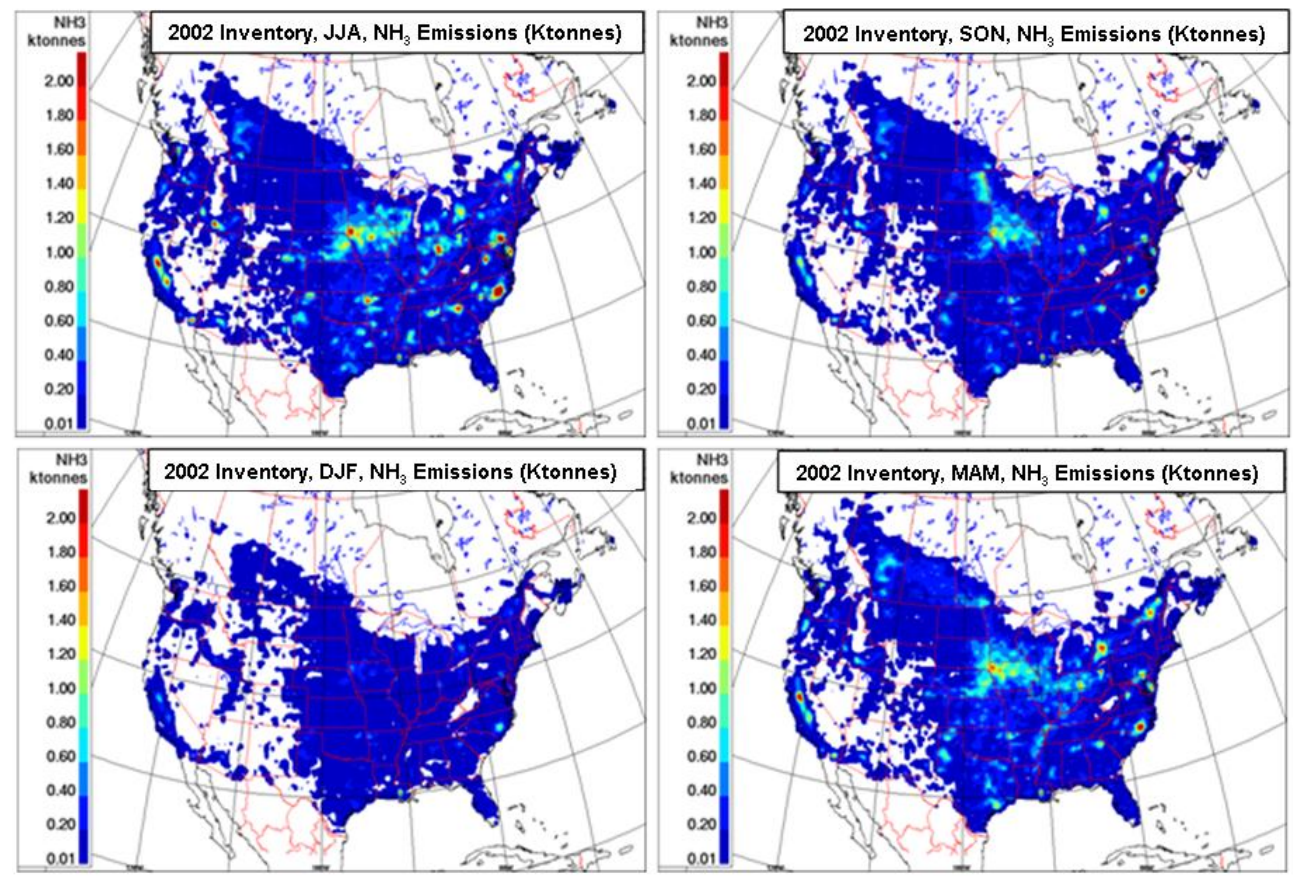

Fig. 2. Ammonia emissions (kilotonnes) in each season. upper left: June-July-August; upper right: September-October-November; lower left: December-January-February; lower right: March-April-May.

of ammonia are known to be very small compared to anthropogenic sources (Denman et al., 2007), and are not included in the current work. The following three 2002 annual emissions scenarios were considered:

(1) Base Case: Canadian 2002 ammonia emissions from the default national inventory were replaced with those resulting from a more detailed inventory constructed as part of the National Agri-Environmental Standards Initiative (NAESI), a multi-year study which included the collection of Canadaspecific emission factors and activity levels (Ayres et al., 2009; Bittman et al., 2008). The scenario using these combined emissions inventories will be referred to hereafter as the "Base Case". The spatial distribution of ammonia gas emissions for the base case on a seasonal basis are shown in Fig. 2. The 2002 Canadian and US agricultural source emissions are presented by source type and month in Tables 1 and 2 , respectively.

(2) $30 \%$ agricultural $\mathrm{NH}_{3}$ emissions reduction, Canada and US: The base case's agricultural emissions of $\mathrm{NH}_{3}$ (including emissions from animal husbandry and from fertilizer application) were reduced by a factor of $30 \%$ at all times and locations in both countries.

(3) $50 \%$ Canadian beef cattle $\mathrm{NH}_{3}$ emissions reduction: A $50 \%$ reduction in Canadian emissions from this single subsector was implemented in order to test model sensitivity to sub-sector-specific inventory uncertainty estimates of a factor of two.

\subsection{Metrics and diagnostic fields for scenario analysis}

The key species of interest in this study are the modelpredicted values of gaseous ammonia, $\mathrm{SO}_{2}$, and nitric acid, as well as the total $\mathrm{PM}_{2.5}$ mass and $\mathrm{PM}_{2.5}$ inorganic composition. Differences between base case and scenario (i.e., \{base case value - scenario value\}) for these species show the impacts of the change in emissions of $\mathrm{NH}_{3}$, with positive values indicating decreases in the mass or concentration arising from the reduction in $\mathrm{NH}_{3}$ emissions.

In order to explain the chemistry associated with the base case, and the chemical reasons for the changes associated with the emissions-reduction scenarios, four chemical metrics based on the ambient air concentrations of several species have been employed. The metrics and their interpretation are given in Table 3.

A number of diagnostic deposition fields were also calculated to help quantify the impacts of changes in $\mathrm{NH}_{3}$ emissions on atmospheric chemistry and deposition. The derived deposition fields include the total amount of sulphur deposited per season (sum of wet deposition and dry deposition of all species containing sulphur), the total amount of nitrate deposited, the total amount of ammonium deposited, and the total amount of nitrogen deposited. Subcomponents of these diagnostics will also be occasionally referenced (e.g., the amount of wet-deposited sulphate $+\mathrm{SO}_{2}$ as a fraction of the total sulphur deposition). 
Table 1. 2002 Canadian emissions of agricultural ammonia by source type (Ayres et al., 2009; Bittman et al., 2008), NAESI 2002 inventory (metric tonnes).

\begin{tabular}{|c|c|c|c|c|c|c|c|c|c|c|c|c|}
\hline Source & Jan & Feb & Mar & Apr & May & Jun & Jul & Aug & Sep & Oct & Nov & Dec \\
\hline Bulls & 1.3 & 1.3 & 1.4 & 2.2 & 6.5 & 4.2 & 4.2 & 5.4 & 6.1 & 4.1 & 1.5 & 1.3 \\
\hline Calves under 1 year & 350.7 & 347.6 & 364.5 & 709.5 & 2440.4 & 1477.2 & 1442.4 & 1808.2 & 2076.6 & 1347.2 & 407.3 & 350.7 \\
\hline Cows & 1482.5 & 1469.4 & 1998.7 & 3738.0 & 6724.4 & 3857.9 & 4259.7 & 4186.0 & 5588.0 & 4123.8 & 2164.4 & 1482.5 \\
\hline Heifers & 113.0 & 112.0 & 148.2 & 263.9 & 446.6 & 255.8 & 285.4 & 279.0 & 371.7 & 278.3 & 158.2 & 113.0 \\
\hline Broiler & 301.8 & 316.7 & 325.6 & 1094.8 & 1456.1 & 600.2 & 791.7 & 828.4 & 1064.5 & 992.8 & 291.7 & 291.2 \\
\hline Lay Hen & 369.1 & 366.7 & 380.0 & 1103.0 & 1460.5 & 670.6 & 789.6 & 894.5 & 1090.2 & 1106.9 & 408.2 & 360.1 \\
\hline Turkey & 121.3 & 126.6 & 134.7 & 447.3 & 563.9 & 264.7 & 346.5 & 433.2 & 467.8 & 424.5 & 130.8 & 108.5 \\
\hline Boars & 6.7 & 6.7 & 7.7 & 16.6 & 29.6 & 16.3 & 16.4 & 16.9 & 21.5 & 21.3 & 9.7 & 6.4 \\
\hline Growing pigs & 2681.6 & 2657.8 & 2905.3 & 4928.1 & 9442.0 & 5492.6 & 5489.3 & 5406.1 & 7023.3 & 6899.5 & 3574.6 & 2776.0 \\
\hline Nursery pigs & 521.6 & 517.0 & 584.0 & 1155.9 & 2825.9 & 1424.5 & 1429.8 & 1345.1 & 1913.5 & 1714.1 & 775.9 & 543.0 \\
\hline Sows & 220.1 & 218.2 & 253.0 & 560.2 & 1059.9 & 543.2 & 558.5 & 574.7 & 783.1 & 788.2 & 348.7 & 226.6 \\
\hline Cows & 1503.7 & 1490.4 & 1565.3 & 3678.9 & 14975.7 & 712151.3 & 310457.8 & 312162.7 & 715740.4 & 411334.6 & 61635.8 & 1503.7 \\
\hline Heifers & 364.3 & 361.1 & 373.4 & 628.0 & 2038.0 & 1718.2 & 1561.9 & 1801.4 & 2203.1 & 1689.7 & 382.7 & 364.3 \\
\hline Bulls & 244.5 & 242.3 & 250.0 & 392.4 & 1185.9 & 1017.8 & 946.7 & 1086.7 & 1320.4 & 1031.4 & 253.6 & 244.5 \\
\hline Calves under 1 year & 480.0 & 475.7 & 513.3 & 1440.0 & 6266.3 & 5011.9 & 4259.2 & 4783.2 & 6360.3 & 4543.1 & 533.0 & 480.0 \\
\hline Steers & 1054.6 & 1045.2 & 1074.3 & 1846.2 & 5006.7 & 4069.6 & 4066.6 & 4487.2 & 5252.7 & 4104.8 & 1132.4 & 1054.6 \\
\hline \multicolumn{13}{|c|}{ (2) } \\
\hline Alfalfa & 0.0 & 0.0 & 50.5 & 340.7 & 1023.2 & 178.4 & 96.5 & 140.1 & 59.3 & 63.5 & 24.3 & 0.0 \\
\hline Barley & 0.0 & 0.0 & 42.5 & 1096.0 & 13047.0 & 681.3 & 54.6 & 0.0 & 58.8 & 1451.6 & 41.0 & 0.0 \\
\hline Beans & 0.0 & 0.0 & 2.7 & 22.2 & 58.4 & 15.6 & 3.5 & 0.0 & 0.4 & 0.4 & 0.0 & 0.0 \\
\hline Buckwheat & 0.0 & 0.0 & 0.3 & 3.0 & 14.3 & 2.1 & 0.4 & 0.0 & 0.1 & 0.9 & 0.0 & 0.0 \\
\hline Canary Seed & 0.0 & 0.0 & 0.0 & 21.7 & 348.8 & 12.7 & 0.0 & 0.0 & 1.2 & 41.5 & 1.2 & 0.0 \\
\hline Canola & 0.0 & 0.0 & 6.2 & 821.4 & 12672.9 & 9485.4 & 7.9 & 0.0 & 58.6 & 1496.3 & 42.2 & 0.0 \\
\hline Carrot & 0.0 & 0.0 & 2.0 & 16.9 & 44.7 & 11.9 & 2.6 & 0.0 & 0.3 & 0.3 & 0.0 & 0.0 \\
\hline Chickpea & 0.0 & 0.0 & 0.0 & 24.2 & 394.2 & 14.1 & 0.0 & 0.0 & 0.5 & 47.0 & 1.3 & 0.0 \\
\hline Corn (grain) & 0.0 & 0.0 & 389.2 & 3214.0 & 8412.2 & 2258.5 & 500.3 & 0.0 & 58.2 & 46.3 & 1.3 & 0.0 \\
\hline Corn with ensilage & 0.0 & 0.0 & 56.0 & 470.5 & 1339.1 & 329.7 & 72.0 & 0.0 & 8.9 & 22.0 & 0.6 & 0.0 \\
\hline Dry field crop peas & 0.0 & 0.0 & 0.1 & 80.3 & 1297.5 & 47.0 & 0.1 & 0.0 & 5.5 & 154.5 & 4.4 & 0.0 \\
\hline Flaxseed & 0.0 & 0.0 & 0.1 & 102.7 & 1662.0 & 60.0 & 0.1 & 0.0 & 7.4 & 198.0 & 5.6 & 0.0 \\
\hline Forage & 0.0 & 0.0 & 4.4 & 559.3 & 891.2 & 134.1 & 8.4 & 141.0 & 59.0 & 87.5 & 61.5 & 0.0 \\
\hline Green Peas & 0.0 & 0.0 & 2.9 & 23.7 & 62.3 & 16.6 & 3.7 & 0.0 & 0.4 & 0.4 & 0.0 & 0.0 \\
\hline Pasture cultivated or sown & 0.0 & 0.0 & 30.3 & 1101.9 & 1973.8 & 308.1 & 57.9 & 266.3 & 121.5 & 177.1 & 115.2 & 0.0 \\
\hline Lentil & 0.0 & 0.0 & 0.0 & 33.7 & 548.8 & 19.7 & 0.0 & 0.0 & 1.7 & 65.5 & 1.8 & 0.0 \\
\hline Mustard Seed & 0.0 & 0.0 & 0.0 & 46.6 & 758.8 & 27.2 & 0.0 & 0.0 & 2.5 & 90.5 & 2.6 & 0.0 \\
\hline Mixed Grains & 0.0 & 0.0 & 14.8 & 144.2 & 679.2 & 98.7 & 19.0 & 0.0 & 3.8 & 44.6 & 1.3 & 0.0 \\
\hline Oats & 0.0 & 0.0 & 19.9 & 473.3 & 5850.2 & 402.4 & 52.4 & 7.1 & 26.7 & 653.7 & 18.4 & 0.0 \\
\hline Other Dry Beans & 0.0 & 0.0 & 2.7 & 29.8 & 181.2 & 20.1 & 3.5 & 0.0 & 1.0 & 15.0 & 0.4 & 0.0 \\
\hline Other Vegetables & 0.0 & 0.0 & 7.5 & 62.4 & 165.4 & 43.8 & 9.7 & 0.0 & 1.1 & 1.2 & 0.0 & 0.0 \\
\hline Other Hay and Fodder & 0.0 & 0.0 & 201.0 & 1179.7 & 3804.1 & 670.1 & 383.8 & 530.7 & 220.3 & 225.2 & 76.9 & 0.0 \\
\hline Potatoes & 0.0 & 0.0 & 36.6 & 325.0 & 1165.8 & 225.6 & 47.0 & 0.0 & 6.9 & 49.1 & 1.4 & 0.0 \\
\hline Fall Rye & 0.0 & 0.0 & 2.6 & 25.6 & 125.5 & 17.9 & 3.4 & 0.0 & 0.6 & 8.6 & 0.2 & 0.0 \\
\hline Spring Rye & 0.0 & 0.0 & 0.0 & 1.0 & 15.7 & 0.6 & 0.0 & 0.0 & 0.0 & 1.9 & 0.1 & 0.0 \\
\hline Soybeans & 0.0 & 0.0 & 45.4 & 373.4 & 962.0 & 262.5 & 58.3 & 0.0 & 6.7 & 3.2 & 0.1 & 0.0 \\
\hline Sugar Beets & 0.0 & 0.0 & 0.0 & 1.6 & 26.4 & 0.9 & 0.0 & 0.0 & 0.0 & 3.2 & 0.1 & 0.0 \\
\hline Sunflowers & 0.0 & 0.0 & 0.1 & 20.1 & 322.0 & 11.8 & 0.1 & 0.0 & 1.5 & 38.3 & 1.1 & 0.0 \\
\hline Sweet Corn & 0.0 & 0.0 & 7.3 & 60.9 & 163.1 & 42.8 & 9.4 & 0.0 & 1.1 & 1.4 & 0.0 & 0.0 \\
\hline Tobacco & 0.0 & 0.0 & 1.9 & 15.5 & 38.9 & 10.9 & 2.4 & 0.0 & 0.3 & 0.0 & 0.0 & 0.0 \\
\hline Tomato & 0.0 & 0.0 & 2.6 & 21.0 & 53.2 & 14.8 & 3.3 & 0.0 & 0.4 & 0.1 & 0.0 & 0.0 \\
\hline Triticale & 0.0 & 0.0 & 0.0 & 6.2 & 100.3 & 3.6 & 0.0 & 0.0 & 0.2 & 12.0 & 0.3 & 0.0 \\
\hline Natural Pastures & 0.0 & 0.0 & 10.0 & 1100.6 & 1767.3 & 266.6 & 19.0 & 207.4 & 106.2 & 172.6 & 120.7 & 0.0 \\
\hline White beans & 0.0 & 0.0 & 2.7 & 31.8 & 208.4 & 21.3 & 3.5 & 0.0 & 1.1 & 18.1 & 0.5 & 0.0 \\
\hline Durham Wheat & 0.0 & 0.0 & 0.0 & 315.4 & 5130.2 & 184.0 & 0.0 & 0.0 & 10.9 & 611.8 & 17.3 & 0.0 \\
\hline Spring Wheat & 0.0 & 0.0 & 21.2 & 1418.5 & 20987.8 & 8932.5 & 48.5 & 5.6 & 88.8 & 2454.5 & 69.2 & 0.0 \\
\hline Winter Wheat & 0.0 & 0.0 & 59.8 & 519.3 & 1710.3 & 361.8 & 76.8 & 0.0 & 8.7 & 57.0 & 1.6 & 0.0 \\
\hline
\end{tabular}


Table 2. 2002 USA agricultural emissions of ammonia by source type, metric tonnes (US EPA).

\begin{tabular}{|c|c|c|c|c|c|c|c|}
\hline Source & Jan & Feb & Mar & Apr & May & Jun & Jul \\
\hline Field burning, all crops & 347.5 & 599.2 & 559.1 & 114.7 & 256.2 & 191.5 & 28.0 \\
\hline Field burning, unspec. Crop & 8.8 & 8.8 & 12.2 & 12.2 & 12.2 & 14.2 & 14.2 \\
\hline Field burning, Alfalfa headfire & 5.1 & 5.1 & 7.1 & 7.1 & 7.1 & 8.2 & 8.2 \\
\hline Field burning, Alfalfa backfire & 0.2 & 0.2 & 0.2 & 0.2 & 0.2 & 0.3 & 0.3 \\
\hline Field burning,Barley & 0.1 & 0.1 & 0.1 & 0.1 & 0.1 & 0.2 & 0.2 \\
\hline Field burning, Red Bean & 7.4 & 7.4 & 10.2 & 10.2 & 10.2 & 11.8 & 11.8 \\
\hline Field burning, corn & 27.0 & 27.0 & 37.2 & 37.2 & 37.2 & 43.2 & 43.2 \\
\hline Field burning, Grasses & 628.1 & 628.1 & 866.3 & 866.3 & 866.3 & 1007.1 & 1007.1 \\
\hline Field burning, wild hay headfire & 27.8 & 27.8 & 38.3 & 38.3 & 38.3 & 44.5 & 44.5 \\
\hline Field burning, wild hay backfire & 2.0 & 2.0 & 2.8 & 2.8 & 2.8 & 3.2 & 3.2 \\
\hline Field burning, Oats headfire & 0.2 & 0.2 & 0.3 & 0.3 & 0.3 & 0.3 & 0.3 \\
\hline Field burning, Oats backfire & 0.0 & 0.0 & 0.0 & 0.0 & 0.0 & 0.1 & 0.1 \\
\hline Field burning, Pea Headfire & 0.0 & 0.0 & 0.1 & 0.1 & 0.1 & 0.1 & 0.1 \\
\hline Field burning, Rice & 8.0 & 8.0 & 11.0 & 11.0 & 11.0 & 12.8 & 12.8 \\
\hline Field burning, Sorghum & 1.6 & 1.6 & 2.2 & 2.2 & 2.2 & 2.6 & 2.6 \\
\hline Field burning, Sugar Cane & 100.1 & 100.1 & 138.1 & 138.1 & 138.1 & 160.5 & 160.5 \\
\hline Field burning, Wheat Headfire & 246.8 & 246.8 & 340.4 & 340.4 & 340.4 & 395.7 & 395.7 \\
\hline Field burning, Wheat Backfire & 17.1 & 17.1 & 23.6 & 23.6 & 23.6 & 27.4 & 27.4 \\
\hline Agricultural propaning, all crop & 0.2 & 0.2 & 0.3 & 0.3 & 0.3 & 0.4 & 0.4 \\
\hline Agricultural stack burning, a & 0.0 & 0.0 & 0.0 & 0.0 & 0.0 & 0.0 & 0.0 \\
\hline Fertilizer: Anhydrous Ammonia & 2274.3 & 4427.9 & 22246.0 & 025535.0 & 022590.2 & 222185.7 & 76127.4 \\
\hline Fertilizer: Aqueous Ammonia & 38.2 & 74.4 & 374.0 & 429.3 & 379.8 & 373.0 & 103.0 \\
\hline Fertilizer: Nitrogen solutions & 4040.7 & 7867.0 & 39524.3 & 345367.8 & 840135.7 & 739417.1 & 110886 \\
\hline Fertilizer: Urea & 7325.1 & 14261.7 & 771651.1 & 182244.5 & 572759.6 & 6714 & 919735.5 \\
\hline Fertilizer: Ammonium Nitrate & 213.4 & 415.4 & 2087.0 & 2395.6 & 2119.3 & 2081.4 & 574.9 \\
\hline Fertilizer: Ammonium Sulfate & 392.2 & 763.6 & 3836.3 & 4403.5 & 3895.6 & 3825.9 & 1056.7 \\
\hline Fertilizer: Ammonium Thiosulfate & 14.9 & 29.1 & 146.0 & 167.6 & 148.3 & 145.6 & 40.2 \\
\hline Fertilizer: Other Straight Nitrogen & 0.0 & 0.0 & 0.0 & 0.0 & 0.0 & 0.0 & 0.0 \\
\hline Fertilizer: Ammo & 0.0 & 0.0 & 0.0 & 0.0 & 0.0 & 0.0 & 0.0 \\
\hline Fertilizer: NPK multigrade fertilizer & 657.7 & 1280.6 & 6433.7 & 7384.9 & 6533.2 & 6416.3 & 1772.1 \\
\hline Fertilizer: Calcium ammonium nitrate & 16.0 & 31.2 & 156.7 & 179.9 & 159.2 & 156.3 & 43.2 \\
\hline Fertilizer: Potass & 3.2 & 6.3 & 31.7 & 36.4 & 32.2 & 31.6 & 8.7 \\
\hline Fertilizer: Diammonium Phosphate & 536.4 & 1044.4 & 5247.1 & 6022.8 & 5328.2 & 5232.8 & 1445.2 \\
\hline Fertilizer: Monoammonium Phosph & 183.0 & 356.4 & 1790.4 & 2055.0 & 1818.0 & 1785.5 & 493.1 \\
\hline Fertilizer: Liquid Ammoni & 119.3 & 232.2 & 1166.6 & 1339.1 & 1184.7 & 1163.4 & 321.3 \\
\hline Fertilizer: Miscellaneous & 388.4 & 756.1 & 3798.9 & 4360.5 & 3857.7 & 3788.6 & 1046.4 \\
\hline Agriculture: Livestock & 3077.3 & 5093.5 & 4365.9 & 8117.8 & 7443.2 & 10459.9 & 914681.7 \\
\hline Beef Cattle: feedlot, confinement & 4127.5 & 7495.3 & 6279.8 & 12547.0 & 011293.5 & 516332.6 & 623384.7 \\
\hline Beef Cattle: Feedlot, manure handling and storage & 1.6 & 2.9 & 2.5 & 4.9 & 4.4 & 6.4 & 9.2 \\
\hline Beef Cattle: feedlot, land application & 3403.6 & 6180.8 & 5178.5 & 10346.6 & 69313.0 & 13468.3 & 319283.7 \\
\hline Beef Cattle: Other & 21.6 & 39.2 & 32.8 & 65.6 & 59.0 & 85.4 & 122.2 \\
\hline Beef Cattle: pasture, confinement & 7972.8 & 14478.2 & 212130.4 & 424236.3 & 321815.1 & 131548.7 & 745171.0 \\
\hline Poultry: dry manure mar & 3190.1 & 5793.1 & 4853.7 & 9697.6 & 8728.8 & 12623.5 & 518074.1 \\
\hline Poultry: dry manure management, land applicatic & 73.8 & 134.0 & 112.3 & 224.3 & 201.9 & 292.0 & 418.1 \\
\hline Poultry: wet manure management, confinement & 177.5 & 322.4 & 270.1 & 539.7 & 485.8 & 702.6 & 1005.9 \\
\hline Poultry: wet manure mana & 481.7 & 874.8 & 732.9 & 1464.4 & 1318.1 & 1906.2 & 2729.3 \\
\hline Poultry: wet manure manageme & 81.0 & 147.1 & 123.2 & 246.2 & 221.6 & 320.5 & 458.9 \\
\hline Poultry: broilers, confinement & 4249.8 & 7717.4 & 6465.9 & 12918.8 & 811628.2 & 216816.5 & 524077.6 \\
\hline Poultry: broilers, manure handling & 771.5 & 1401.0 & 1173.8 & 2345.2 & 2110.9 & 3052.8 & 4371.0 \\
\hline Poultry: broilers, land applicati & 3473.2 & 6307.1 & 5284.3 & 10558.0 & 09503.3 & 13743.5 & 519677.8 \\
\hline Poultry: turkeys, confinement & 728.3 & 728.3 & 1607.3 & 1732.9 & 1883.5 & 3842.4 & 4344.7 \\
\hline Poultry: turkeys, & 131.0 & 131.0 & 289.1 & 311.7 & 338.8 & 691.2 & 781.5 \\
\hline Poultry: turke & 655.5 & 655.5 & 1446.7 & 1559.7 & 1695.4 & 3458.5 & 3910.6 \\
\hline Dairy cattle composite & 735.4 & 735.4 & 1623.1 & 1749.9 & 1902.0 & 3880.1 & 4387.3 \\
\hline Dairy cattle flush dairy, $c$ & 447.4 & 447.4 & 987.4 & 1064.6 & 1157.1 & 2360.5 & 2669.1 \\
\hline Dairy cattle fl & 1247.6 & 1247.6 & 2753.4 & 2968.5 & 3226.6 & 6582.3 & 7442.8 \\
\hline Dairy cattle flush dairy, land ap & 112.6 & 112.6 & 248.6 & 268.0 & 291.3 & 594.3 & 672.0 \\
\hline Cattle and calves: milk cows & 3806 & 691.2 & 5791 & 1157.0 & 1041.4 & 1506.1 & 2156.4 \\
\hline Cattle and calves: beef cows & 1003.5 & 1822.3 & 1526.8 & 3050.4 & 2745.7 & 3970.8 & 5685.3 \\
\hline Cattle and calves: heifer and heifer calv & 802.0 & 1456.4 & 1220.2 & 2438.0 & 2194.5 & 3173.6 & 4543.9 \\
\hline Cattle & 223 & 1674.8 & 1403.2 & 2803.6 & 2523.5 & 3649.4 & 5225.2 \\
\hline Dairy cattle scrape dairy, $c$ & 1084.3 & 1084.3 & 2392.9 & 2579.9 & 2804.2 & 5720.6 & 6468.4 \\
\hline Dairy & 1753.2 & 1753.2 & 3869.1 & 4171.3 & 4534.1 & 9249.5 & 10458.6 \\
\hline Dair & 064.1 & 2064.1 & 4555.3 & 4911.2 & 5338.3 & 10890.1 & 112313.6 \\
\hline Dairy cattle, deep pit dairy, confinement & 127.4 & 127.4 & 281.1 & 303.0 & 329.4 & 672.0 & 759.8 \\
\hline Dairy & 5.9 & 5.9 & 13.1 & 14.1 & 15.4 & 31.3 & 35.4 \\
\hline Dair & 724 & 72.4 & 159.8 & 172.3 & 187.3 & 38 & 432.1 \\
\hline Dairy cattle drylot $/ \mathrm{p}$ & 1011.7 & 1011.7 & 2232.8 & 2407.2 & 2616.5 & 5337.7 & 6035.5 \\
\hline Dairy & 21.0 & 21.0 & 46.4 & 50.0 & 54.4 & 110.9 & 125.4 \\
\hline Dairy & 1261.9 & 1261.9 & 2784.8 & 3002.4 & 3263.5 & 6657.4 & 7527.7 \\
\hline Swin production composite & 1943.5 & 3529.3 & 2957.0 & 5907.9 & 5317.7 & 7690.5 & 11011.1 \\
\hline Poultry waste & 1229.7 & 2233.0 & 1870.9 & 3738.0 & 3364.6 & 4865.8 & 6966.8 \\
\hline Poultry & 12 & 385 & 322 & 64.4 & 57.9 & 83.8 & 120.0 \\
\hline Poultry waste emissions, pullet and chicks $>=13$ weeks & 15.5 & 28.1 & 23.6 & 47.1 & 42.4 & 61.3 & 87.8 \\
\hline Poultry & 101.2 & 183.8 & 154.0 & 307.7 & 276.9 & 400.5 & 573.5 \\
\hline Poultry & 486 & 88 & 74.0 & 147.8 & 133.1 & 192.4 & 275.5 \\
\hline Poultry waste emissions, Ducks & 85.4 & 155.1 & 129.9 & 259.6 & 233.6 & 337.9 & 483.8 \\
\hline Poultry $\mathrm{v}$ & 4.9 & 8.9 & 7.5 & 14.9 & 13.4 & 19.4 & 27.8 \\
\hline Poultry & 40 & 619.1 & 518.7 & 1036.3 & 932.8 & 1349.0 & 1931.5 \\
\hline Horses and Ponies waste emissions & 1345.5 & 2443.3 & 2047.1 & 4090.1 & 3681.5 & 5324.1 & 7622.9 \\
\hline Swine production, lagoons, $\mathrm{c}$ & 1901.4 & 3452.8 & 2892.9 & 5779.9 & 5202.5 & 7523.8 & 10772. \\
\hline Swine production, lagoons, $\mathrm{m}$ & 3734.2 & 6781.1 & 5681.5 & 11351.5 & 510217. & 514776.5 & 521156 \\
\hline Swine production, lagoons, land application of manure & 308.7 & 560.6 & 469.7 & 938.4 & 844.6 & 1221.5 & 1748.9 \\
\hline Sheep and lambs waste emissions & 553.8 & 1005.7 & 842.6 & 1683.5 & 1515.3 & 2191.4 & 3137.6 \\
\hline Goats & 481.7 & 874.7 & 732.8 & 1464.2 & 1317.9 & 1906.0 & 2728.9 \\
\hline Goats waste emissions, Angora & 0.2 & 0.3 & 0.3 & 0.5 & 0.5 & 0.7 & 1.0 \\
\hline Goats waste emissions, Milk & 0.2 & 0.4 & 0.3 & 0.6 & 0.5 & 0.8 & 1.1 \\
\hline & & 4731.2 & & 7919.9 & 7128.7 & 10309.5 & 514760 \\
\hline Swine production, deep-pit, land application of manure & 1153.4 & 2094.6 & 1754.9 & 3506.3 & 3156.0 & 4564.2 & 6534.9 \\
\hline Swine production, outdoor, Confinement & 20.2 & 36.8 & 30.8 & 61.5 & 55.4 & 80.1 & 114.7 \\
\hline
\end{tabular}


Table 3. Metrics for chemical evaluation of model responses to $\mathrm{NH}_{3}$ emission changes.

\begin{tabular}{|c|c|c|}
\hline Metric & Formula & Significance \\
\hline Particle Neutralization Ratio & $\frac{\left(\mathrm{p}-\mathrm{NH}_{4}\right)}{2\left(\mathrm{p}-\mathrm{SO}_{4}\right)+\left(\mathrm{p}-\mathrm{NO}_{3}\right)}$ & $\begin{array}{l}\text { Ratio of total ammonium charge to the net sulphate and } \\
\text { nitrate charge (each particle species variable is the sum } \\
\text { over all particle sizes). Values of } 1 \text { indicate that the parti- } \\
\text { cles are } \mathrm{NH}_{3} \text {-saturated, so that significant } \mathrm{NH}_{3} \text { reductions } \\
\text { may be required to reduce particulate mass. Regions with } \\
\text { values less than unity are more } \mathrm{NH}_{3} \text { - limited; smaller re- } \\
\text { ductions in } \mathrm{NH}_{3} \text { may result in significant reductions in } \\
\text { particulate mass. }\end{array}$ \\
\hline $\begin{array}{l}\text { Total ammonia to sulphate } \\
\text { mole ratio }\end{array}$ & $\frac{\left(\mathrm{NH}_{3}(\mathrm{~g})\right)+\left(\mathrm{p}-\mathrm{NH}_{4}\right)}{\left(\mathrm{p}-\mathrm{SO}_{4}\right)}$ & $\begin{array}{l}\text { Mole ratio of ammonia gas + particle ammonia to parti- } \\
\text { cle sulphate. This defines the chemical regime: values } \\
\text { less than unity denote acidic conditions (e.g., ammonium } \\
\text { bisulphate, sulphuric acid present in the particles); values } \\
\text { between } 1.0 \text { and } 2.0 \text { denote intermediate acidity (ammo- } \\
\text { nium bisulphate, letovicite, ammonium sulphate present), } \\
\text { and values greater than } 2 \text { indicate less acidic particles } \\
\text { (ammonium sulphate, ammonium nitrate may be present } \\
\text { in the particles). Note that a decrease in the value of the } \\
\text { ratio does not necessarily imply a significant change in } \\
\text { the particle composition, if the initial and final values of } \\
\text { the ratio are both high. }\end{array}$ \\
\hline $\begin{array}{l}\text { Gas-phase ammonia mass } \\
\text { fraction }\end{array}$ & $\frac{\left(\mathrm{NH}_{3}\right)}{\left(\mathrm{PM}_{2.5}-\mathrm{NH}_{4}\right)+\left(\mathrm{NH}_{3}\right)}$ & $\begin{array}{l}\text { Relative mass of } \mathrm{NH}_{3} \text { in the gas phase to total ammo- } \\
\text { nia + ammonium mass. Changes in this parameter indi- } \\
\text { cate a change in the mass partitioning of ambient } \mathrm{NH}_{3} \text { in } \\
\text { response to changes in } \mathrm{NH}_{3} \text { emissions. }\end{array}$ \\
\hline $\begin{array}{l}\mathrm{PM}_{2.5} \mathrm{Ammonium}+\text { Nitrate } \\
\text { to total } \mathrm{PM}_{2.5} \text { mass ratio }\end{array}$ & $\frac{\left(\mathrm{PM}_{2.5}-\mathrm{NH}_{4}\right)+\left(\mathrm{PM}_{2.5}-\mathrm{NO}_{3}\right)}{\left(\mathrm{PM}_{2.5}\right)}$ & $\begin{array}{l}\text { Fraction of fine particle mass that is directly ammonia- } \\
\text { sensitive. A diagnostic of the direct impact of emissions } \\
\text { reductions. }\end{array}$ \\
\hline
\end{tabular}

Another important set of diagnostic outputs calculated for the AURAMS analysis were exceedances of annual critical loads in Canada. The "critical load" of an ecosystem refers to its ability to buffer acidifying precipitation. The underlying concept is that an ecosystem will have the ability to absorb a certain amount of acidifying sulphur and nitrogen compounds, including $\mathrm{NH}_{3}$ and $\mathrm{p}-\mathrm{NH}_{4}$, without damage to the ecosystem itself. If the rate of deposition of these compounds exceeds the rate at which the ecosystem can naturally absorb the compounds, however, ecosystem damage begins to occur. The maximum amount of acidifying mass that an ecosystem can absorb per unit area in a year is known as its annual critical load, and any additional deposited mass that exceeds that amount is known as an annual critical load exceedance (e.g., Jeffries et al., 1999; Hall et al., 2001; Jeffries and Ouimet, 2005; McNulty et al., 2007). Critical-load values depend on local bedrock type, soil type and thickness, and other factors.

Sulphur deposition is essentially entirely acidifying, but nitrogen has a large biological activity, and may be stored in various catchment compartments within an ecosystem (Jeffries and Ouimet, 2005). Eventually, though, an ecosystem may reach a steady state with regard to nitrogen de- position (termed "nitrogen saturation"), after which all further nitrogen deposition is acidifying. Sulphur criticalload exceedance thus describes conditions where immediate ecosystem damage will occur, whereas sulphur + nitrogen critical-load exceedance describes conditions where ecosystem damage will once the ecosystem's ability to absorb nitrogen is overwhelmed. Critical-load exceedances for sulphur + nitrogen thus describe a worst-case scenario, in which all of the deposited nitrogen is assumed to be acidifying. At the current time, Canadian ecosystems are not nitrogensaturated (Jeffries and Ouimet, 2005); exceedances of sulphur + nitrogen critical loads thus indicate the potential for future ecosystem damage, as opposed to current ecosystem damage.

\section{Model performance evaluation for the base case}

The statistics used here for evaluation of the base case for the AURAMS simulations were used previously as part of an extensive AURAMS performance evaluation against measurements for the 2002 calendar year (Moran et al., 2007, 2008). The statistical measures used for the comparison are shown 
Table 4. Statistical measures of model performance. $\mathrm{N}$ is the number of paired observed-model values, $\bar{O}$ is the mean observed value, $\bar{M}$ is the mean model value.

\begin{tabular}{|c|c|c|}
\hline $\begin{array}{l}\text { Statistical } \\
\text { Measure }\end{array}$ & Description & Formula \\
\hline \multirow{2}{*}{$R$} & \multirow{2}{*}{ Pearson Correlation Coefficient } & \multirow{2}{*}{$R=\frac{N \sum_{i=1}^{N}\left(O_{i} \cdot M_{i}\right)-\sum_{i=1}^{N}\left(M_{i}\right) \sum_{i=1}^{N}\left(O_{i}\right)}{\sqrt{N \sum_{i=1}^{N}\left(M_{i} \cdot M_{i}\right)-\sum_{i=1}^{N}\left(M_{i}\right) \cdot \sum_{i=1}^{N}\left(M_{i}\right)} \sqrt{N \sum_{i=1}^{N}\left(O_{i} \cdot O_{i}\right)-\sum_{i=1}^{N}\left(O_{i}\right) \cdot \sum_{i=1}^{N}\left(O_{i}\right)}}$} \\
\hline & & \\
\hline$b$ & Slope of observations vs. model best-fit line & $b=\frac{\sum_{i=1}^{N}\left[\left(O_{i}-\bar{O}\right)\left(M_{i}-\bar{M}\right)\right]}{\sum_{i=1}^{N}\left[\left(O_{i}-\bar{O}\right)^{2}\right]}$ \\
\hline$a$ & Intercept of observations vs. model best-fit line & $a=\bar{M}-b \cdot \bar{O}$ \\
\hline$M B$ & Mean bias & $M B=\frac{1}{N} \sum_{i=1}^{N}\left(M_{i}-O_{i}\right)$ \\
\hline RMSE & Root Mean Square Error & $\mathrm{RMSE}=\sqrt{\frac{1}{N} \sum_{i=1}^{N}\left(M_{i}-O_{i}\right)^{2}}$ \\
\hline NMB & Normalized Mean Bias & $\mathrm{NMB}=\frac{\sum_{i=1}^{N}\left(M_{i}-O_{i}\right)}{\sum_{i=1}^{N} O_{i}} \times 100$ \\
\hline NME & Normalized Mean Error & $\mathrm{NME}=\frac{\sum_{i=1}^{N}\left|M_{i}-O_{i}\right|}{\sum_{i=1}^{N} O_{i}} \times 100$ \\
\hline
\end{tabular}

in Table 4. Measurements from 15 different Canadian and US air-chemistry and precipitation-chemistry networks and subnetworks were used to evaluate the base-case fields.

A number of steps were followed in preparing the measurements for comparison with model predictions. For example, units reported by individual networks were adjusted as required to a common set of units (e.g., concentrations at ambient conditions to concentrations at STP). Data records from individual stations were screened for temporal completeness, and if they passed, then measurements were combined to create seasonal and annual values for the station. In locations where more than one station was located in an AURAMS CTM grid cell, the measurements were averaged. Even so, measurements from multiple air-chemistry networks are quite heterogeneous, since individual networks have different goals and objectives, choose different types of sampling locations, employ different sampling instruments, techniques, and protocols, and measure different species (e.g., Eder and Yu, 2006). For example, individual networks have very different sampling periods, ranging from hourly to weekly, and sampling intervals that vary from hourly, to 1 day in 6, to weekly. Combining measurements from different network does provide the benefits of increased sample size, spatial coverage, and spatial density, but the price paid is greater variability within the combined measurement data set.
The resulting annual statistics for ambient concentrations of the key species related to $\mathrm{pNH}_{4}$ formation and removal, with the exception of $\mathrm{NH}_{3}$, for which routine measurements are not available, are shown in Table 5, and those relating to wet deposition are shown in Table 6.

These comparisons to observations show that, on an annual basis, AURAMS under-predicted the 2002 base-case $\mathrm{PM}_{2.5}$ bulk mass by $31 \%$, the $\mathrm{PM}_{2.5}$ inorganic species concentrations by $18 \%$ to $19 \%$, the concentration of inorganic ions in precipitation by $11 \%$ to $33 \%$, and the wet deposition of inorganic ions by $6 \%$ to $24 \%$ (negative normalized mean biases). The implication of the comparison is that the model estimates for the base case for the $\mathrm{PM}_{2.5}$ components and precipitation species are likely to be lower than the ambient atmosphere, and hence the model-predicted critical-load exceedances, described below, are likely to be underestimates. The impact of the model bias on the scenarios is harder to quantify. The usual assumption that is made is that the bias will be linear, so that the scenarios will have the same normalized biases as the base case. The absence of coarse-mode cation chemistry in AURAMS may increase the sensitivity of the model in weakly ammonia-limited environments towards changes in ammonia emissions. The impacts of ammonia emission reductions on the real atmosphere are therefore expected to be similar in sign as simulated here but may vary in the absolute sense. 
Table 5. Annual statistics for selected AURAMS gas- and particle-phase species. Statistical metrics are defined in Table 4.

\begin{tabular}{lcccccc}
\hline Statistic & $\begin{array}{c}\mathrm{SO}_{2} \\
(\mathrm{ppbv})\end{array}$ & $\begin{array}{c}\mathrm{HNO}_{3} \\
(\mathrm{ppbv})\end{array}$ & $\begin{array}{c}\mathrm{PM}_{2.5} \\
\left(\mu \mathrm{g} \mathrm{m}^{-3}, \mathrm{STP}\right)\end{array}$ & $\begin{array}{c}\mathrm{PM}_{2.5}-\mathrm{SO}_{4} \\
\left(\mu \mathrm{g} \mathrm{m}^{-3}, \mathrm{STP}\right)\end{array}$ & $\begin{array}{c}\mathrm{PM}_{2.5}-\mathrm{NO}_{3} \\
\left(\mu \mathrm{g} \mathrm{m}^{-3}, \mathrm{STP}\right)\end{array}$ & $\begin{array}{c}\mathrm{PM}_{2.5}-\mathrm{NH}_{4} \\
\left(\mu \mathrm{g} \mathrm{m}^{-3}, \mathrm{STP}\right.\end{array}$ \\
\hline Networks & $\mathrm{a}, \mathrm{d}, \mathrm{e}, \mathrm{g}$ & $\mathrm{d}, \mathrm{e}$ & $\mathrm{a}, \mathrm{b}, \mathrm{c}, \mathrm{f}, \mathrm{g}, \mathrm{h}$ & $\mathrm{c}, \mathrm{f}, \mathrm{h}$ & $\mathrm{c}, \mathrm{f}, \mathrm{h}$ & $\mathrm{c}, \mathrm{h}$ \\
$\mathrm{N}$ & 451 & 86 & 845 & 265 & 254 & 141 \\
$\bar{O}$ & 3.32 & 0.53 & 11.33 & 2.77 & 1.28 & 1.53 \\
$\bar{M}$ & 3.55 & 0.66 & 7.87 & 2.26 & 1.05 & 1.25 \\
$\mathrm{a}$ & 1.01 & 0.08 & -0.74 & -0.64 & 0.12 & 0.23 \\
$\mathrm{~b}$ & 0.77 & 1.10 & 0.76 & 1.04 & 0.73 & 0.66 \\
$\mathrm{R}$ & 0.56 & 0.81 & 0.65 & 0.92 & 0.77 & 0.76 \\
$\mathrm{MB}$ & 0.23 & 0.13 & -3.46 & -0.51 & -0.23 & -0.29 \\
$\mathrm{RMSE}$ & 2.88 & 0.28 & 5.00 & 0.95 & 1.01 & 0.54 \\
$\mathrm{NMB}(\%)$ & 7.0 & 25.2 & -30.5 & -18.5 & -17.9 & -18.7 \\
NME $(\%)$ & 51.7 & 38.3 & 36.8 & 27.3 & 43.5 & 27.2 \\
\hline
\end{tabular}

Networks: a: AQS-continuous, b: AQS-filter; c: AQS-STN; d: CAPMoN, e: CASTNet, f: IMPROVE, g: NAPS-continuous, h: NAPS-filter

Table 6. Annual statistics for several AURAMS wet deposited species. Measurements were obtained from five Canadian precipitationchemistry networks (CAPMoN, BCPCSN, NBPMN, PQMPA, REPQ) and one US network (NADP).

\begin{tabular}{|c|c|c|c|c|c|c|}
\hline Statistic & $\begin{array}{l}\mathrm{SO}_{4}^{2-} \text { conc. } \\
\text { in precip. }\left(\mathrm{mg} \mathrm{SO}_{4} / \mathrm{L}\right)\end{array}$ & $\begin{array}{c}\mathrm{NO}_{3}^{-} \text {conc. } \\
\text { in precip.( }\left(\mathrm{mg} \mathrm{NO}_{3} / \mathrm{L}\right)\end{array}$ & $\begin{array}{c}\mathrm{NH}_{4}^{+} \text {conc. } \\
\text { in precip. }\left(\mathrm{mg} \mathrm{NH} \mathrm{N}_{4} / \mathrm{L}\right)\end{array}$ & $\begin{array}{l}\mathrm{SO}_{4}^{2-} \text { wet dep. } \\
\left(\mathrm{kg} \mathrm{SO}_{4} / \mathrm{ha} / \mathrm{y}\right)\end{array}$ & $\begin{array}{l}\mathrm{NO}_{3}^{-} \text {wet dep. } \\
\left(\mathrm{kg} \mathrm{NO}_{3} / \mathrm{ha} / \mathrm{y}\right)\end{array}$ & $\begin{array}{l}\mathrm{NH}_{4}^{+} \text {wet dep. } \\
(\mathrm{kg} \mathrm{NH} / \mathrm{ha} / \mathrm{y})\end{array}$ \\
\hline $\mathrm{N}$ & 277 & 270 & 271 & 277 & 270 & 271 \\
\hline $\bar{O}$ & 1.08 & 1.11 & 0.31 & 10.1 & 9.39 & 2.39 \\
\hline $\bar{M}$ & 0.96 & 0.94 & 0.21 & 9.54 & 8.30 & 1.81 \\
\hline a & -0.03 & 0.202 & 0.021 & 0.449 & 1.46 & 0.11 \\
\hline $\mathrm{b}$ & 0.91 & 0.67 & 0.60 & 0.90 & 0.73 & 0.71 \\
\hline $\mathrm{R}$ & 0.81 & 0.61 & 0.76 & 0.84 & 0.71 & 0.78 \\
\hline MB & -0.12 & -0.17 & -0.10 & -0.58 & -1.09 & -0.58 \\
\hline RMSE & 0.37 & 0.50 & 0.16 & 3.94 & 4.24 & 1.07 \\
\hline NMB (\%) & -11.4 & -15.0 & -33.1 & -5.8 & -11.6 & -24.1 \\
\hline NME (\%) & 24.8 & 33.4 & 36.2 & 28.3 & 33.7 & 33.9 \\
\hline
\end{tabular}

\section{Scenario analysis}

\subsection{Analysis of the base case}

One means of identifying strongly $\mathrm{NH}_{3}$-limited environments is to calculate the total (ammonia + ammonium) to sulphate mole ratio (cf. Table 3). Seasonal fields of this metric for the 2002 base case are shown in Fig. 3. Yellow to red areas in this figure have a large excess of $\mathrm{NH}_{3}$ and are not strongly $\mathrm{NH}_{3}$-limited: significant reductions in $\mathrm{NH}_{3}$ emissions would be required to reach strongly $\mathrm{NH}_{3}$-limited conditions. These areas tend to correspond to areas of high $\mathrm{NH}_{3}$ emissions (cf. Fig. 2). Green to blue regions, on the other hand, are strongly $\mathrm{NH}_{3}$-limited, with more acidic conditions. Reductions in $\mathrm{NH}_{3}$ emissions in these areas would have an immediate impact on ambient $\mathrm{PM}_{2.5}$ levels, whereas reductions in other, weakly $\mathrm{NH}_{3}$-limited regions will depend on the other ions in equation (2b). Pronounced seasonal and local variations can also be seen; summer and winter have the largest spatial extent of strongly $\mathrm{NH}_{3}$-limited regions. These seasonal variations are due to (1) seasonal variations in the ammonia emissions (cf. Fig. 2, which shows the lowest ammonia emissions occurring in the winter, the highest in the spring, summer and fall), and (2) increased levels of sulphate production in the summer, due to higher oxidation of $\mathrm{SO}_{2}$ to sulphate in the gas and aqueous phases. The low winter ammonia emissions helps reduce the ratio in the winter; high summer sulphate production helps reduce the ratio in the summer.

One implication of the above analysis is that the regions that may benefit from $\mathrm{NH}_{3}$ reductions will not necessarily be the regions that have the highest $\mathrm{NH}_{3}$ emissions. For example, the region of highest total ammonia to sulphate mole ratio in Fig. 3 is centered on the US states of Minnesota, South Dakota, Nebraska, and Iowa - this also corresponds to the region of greatest $\mathrm{NH}_{3}$ emissions. Reductions in $\mathrm{NH}_{3}$ in this region are unlikely to significantly impact PM concentrations, due to the locally $\mathrm{NH}_{3}$-saturated chemistry. However, 


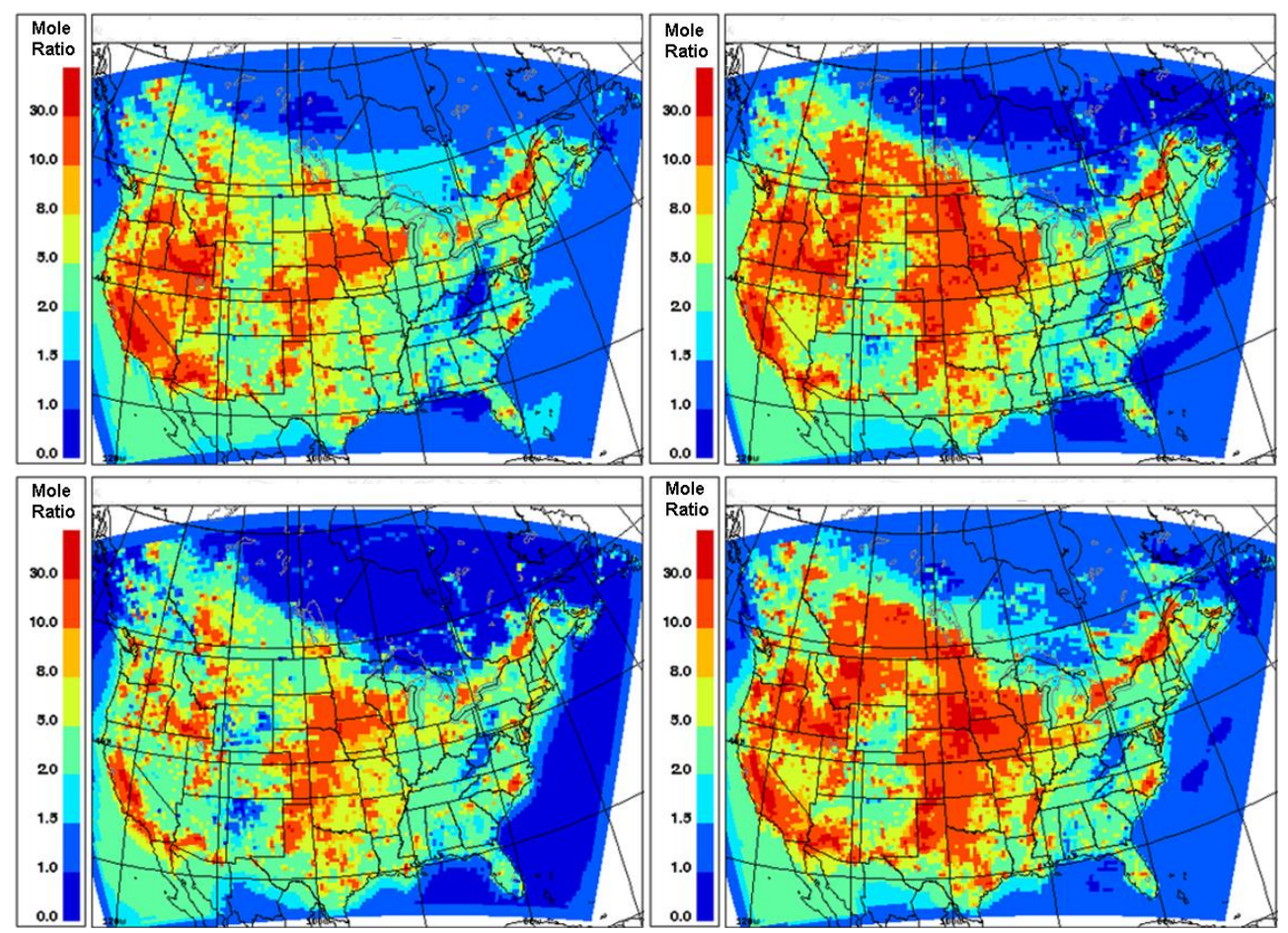

Fig. 3. Seasonal average total $\mathrm{NH}_{3}$ to sulphate mole ratio for base-case simulation: summer - upper left; fall - upper right; winter - lower left; spring - lower right.

further to the east and downwind from this source region are the strongly $\mathrm{NH}_{3}$-limited regions of the Great Lakes, the Ohio River Valley, and the Appalachian mountains. Depending on the extent to which $\mathrm{NH}_{3}$ is transported, PM reductions may also occur in these downwind regions,. The impact of $\mathrm{NH}_{3}$ reductions will therefore be a combination of local chemistry and transport from higher-emission $\mathrm{NH}_{3}$-saturated regions to lower-emission strongly $\mathrm{NH}_{3}$-limited regions.

\subsection{Analysis of continental agricultural $\mathrm{NH}_{3}$ emission reduction scenario}

In this scenario, $\mathrm{NH}_{3}$ emissions from agricultural sources were decreased uniformly by $30 \%$ in both Canada and the United States. In the following figures, the difference between base-case and scenario concentration fields will be displayed [(base case) - (scenario)], and the same difference formats will be used for the metrics. Positive values in the difference plots thus indicate decreases in the scenario concentrations relative to the base case; negative values indicate increases in the scenario concentrations relative to the base case. It is also important to note that seasonal average differences are being displayed unless noted otherwise; within each season, shorter duration events will occur with larger (and smaller) impacts than those depicted here.

\subsection{1 $\mathrm{NH}_{3}$ concentrations}

The greatest decreases in seasonal $\mathrm{NH}_{3}$ concentrations (Fig. 4) are closely matched with the locations of the main $\mathrm{NH}_{3}$ emissions regions (Fig. 2). The effect of reductions in $\mathrm{NH}_{3}$ emissions on $\mathrm{NH}_{3}$ gas concentrations is therefore primarily local; most of the $\mathrm{NH}_{3}$ is removed close to the source, either through deposition or gas-to-particle partitioning.

The influence of seasonal variations in the $\mathrm{NH}_{3}$ emissions can also be seen in Fig. 4. Agricultural emissions in North America are highest in the spring and lowest in the winter (e.g., Gilliland et al., 2006; see also Tables 1 and 2). As a consequence, the predicted change in concentration of $\mathrm{NH}_{3}$ gas in the winter is lower than in the other seasons. For example, the decrease in ammonia concentrations in the high emissions region of southern Minnesota in the summer is on the order of $2.5 \mathrm{ppbv}$, while the wintertime value in the same region is on the order of $0.5 \mathrm{ppbv}$.

\subsection{2 $\mathrm{M}_{2.5}$ concentrations}

The impact of the $\mathrm{NH}_{3}$ emissions reductions on average seasonal $\mathrm{PM}_{2.5}$ mass is shown in Fig. 5. Seasonally-averaged $\mathrm{PM}_{2.5}$ changes resulting from a 30\% reduction in $\mathrm{NH}_{3}$ emissions range from an increase of 0.07 to a decrease of $3.99 \mu \mathrm{g} \mathrm{m}^{-3}$. The greatest overall reductions in mass occur in spring and summer, and occur in specific regions. The 

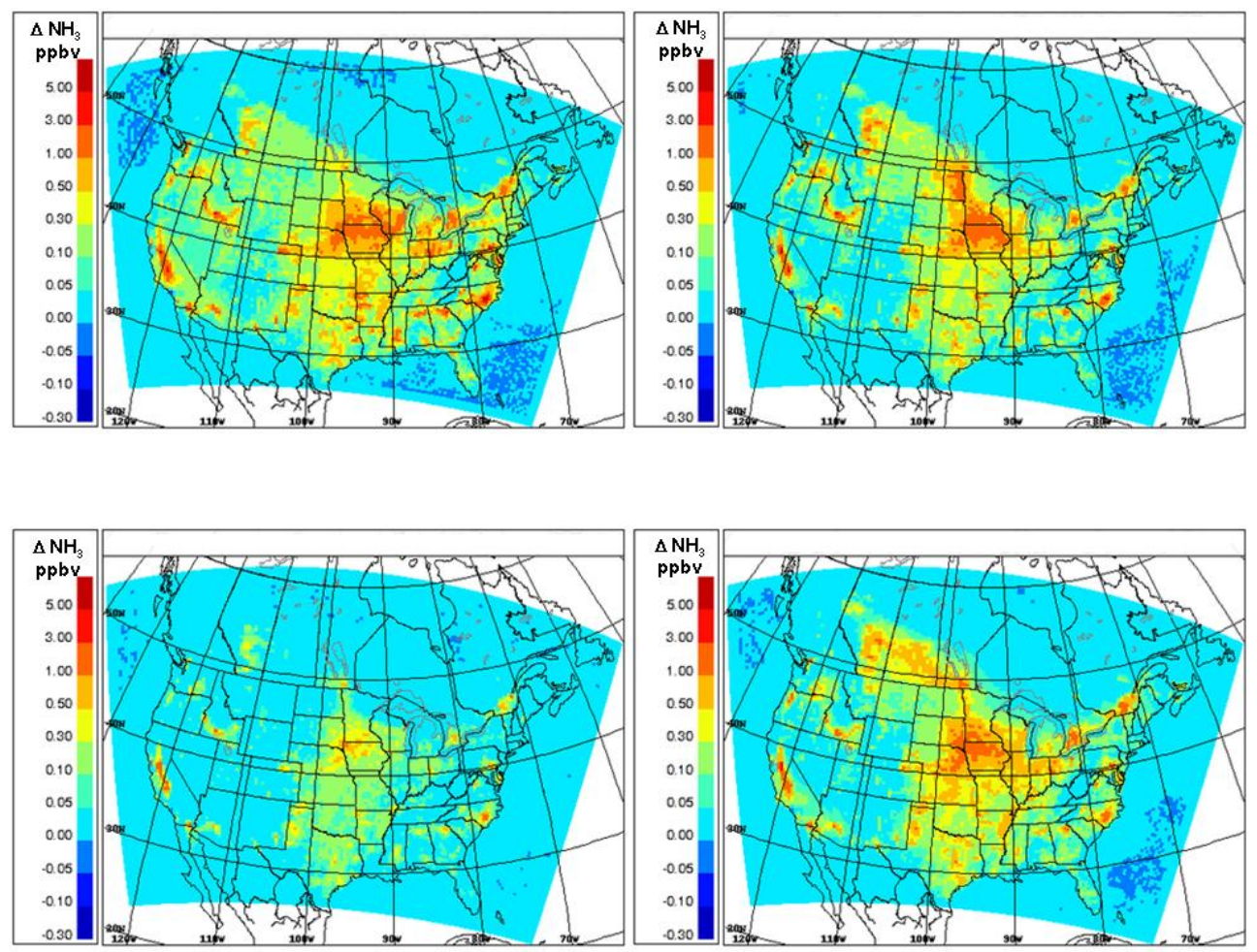

Fig. 4. Seasonal average change in $\mathrm{NH}_{3}$ concentration, ppbv, associated with a $30 \%$ reduction in agricultural $\mathrm{NH}_{3}$ emissions. Panels arranged as in Fig. 2.

largest of these regions is centered over the Ohio River valley and southern Ontario; most of the eastern US and southern Ontario and Quebec experience reductions in $\mathrm{PM}_{2.5}$. Another region with reductions greater than $1 \mu \mathrm{g} / \mathrm{m}^{-3}$ occurs in the US eastern seaboard corridor. Significantly, these regions do not coincide with the regions of largest $\mathrm{NH}_{3}$ emission reductions (cf. Fig. 4). The San Joaquin valley of central California also shows seasonal average $\mathrm{PM}_{2.5}$ reductions greater than $0.5 \mu \mathrm{g} \mathrm{m}^{-3}$ and locally as large as $2 \mu \mathrm{g} \mathrm{m}^{-3}$. The Vancouver to Seattle region close to the western border of the model domain has $\mathrm{PM}_{2.5}$ reductions up to $1.5 \mu \mathrm{g} \mathrm{m}^{-3}$ in the summer; this effect is highly seasonal however, with a reduction of only $0.25 \mu \mathrm{g} \mathrm{m}^{-3}$ in the winter and intermediate reductions in the transition seasons. The AlbertaSaskatchewan area of western Canada has smaller reductions in $\mathrm{PM}_{2.5}$, on the order of 0.25 to $0.5 \mu \mathrm{g} / \mathrm{m}^{-3}$, with the greatest reductions in the spring and fall.

The seasonal change in $\mathrm{PM}_{2.5}$ ammonium, sulphate and nitrate mass resulting from the reduction in ammonia emissions is shown in Figs. 6, 7 and 8, respectively. Of the three inorganic components, particle nitrate accounts for the largest fraction of the total change in particle mass, fol- lowed by ammonium, then sulphate (note that the scales change between the figures). Individual particulate species show a stronger seasonal variation than does the total particle mass: the greatest reductions in ammonium and nitrate mass (Figs. 6, 8) occur in spring, summer and fall, while the greatest reductions in sulphate mass (Fig. 7) occur in fall, winter and spring. Particle sulphate is predicted to increase slightly in the summer (Fig. 7, upper left panel, blue region) in much of eastern North America following the reduction in ammonia gas emissions. This increase in sulphate, however, is more than compensated by the decreases in ammonium and nitrate, with the net result that the total $\mathrm{PM}_{2.5}$ mass in the summer decreases in the same region (Fig. 5, upper left panel). The spatial distribution of the mass reductions also varies between the species: ammonium and nitrate reductions occur largely in regions downwind of the main ammonia emitting areas (compare to Fig. 2), whereas particle sulphate reductions (in the colder three seasons of the year) are coincident with the ammonia emitting regions.

Our interpretation of these results is as follows:

(1) Most of the reduction in $\mathrm{PM}_{2.5}$ mass is due to decreases in ammonium and nitrate mass. 

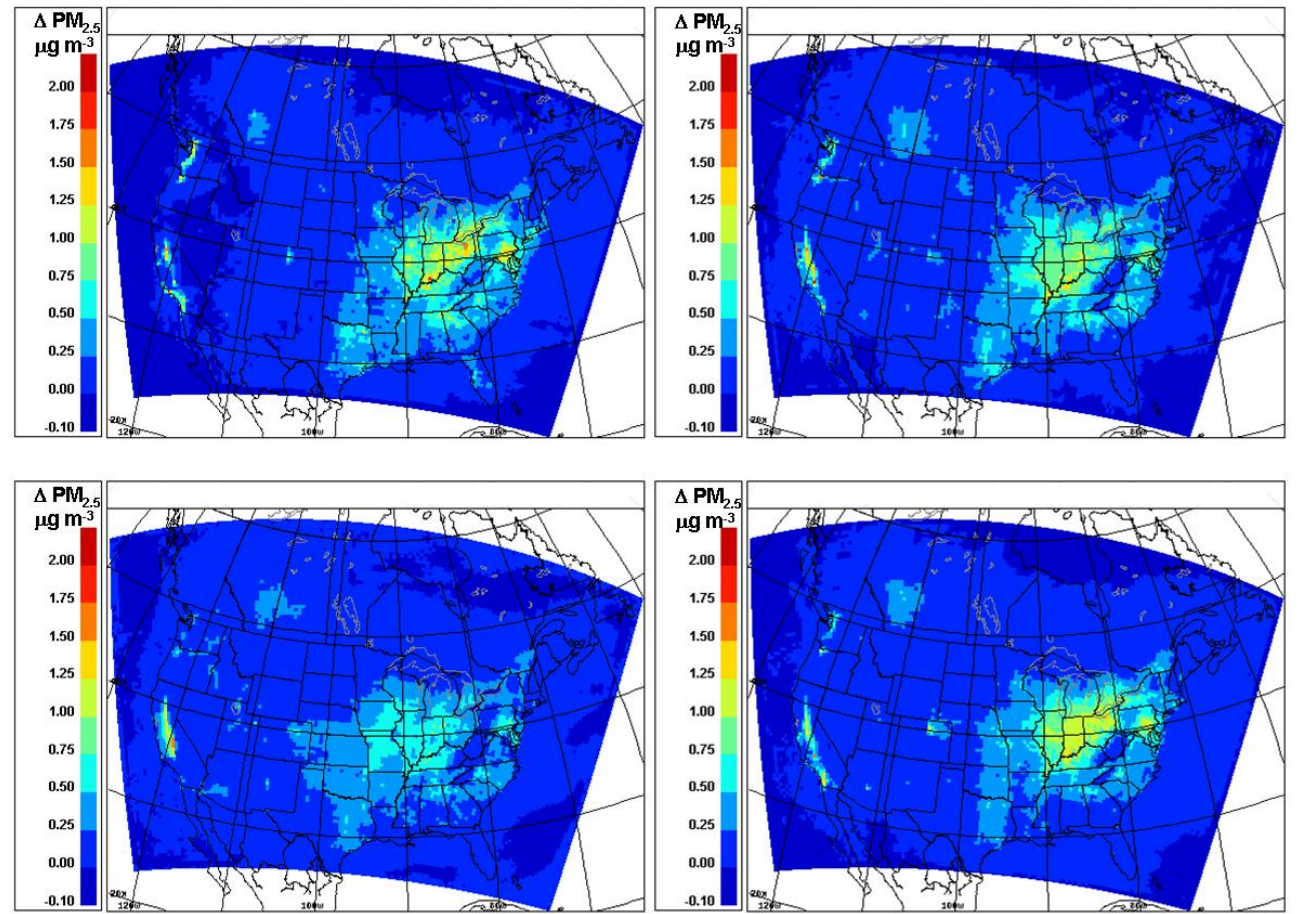

Fig. 5. Seasonal average change in $\mathrm{PM}_{2.5}$ mass, $\mu \mathrm{g} \mathrm{m}{ }^{-3}$, associated with a $30 \%$ reduction in agricultural $\mathrm{NH}_{3}$ emissions. Reductions in $\mathrm{PM}_{2.5}$ are shown as positive values. Panels arranged as in Fig. 2.
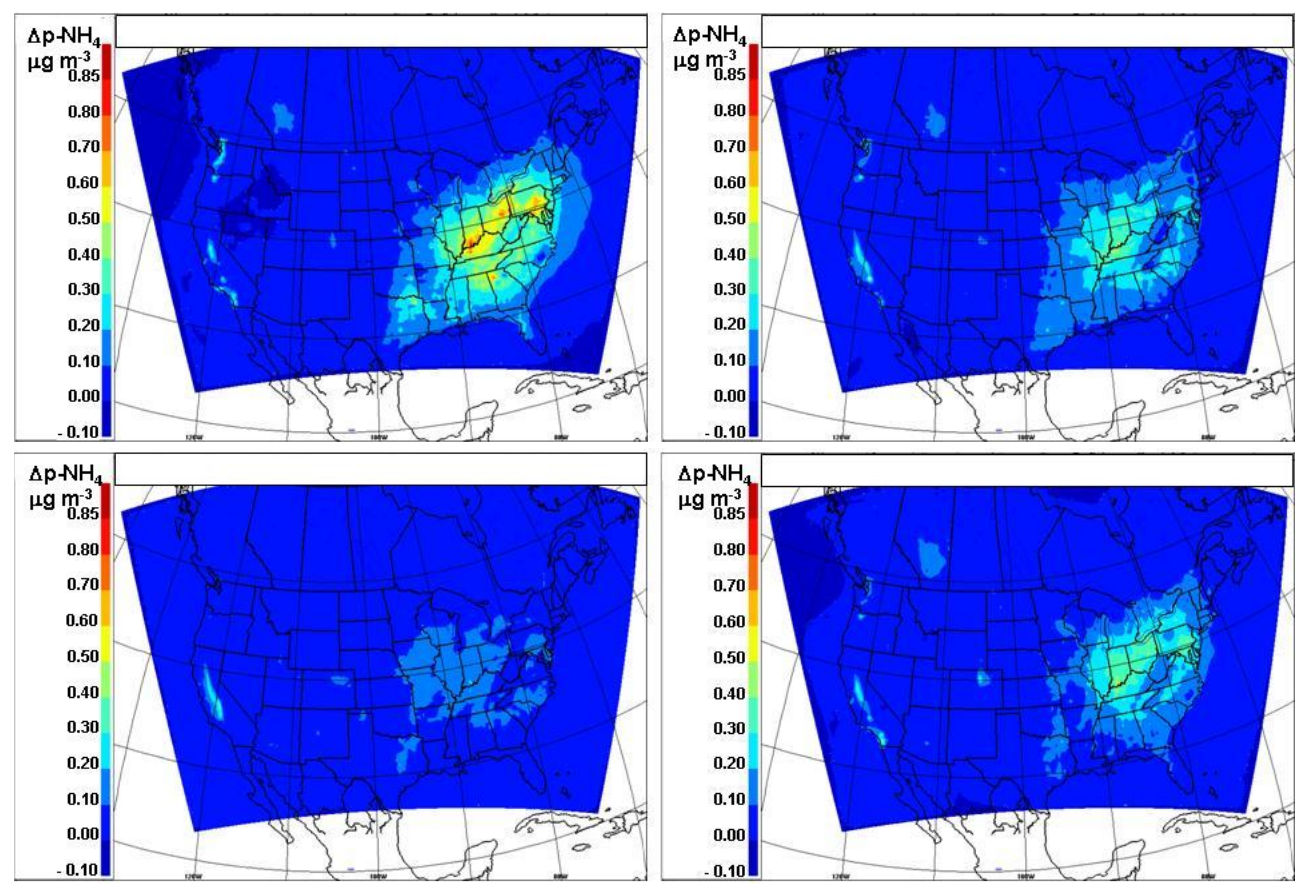

Fig. 6. Same as for Figure 5, but for the $\mathrm{p}-\mathrm{NH}_{4}$ component of $\mathrm{PM}_{2.5}$. 


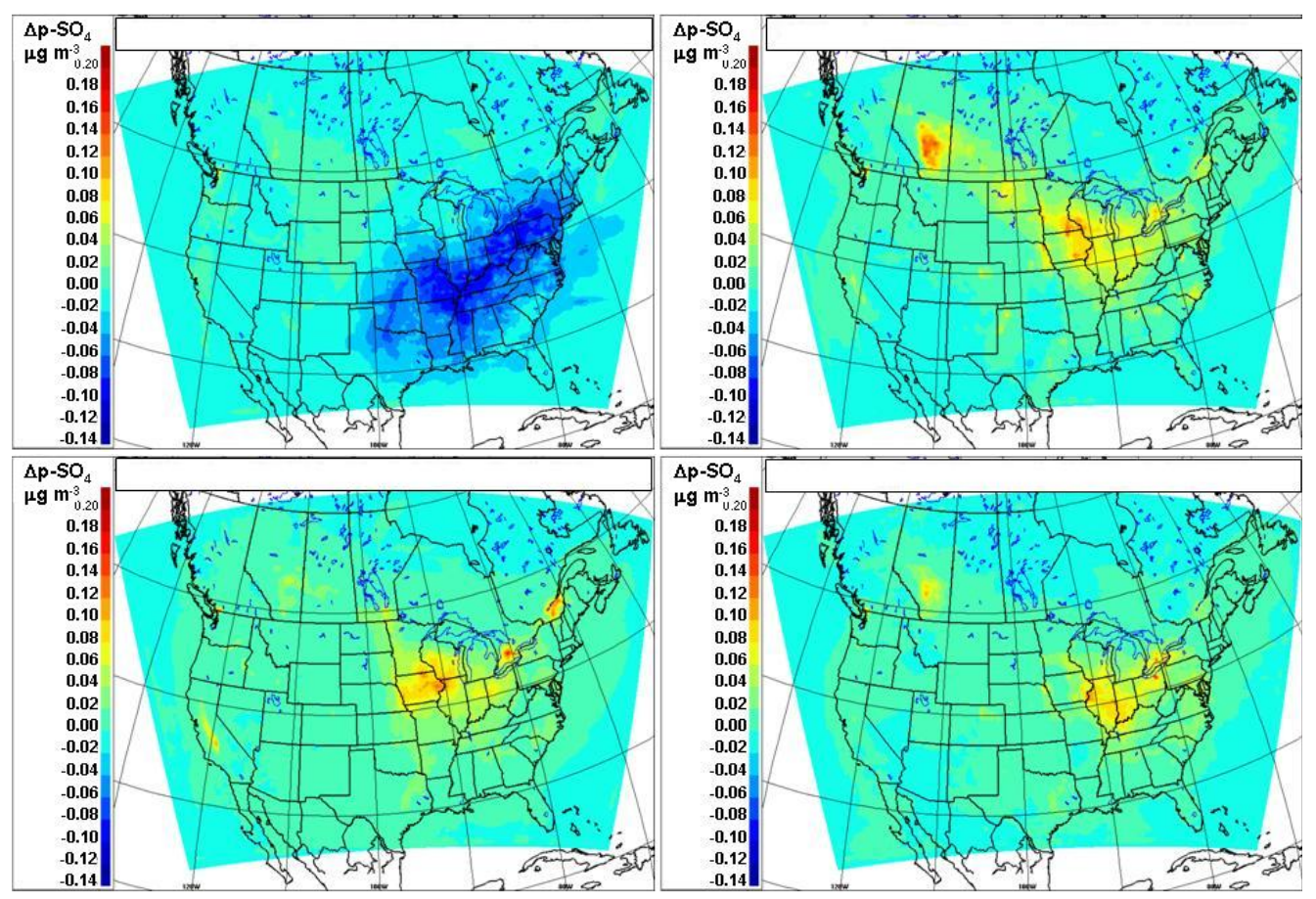

Fig. 7. Same as for Fig. 5, but for the $\mathrm{p}^{-\mathrm{SO}_{4}}$ component of $\mathrm{PM}_{2.5}$.

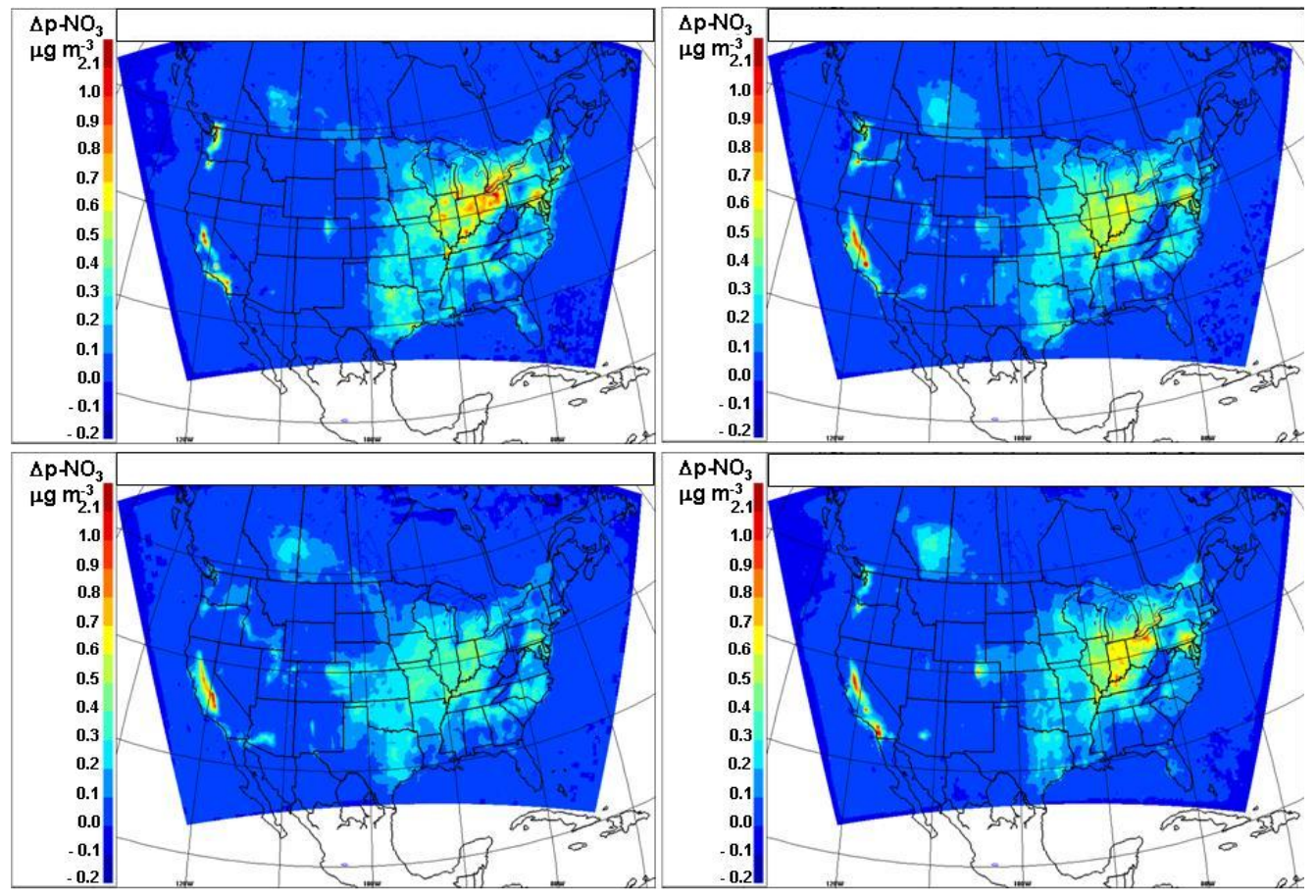

Fig. 8. Same as for Fig. 5, but for the $\mathrm{p}-\mathrm{NO}_{3}$ component of $\mathrm{PM}_{2.5}$. 


\section{CAPMoN Filter Chemistry Monitors in 2002}

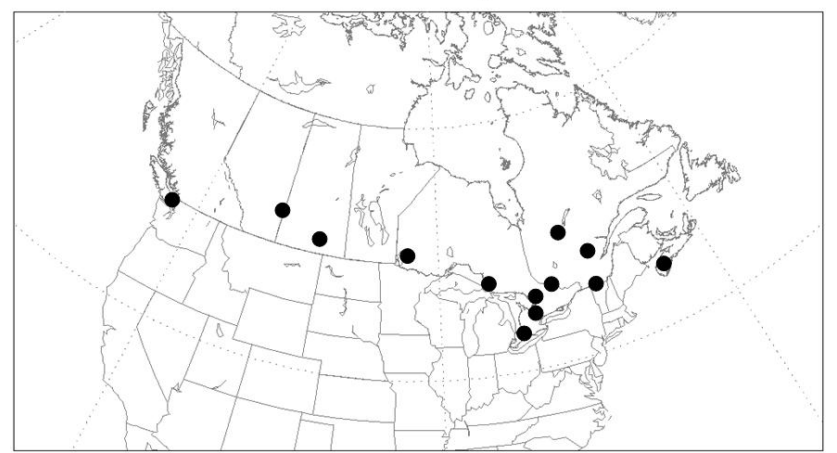

CASTNet Filter Chemistry Monitors in 2002

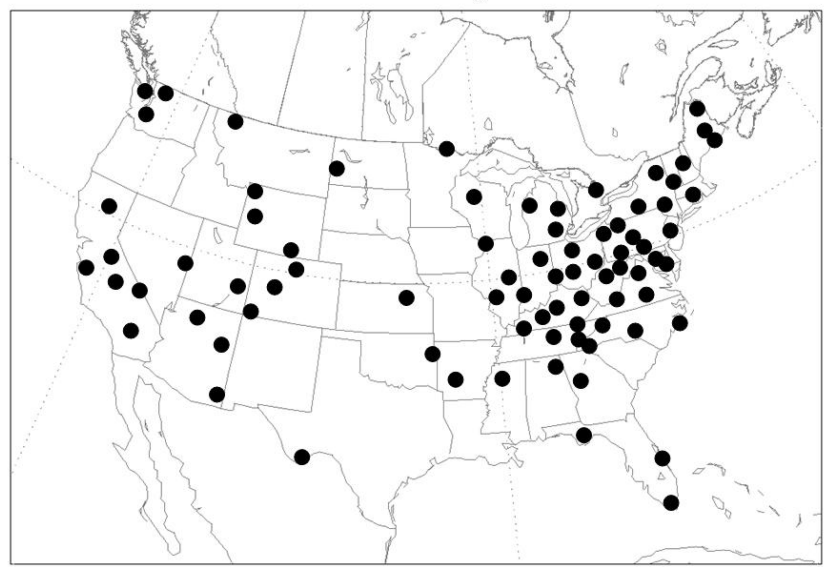

Fig. 9. Locations of sites used in analysis of episodic nature of ammonia emissions reductions: (a) Canadian CAPMoN sites; (b) US CASTNet sites.

(2) Cold-month decreases in sulphate, co-located with the ammonia emissions regions, are due to (a) increased hydrogen ion concentrations in cloudwater, which causes the $\mathrm{SO}_{2}(\mathrm{~g})+\mathrm{H}_{2} \mathrm{O} \quad \mathrm{H}^{+}(\mathrm{aq})+\mathrm{HSO}_{3}^{-}(\mathrm{aq})$ equilibrium to shift to the left, reducing further uptake of sulphur into clouds, (b) a decrease in the rate of cloudwater oxidation of $\mathrm{HSO}_{3}^{-}(\mathrm{aq})$ to $\mathrm{SO}_{4}^{2-}(\mathrm{aq})$ by ozone due to increased $\mathrm{H}^{+}(\mathrm{aq})$ concentrations.

(3) The small summer increases in particle sulphate concentration result from the conversion of $\mathrm{HSO}_{3}^{-}$(aq) to $\mathrm{SO}_{4}^{2-}(\mathrm{aq})$ becoming more efficient at higher hydrogen ion concentrations and higher temperatures: the aqueous phase oxidation rates of $\mathrm{HSO}_{3}^{-}$(aq) to $\mathrm{SO}_{4}^{2-}$ (aq) by hydrogen peroxide and organic peroxides are proportional to the $\mathrm{H}^{+}$(aq) concentration, which increases as ammonia decreases (e.g. Fung et al., 1991). This increased irreversible conversion of $\mathrm{HSO}_{3}^{-}(\mathrm{aq})$ to $\mathrm{SO}_{4}^{2-}(\mathrm{aq})$ counteracts the cold-month equilibrium between $\mathrm{SO}_{2}(\mathrm{~g})$ and $\mathrm{HSO}_{3}^{-}(\mathrm{aq})$, allowing the net uptake of $\mathrm{SO}_{2}$ in clouds to increase. This effect occurs where the base case $\mathrm{H}^{+}(\mathrm{aq})$ concentration was already high (i.e. the ozone oxidation pathway was already weak, due to high $\mathrm{H}^{+}(\mathrm{aq})$ concentrations, and is weakened further by the increase in acidity).
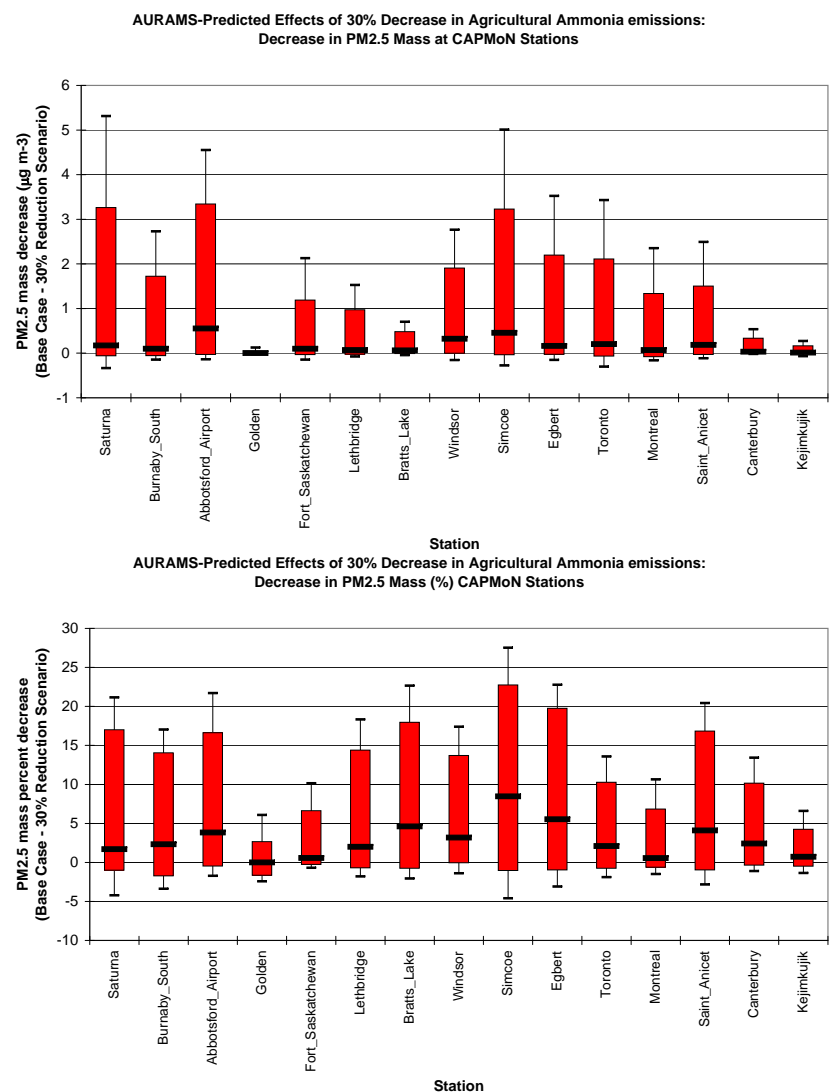

Fig. 10. AURAMS-predicted annual frequency distributions of the decrease in hourly $\mathrm{PM}_{2.5}$ concentrations associated with a $30 \%$ decrease in $\mathrm{NH}_{3}$ emissions at CAPMoN stations (numbered sites from Fig. 9a): (a) expressed in mass units; (b) Expressed as percentage difference relative to the base case. Median : solid horizontal bar; 5th and 95th percentiles: limits of red vertical bar; 2nd and 98th percentiles: thin horizontal bars.

The episodic nature of the changes in $\mathrm{PM}_{2.5}$ mass resulting from ammonia emissions reductions has been examined by constructing annual frequency distributions of hourly mass difference and hourly percent mass difference between the base case and the 30\%-reduction scenario. Hourly model values of the changes in $\mathrm{PM}_{2.5}$ were first extracted for those model grid cells containing the CAPMoN and CASTNET monitoring stations shown in Fig. 9 and were then used to construct annual frequency distributions of hourly mass change (Figs. 10a, 11a) and percent mass change (Figs. 10b, 11b). In both Figs. 10 and 11, the sites are arranged roughly from the west of the continent on the left to the east of the continent on the right, and positive values indicate reductions relative to the base case. Both figures show that median hourly $\mathrm{PM}_{2.5}$ reductions are usually less than $1 \mu \mathrm{g} \mathrm{m}^{-3}$, or on the order of $5 \%$ of the $\mathrm{PM}_{2.5}$ mass at any given location, while the reductions during episodes (e.g. 95th percentiles, top of red bar) may be considerably higher. For the Canadian 


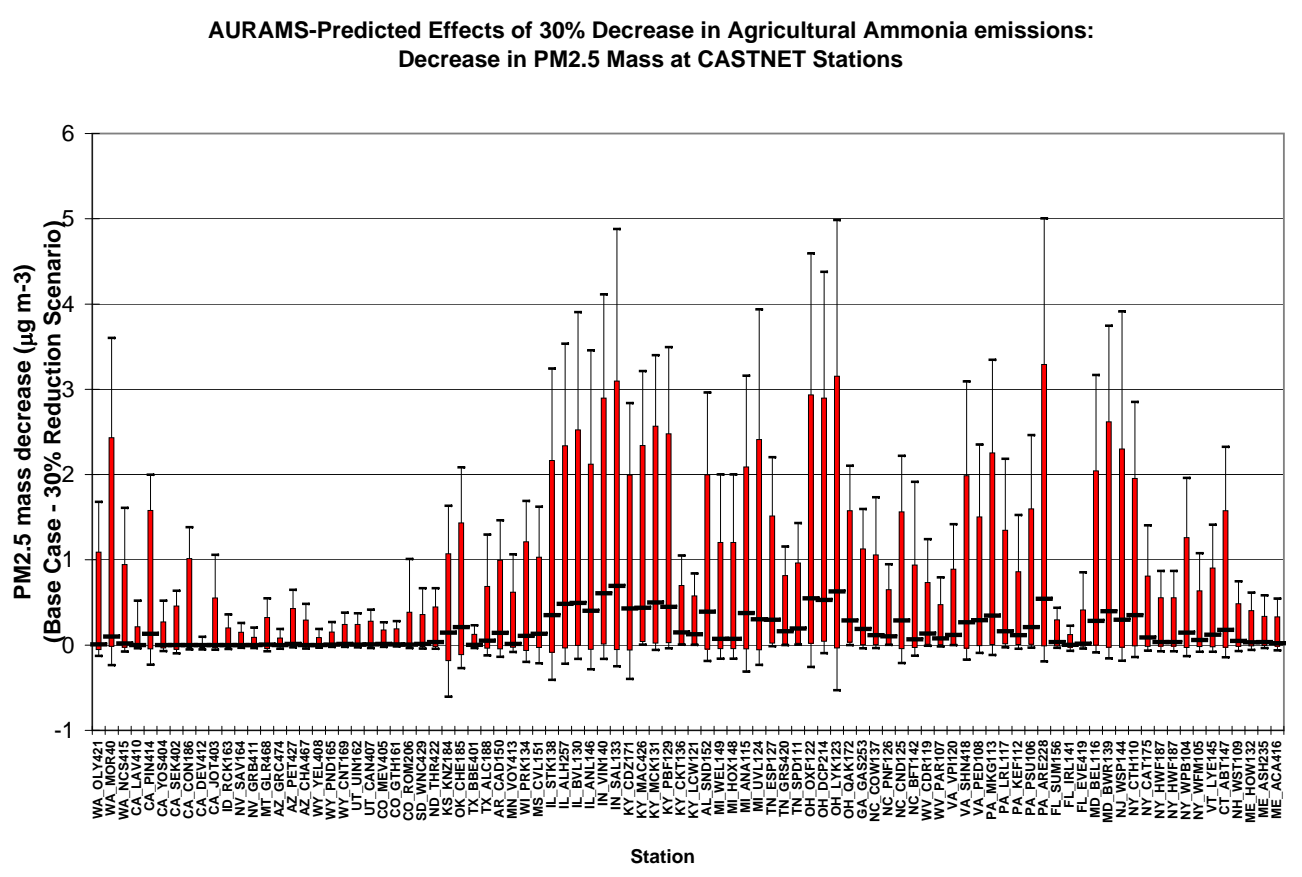

AURAMS-Predicted Effects of $30 \%$ Decrease in Agricultural Ammonia emissions: Decrease in PM2.5 Mass (\%) CASTNET Stations

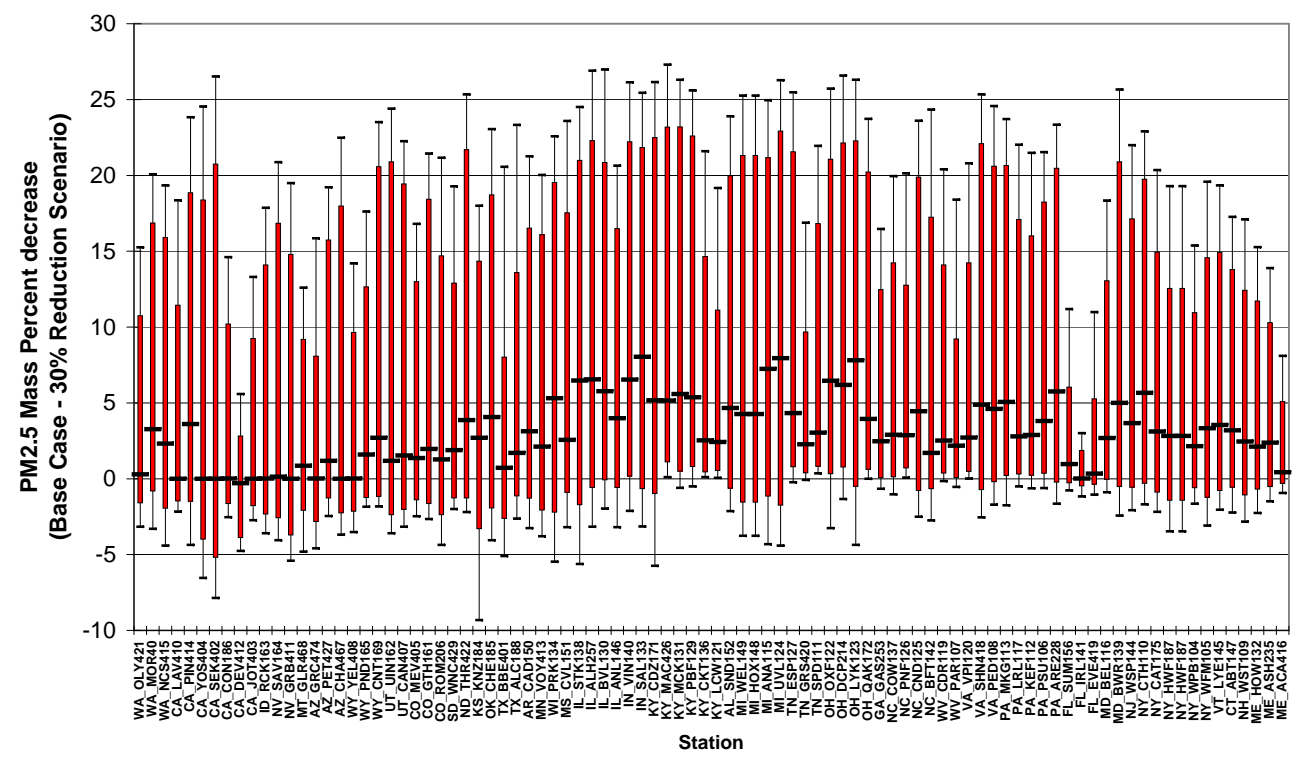

Fig. 11. (a) Same as Fig. 10a but for CASTNet station sites shown in Fig. 9. (b) Same as Fig. 10b but for CASTNet station sites shown in Fig. 9.

sites (CAPMoN), the largest median mass reductions (Figure 10a) are at Abbotsford Airport $\left(0.55 \mu \mathrm{g} \mathrm{m}^{-3}\right)$ located in an agricultural area to the east of Vancouver, British Columbia, and Simcoe, Ontario, located in an agricultural area to the east of the Detroit/Windsor conurbation $\left(0.50 \mu \mathrm{g} \mathrm{m}^{-3}\right)$. The median values at all sites are much lower than the 95thpercentile limits (e.g., Abbotsford Airport, 95th percentile value of $3.3 \mu \mathrm{g} \mathrm{m}^{-3}$; Simcoe, $3.2 \mu \mathrm{g} \mathrm{m}^{-3}$ ). Median percent reductions (Fig. 10b) are more centered in the frequency distributions, although the upper ends of the range are still considerably higher than the medians (e.g., Abbotsford Airport median and 95th-percentile values of $3.8 \%$ and $17 \%$; Simcoe $8.5 \%$ and $23 \%$, respectively). A similar pattern may be observed at US sites (CASTNET), with median and 95th mass percentile values in Indiana and Ohio reaching 0.69 and $3.1 \mu \mathrm{g} \mathrm{m}^{-3}$, and 0.63 and $3.2 \mu \mathrm{g} \mathrm{m}^{-3}$ respectively, and 

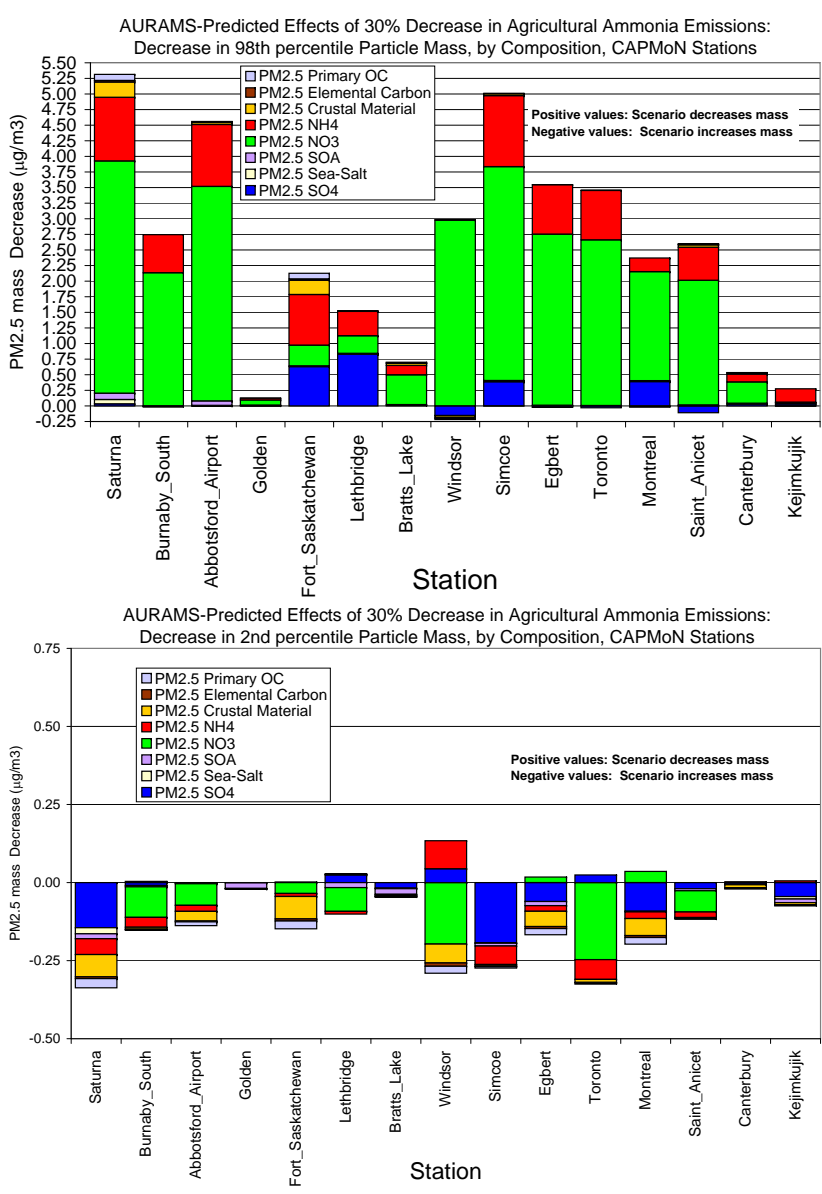

Fig. 12. AURAMS-predicted $\mathrm{PM}_{2.5}$ composition change associated with a $30 \%$ decrease in $\mathrm{NH}_{3}$ emissions at CAPMoN statons for (a) the 98th percentile $\mathrm{PM}_{2.5}$ mass change at each station, and (b) the 2nd percentile mass change at each station. Note the difference in vertical scale between (a) and (b).

corresponding percent reduction median and 95th-percentile values of $8 \%$ and $22 \%$, and $7.8 \%$ and $22 \%$, respectively. The mass reduction distributions (Figures 10a, 11a) suggest that the impact of ammonia controls on $\mathrm{PM}_{2.5}$ mass will be episodic, with mass reductions during periods of elevated $\mathrm{PM}_{2.5}$ levels being as much as 4 to 6 times greater than the median mass reduction. The percent mass reduction distributions (Figs. 10b, 11b) show that median percent mass decreases of 0 to $8 \%$ are predicted at the network locations in both countries, with 95th-percentile values of up to $22 \%$. However, Figs. 10 and 11 also show that $\mathrm{NH}_{3}$ emission decreases can also lead to lower-magnitude episodic increases of $\mathrm{PM}_{2.5}$ mass.

The speciation of the change in particle mass for the 98th and 2nd percentile $\mathrm{PM}_{2.5}$ mass changes from Figures 10 and 11 are shown in Figs. 12 and 13, respectively. This analysis shows that the large decreases in $\mathrm{PM}_{2.5}$ mass (98th percentile; Figs. 2a and 13a) are mostly due to decreases in par- ticle ammonium and particle nitrate mass, in accord with the seasonal average concentration diagrams discussed above. The small decreases in $\mathrm{PM}_{2.5}$ mass (2nd percentile, Figs. 12b and $13 \mathrm{~b}$ ) show a variety of causes in Canada (12b), but in the eastern USA. they are clearly linked with the increase in sulphate mass noted in the analysis above in the summer months, particularly in the eastern United States of America (13b). It is interesting to contrast these sulphate results with those of Tsimpidi et al. (2008): in their case, a 50\% reduction in ammonia emissions for an eastern US domain resulted in minor sulphate reductions in a single winter month, and no change in sulphate in a single summer month. Our trend is the same, though we predict small sulphate increases in the summer due to the impact of increased cloudwater acidity on aqueous-phase oxidation processes, described above. The differences between our results and those of Tsimpidi et al. (2008) may relate differences in the equilibrium and reaction rate expressions used in the two different models, and in the temperatures during the respective test periods. Other small decreases may be due to reductions in ammonia emissions upwind of the site leading to less particle growth and hence to less particle dry deposition prior to reaching the downwind site (i.e. extreme cases where the base case particle ammonium nitrate is sufficiently high that some particle nitrate is lost en-route to the measurement station location).

\subsection{3 $\quad \mathrm{PM}_{2.5}$ chemistry}

The manner in which the reductions in $\mathrm{NH}_{3}$ emissions create the $\mathrm{PM}_{2.5}$ mass reductions described above can be examined by considering the changes in the metrics of Table 3 .

The predicted change in particle neutralization ratio resulting from a $30 \%$ reduction in $\mathrm{NH}_{3}$ emissions relative to the base case is shown in Fig. 14. Positive regions indicate areas where the neutralization ratio has decreased (i.e., the particles have become more acidic) compared to the base case, and negative regions indicate areas where the neutralization ratio has increased (i.e., the particles have become less acidic). The main $\mathrm{NH}_{3}$ emitting regions in the US midwest display relatively little change in particle charge balance; these regions are $\mathrm{NH}_{3}$-saturated, so there is little impact on particle charge balance in spite of the predicted concurrent decreases in ambient $\mathrm{NH}_{3}$ concentrations (cf. Fig. 4). Substantial decreases in the particle neutralization ratio (i.e., increases in particle acidity and changes in particle composition) do occur downwind and on the fringes of the $\mathrm{NH}_{3}$ emissions regions.

The predicted change in the total ammonium to sulphate mole ratio resulting from the $30 \%$ change in $\mathrm{NH}_{3}$ emissions is shown in Fig. 15. The total ammonium to sulphate ratio describes the chemical regime, and Figure 15 shows that the reduction in emitted $\mathrm{NH}_{3}$ has resulted in a more acidic chemical regime over the $\mathrm{NH}_{3}$ source regions, with relatively little change outside of those source regions. Figures 14 and 15 suggest that the composition of particles formed over the 


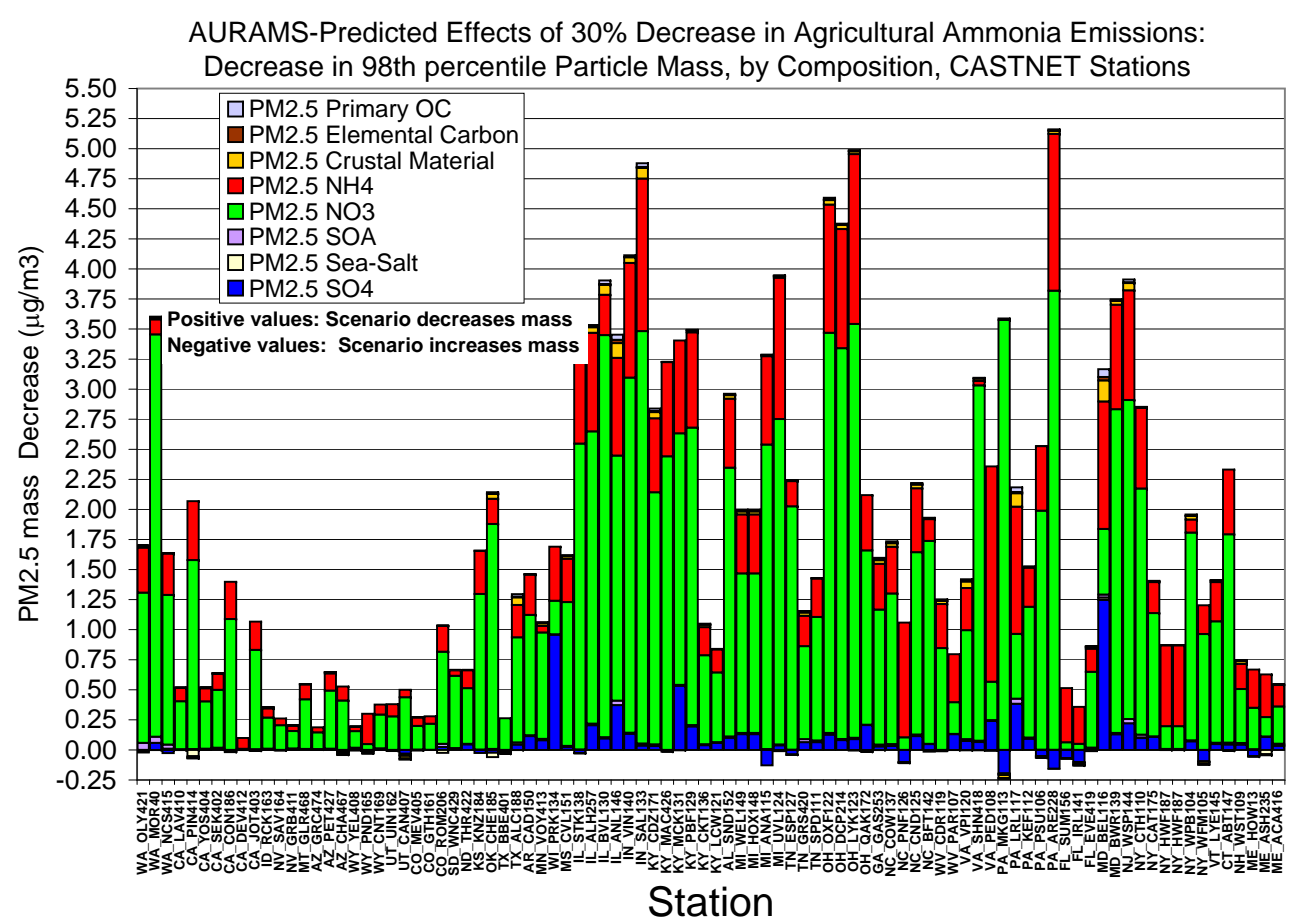

AURAMS-Predicted Effects of 30\% Decrease in Agricultural Ammonia Emissions: Decrease in 2nd percentile Particle Mass, by Composition, CASTNET Stations

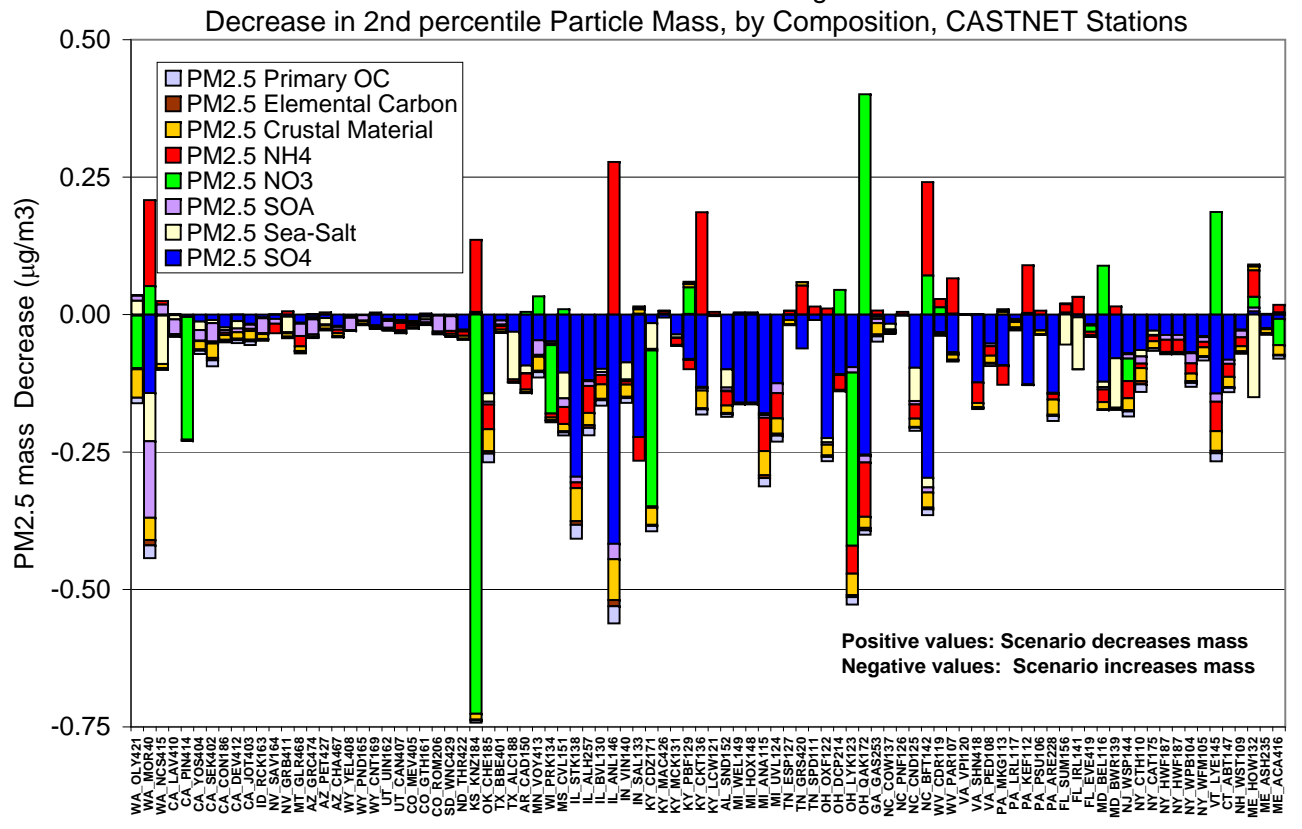

Station

Fig. 13. (a) Same as Fig. 12, for CASTNet stations. (b) Same as Fig. 12, for CASTNet stations.

$\mathrm{NH}_{3}$ source regions will change. For example, given the minor change in neutralization ratio in southern Minnesota (Fig. 14), the drop in total ammonium to sulphate mole ratio in these regions (Fig. 15) suggests that the particles may have more acidic components (hydrogen ion, etc.) over the source regions. That is, these two figures taken together sug- gest that particle nitrate is the dominant means of transport of $\mathrm{NH}_{3}$ from the source regions to regions downwind; the mass of particle sulphate in the $\mathrm{NH}_{3}$ source regions is invariant, and the lack of change in the neutralization ratio there shows that reductions in particle ammonium are being accompanied by reductions in particle nitrate (see Figs. 6 and 


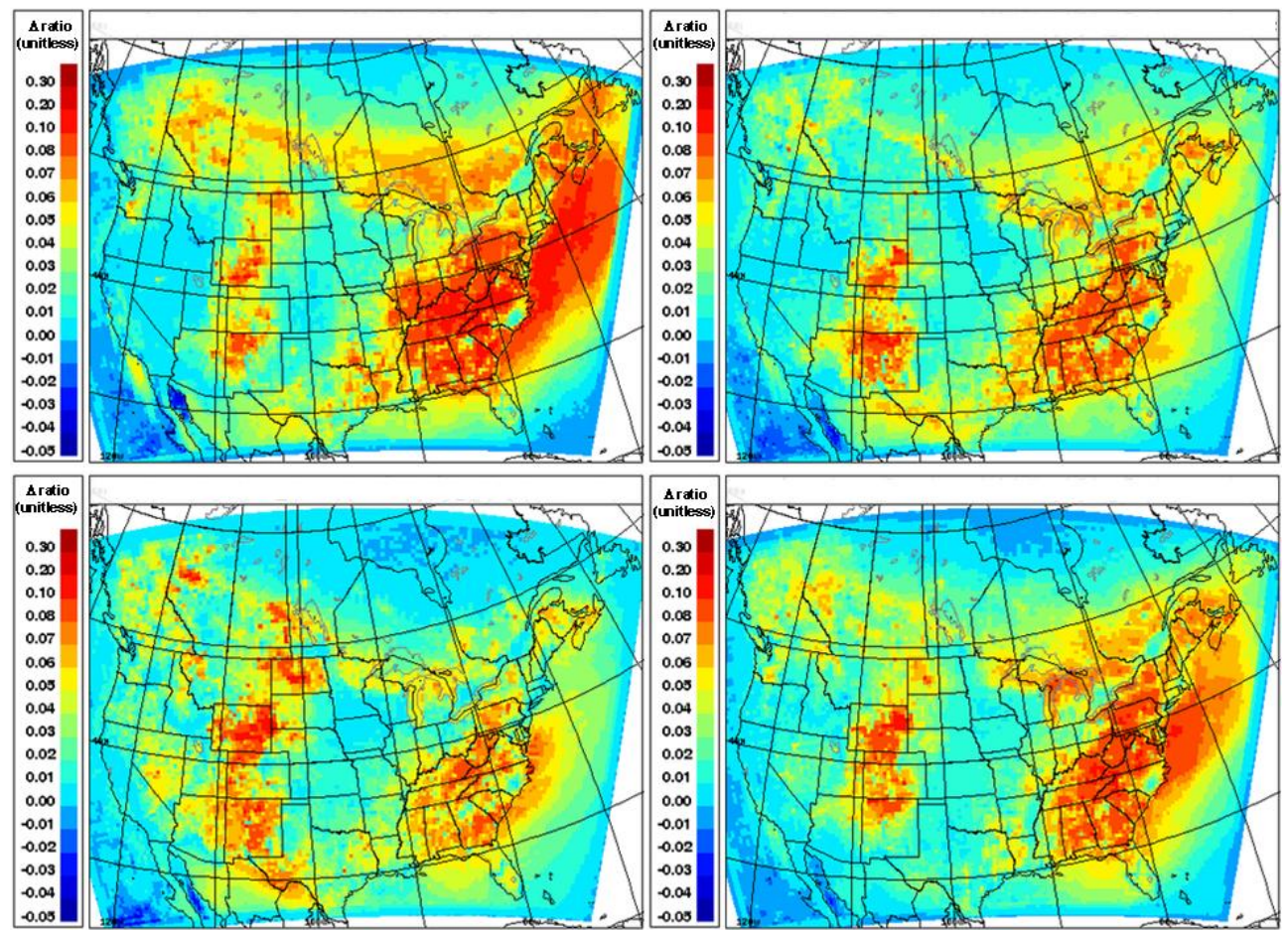

Fig. 14. Change in particle neutralization ratio due to $30 \%$ reduction in $\mathrm{NH}_{3}$ emissions. Positive regions indicate increased particle acidity relative to the base case. Panels arranged as in Fig. 2.

8). The downwind impact of the $\mathrm{NH}_{3}$ emissions is therefore due in part to particle ammonium nitrate transport.

A strong seasonal variation in changes to chemical regime can also be seen in Fig. 15, particularly over the Canadian Prairies. Spring and fall have the greatest increase in particle regime acidity, while summer and winter have smaller changes.

The change in the mass fraction of $\mathrm{NH}_{3}$ (i.e., $\left[\mathrm{NH}_{3}(\mathrm{~g})\right] /\left\{\left[\mathrm{NH}_{3}(\mathrm{~g})\right]+\left[\mathrm{PM}_{2.5}-\mathrm{NH}_{4}\right]\right\}$ on a mass basis) is shown in Fig. 16. The differences are positive over most of the domain and over all seasons, showing that a greater proportion of the remaining (ammonia + ammonium) mass resides in the particle phase instead of the gas phase following a reduction in $\mathrm{NH}_{3}$ emissions. The effect is strongest in the summer and weakest in the winter. The figure suggests that reductions in $\mathrm{NH}_{3}$ gas emissions will result in a nonlinear reduction in $\mathrm{NH}_{3}$ gas concentrations due to thermodynamics: a shift in phase will reduce the relative amount of $\mathrm{NH}_{3}$ that remains in the gas-phase.

The ratio of the sum of $\mathrm{PM}_{2.5}$ nitrate and ammonium mass to total $\mathbf{P M}_{2.5}$ mass is shown in Fig. 17. This figure shows that the relative amount of $\mathrm{PM}_{2.5}$ composed of these $\mathrm{NH}_{3}$ sensitive species has decreased in the $30 \%$ reduction scenario. The figure is also of interest in that it confirms ammonium nitrate as the means of long-range transport of $\mathrm{NH}_{3}$ mass. Comparing the summer (upper left) panels of Figs. 17, 4 , and 5 , it can be seen that:
1. The largest ammonia source region is located in southern Minnesota and northern Iowa (Fig. 4), while the largest particle mass reductions occur further to the east, north of the Ohio River (Fig. 5).

2. The region of greatest particle ammonium and nitrate reduction (Figs. 6, 8 and 17) occurs over the state of Illinois i.e., between the ammonia source region and the region of greatest particle mass reduction.

The change in the fraction of directly $\mathrm{NH}_{3}$-sensitive particle mass has a strong seasonal variation, with the greatest impact in the winter (lower left panel, Fig. 17). This is consistent with the strong dependence of particle nitrate formation on temperature, with colder temperatures resulting in a greater proportion of ammonia and nitric acid gas being converted to particle ammonium nitrate, ammonium, and nitrate ions.

\subsubsection{Total deposition}

AURAMS calculates the wet and dry deposition of various species to the Earth's surface as moles $\mathrm{m}^{-2}$ hour $^{-1}$. The hourly wet and dry deposition fields have been added together and summed to seasonal mass totals ( $\mathrm{kg} / \mathrm{ha} / \mathrm{season}$ ) for the following analysis. As before, scenario values are then subtracted from the base case to determine the impact of the reduced $\mathrm{NH}_{3}$ emissions. 

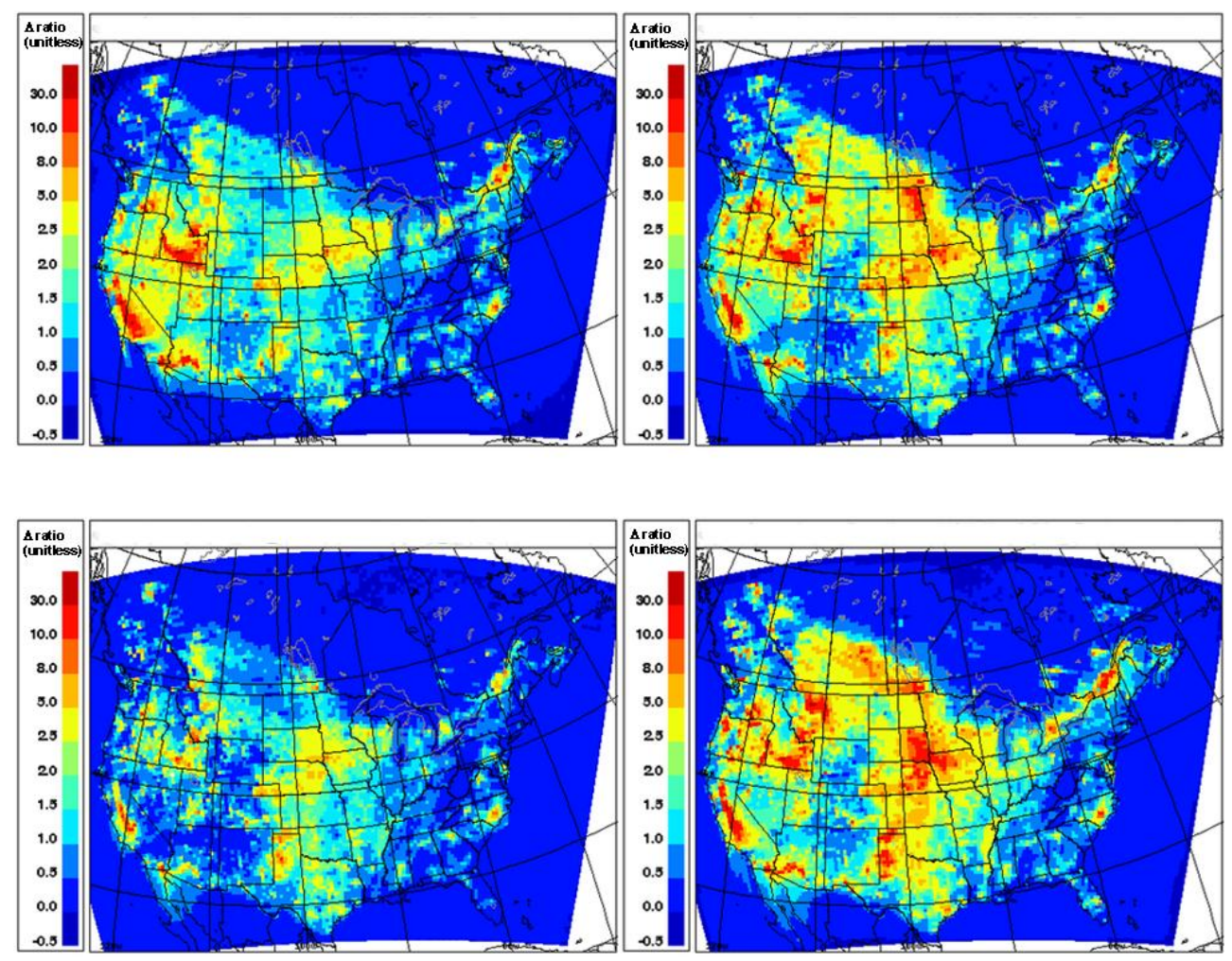

Fig. 15. Change in total ammonia to sulphate mole ratio due to $30 \%$ reduction in $\mathrm{NH}_{3}$ emissions. Positive regions indicate decreases in the ratio (more acidic chemical regimes) relative to the base case. Panels arranged as in Fig. 2.

The predicted change in total deposition of all forms of sulphur $\left(\mathrm{SO}_{2}+\mathrm{H}_{2} \mathrm{SO}_{4}+\mathrm{p}-\mathrm{SO}_{4}\right.$ dry deposition and wet deposition) is depicted in Fig. 18. The 30\% reduction in the emissions of $\mathrm{NH}_{3}$ has resulted in decreases in sulphur total deposition (red) in many regions in both Canada and the USA.. Increases in sulphur deposition are also present, in the colder seasons (SE US, Atlantic provinces). It should be noted that these predicted changes to the sulphur deposition associated with ammonia emissions reductions, while significant, are relatively small in magnitude relative to the total sulphur deposited: on the order of $1 \%$ of the total sulphur total deposition.

The predicted changes in sulphur total deposition are the result of the following $\mathrm{NH}_{3}$ emissions-reduction-induced changes in the state of atmospheric sulphur:

1. A reduction in $\mathrm{NH}_{3}$ reduces the capacity of cloud water and rain to absorb $\mathrm{SO}_{2}$, via the net equilibrium: $\mathrm{NH}_{3}(\mathrm{~g})+\mathrm{SO}_{2}(\mathrm{~g})+\mathrm{H}_{2} \mathrm{O} \Leftrightarrow \mathrm{NH}_{4}^{+}(\mathrm{aq})+\mathrm{HSO}_{3}^{-}(\mathrm{aq})$.

The concentration of the ammonium ion decreases, hence less $\mathrm{SO}_{2}(\mathrm{~g})$ can enter the aqueous phase as $\mathrm{HSO}_{3}^{-}(\mathrm{aq})$ in the absence of the buffering provided by $\mathrm{NH}_{3}$. The reduction of the sulphur content in cloud water and rain results in less sulphur being removed by wet deposition. Note that in the presence of higher temperatures and sufficient aqueous-phase oxidation of $\mathrm{HSO}_{3}^{-}(\mathrm{aq})$, this equilibrium will shift to the right (see discussion above in section 4.2.2).

1. A corollary to (1) is that less sulphur is removed in precipitation. The sulphur, which remains in the form of $\mathrm{SO}_{2}(\mathrm{~g})$, will therefore be transported longer distances due to decreased rainout/washout. The increases in sulphur deposition that takes place in the colder seasons in Fig. 18 (eastern seaboard of US, Atlantic Ocean) results from the transport and subsequent deposition of $\mathrm{SO}_{2}$ to greater downwind distances.

2. Another corollary to (1) is that reductions in $\mathrm{NH}_{3}$ emissions will reduce the amount of ammonium ion in the cloud droplets and water, and hence will reduce the amount of nitrate taken up in cloud water and rain, and thus the amount of nitrate removed by wet deposition. Total nitrogen deposition therefore decreases due to decreases in both reduced and oxidized nitrogen deposition, as discussed below. 


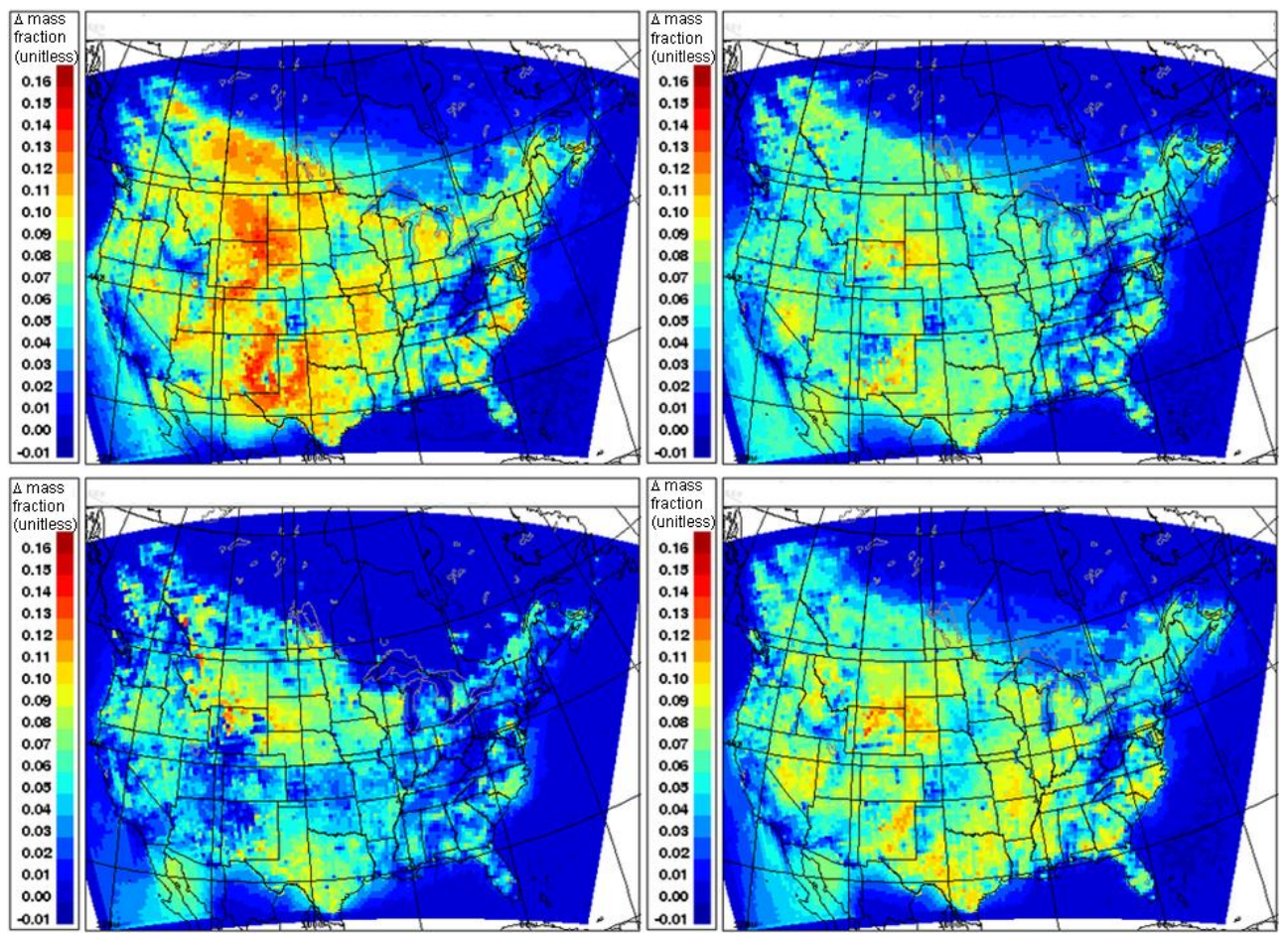

Fig. 16. Change in gas-phase $\mathrm{NH}_{3}$ mass fraction due to $30 \%$ reduction in $\mathrm{NH}_{3}$ emissions. Positive regions indicate decreases in mass fraction (i.e., proportionately more ammonium in the particle phase) relative to the base case. Panels arranged as in Fig. 2.

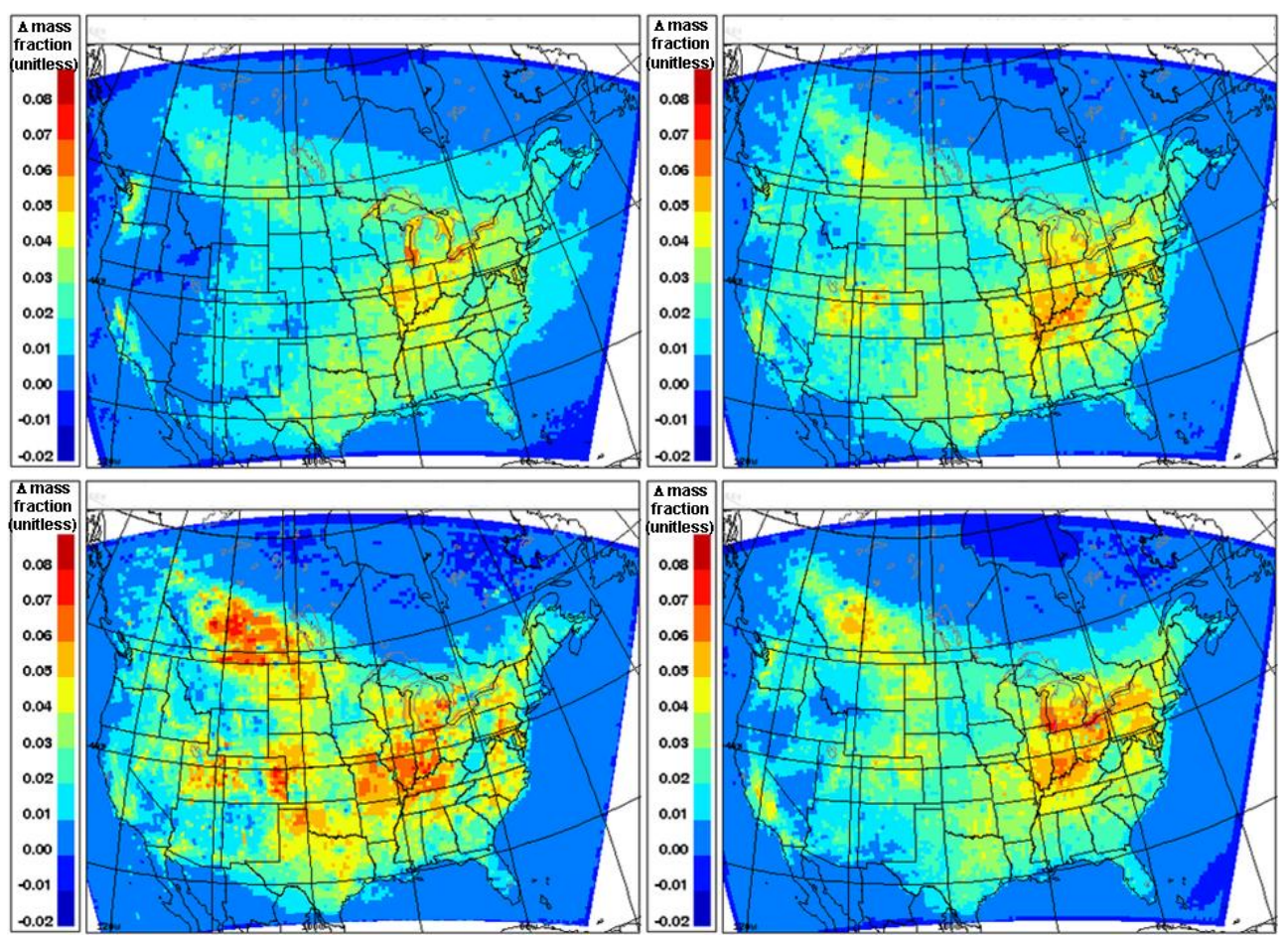

Fig. 17. Change in fraction of ammonium + nitrate mass in $\mathrm{PM}_{2.5}$ relative to the total $\mathrm{PM}_{2.5}$ mass. Positive regions indicate decreases in ammonium and nitrate mass fraction (i.e., particles composed of proportionately less ammonium and nitrate) relative to the base case. Panels arranged as in Fig. 2. 

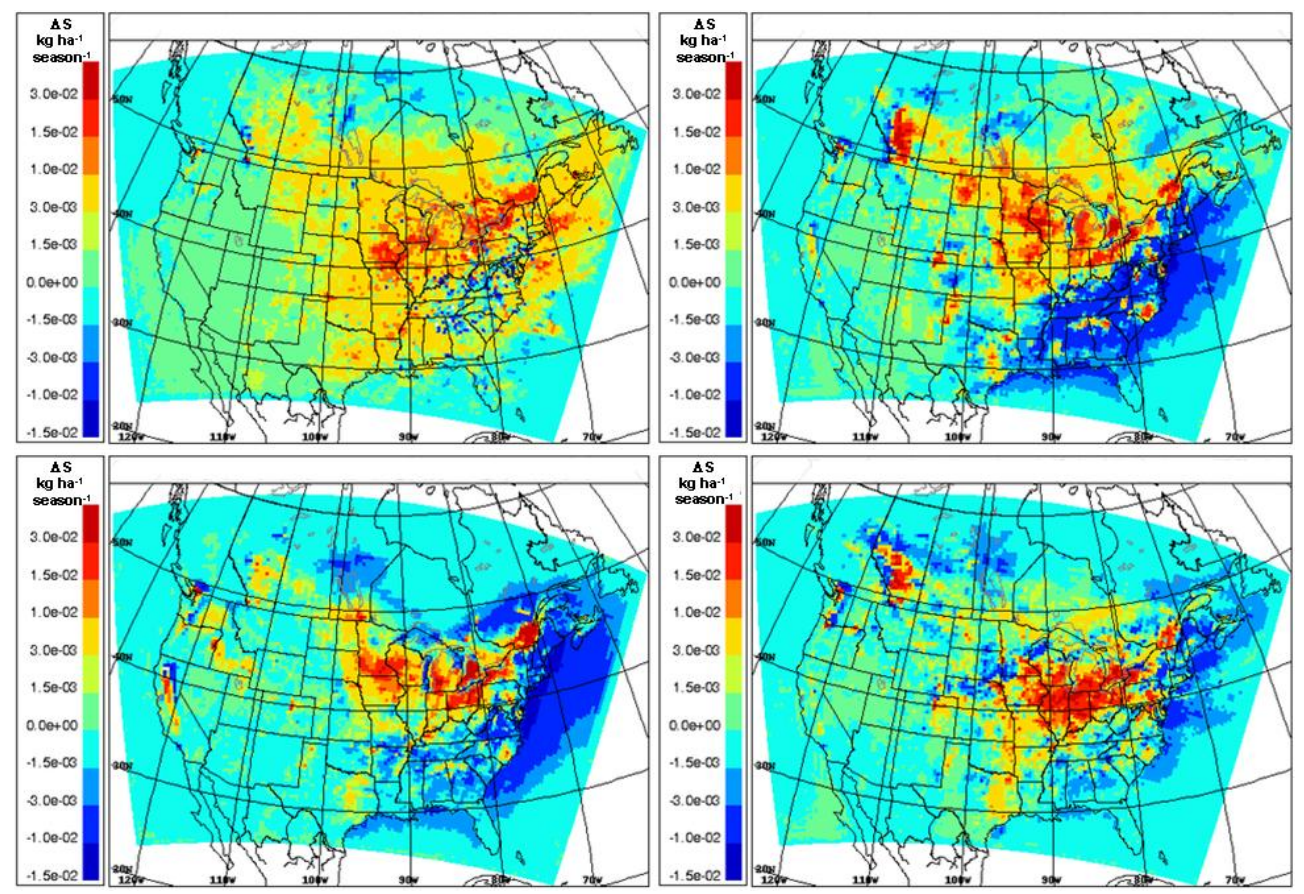

Fig. 18. Change in total - sulphur total deposition $\left(\mathrm{kg} \mathrm{S} / \mathrm{ha} / \mathrm{season}\right.$ ) due to $30 \%$ reduction in $\mathrm{NH}_{3}$ emissions. Positive values (green to red colours) indicate decreases in sulphur deposition resulting from decreasing $\mathrm{NH}_{3}$ emissions; negative values (blue) indicate increases in sulphur deposition resulting from decreasing $\mathrm{NH}_{3}$ emissions. Panels arranged as in Fig. 2.

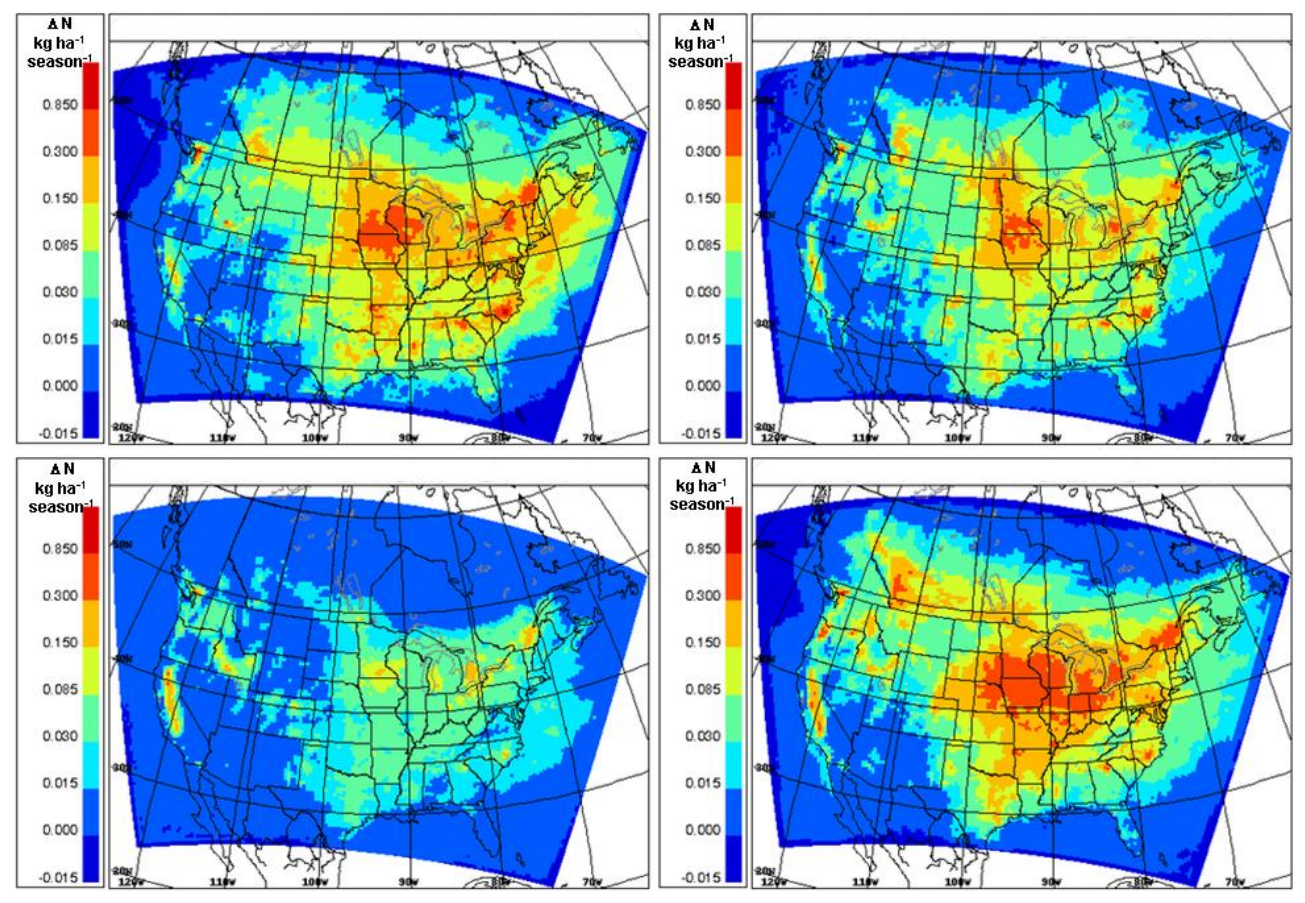

Fig. 19. Change in total - nitrogen total deposition ( $\mathrm{kg} \mathrm{N} / \mathrm{ha} /$ season) due to $30 \%$ reduction in $\mathrm{NH}_{3}$ emissions. Positive values (light blue to red colours) indicate decreases in nitrogen deposition resulting from decreasing $\mathrm{NH}_{3}$ emissions; negative values (dark blue) indicate increases in nitrogen deposition resulting from decreasing $\mathrm{NH}_{3}$ emissions. Panels arranged as in Fig. 2. 
3. Reductions in $\mathrm{NH}_{3}$ emissions may also cause a reduction in the size of ambient particles, since less $\mathrm{NH}_{3}$ leads to less $\mathrm{p}-\mathrm{NH}_{4}$ and $\mathrm{p}-\mathrm{NO}_{3}$ in the particle phase, hence smaller particles, which may have a smaller deposition velocity.

The change in total deposition of all
phases of nitrogen related to ammonia chemistry (sum of $\left\{\mathrm{NH}_{4}^{+}(\mathrm{aq})+\mathrm{NH}_{3}(\mathrm{~g})+\mathrm{PM}_{2.5}\right.$ $\mathrm{NH}_{4}+\mathrm{NO}_{3}^{-}(\mathrm{aq})+\mathrm{HNO}_{3}(\mathrm{~g})+\mathrm{PM}_{2.5} \quad \mathrm{NO}_{3} \quad$ \}) is shown in Fig. 19. The reduction in $\mathrm{NH}_{3}$ emissions by $30 \%$ has resulted in substantial reductions in deposited nitrogen (similar in magnitude to the total deposited nitrogen in many locations). The greatest spatial extent of nitrogen deposition reduction occurs in the spring (lower right panel), when $\mathrm{NH}_{3}$ emissions are highest, and the smallest change occurs in the winter (lower left panel), when $\mathrm{NH}_{3}$ emissions are lowest. The location of the largest reductions in nitrogen deposition occurs over the $\mathrm{NH}_{3}$ emitting areas (compare Figs. 4 and 19. Less than $10 \%$ of the total change in deposited nitrogen is associated with the various forms of nitrate, and is instead dominated by the ammonium components (not shown). The change in total ammonia/um deposition is itself dominated by aqueous ammonium wet deposition (approximately $5 / 6$ of the total) and $\mathrm{NH}_{3}$ dry deposition (remaining 1/6), with changes to $\mathrm{p}-\mathrm{NH}_{4}$ dry deposition being relatively insignificant for the nitrogen budget.

The main results of the deposition analysis for a 30\% reduction in agricultural $\mathrm{NH}_{3}$ emissions are thus:

1. Sulphur deposition close to the sources of sulphur decreases slightly, due largely to a reduction in $\mathrm{SO}_{2}(\mathrm{~g})$ uptake in clouds. Sulphur deposition further downwind of the sources may increase as a consequence, depending on the season.

2. Nitrogen deposition decreases significantly, driven largely by decreases in aqueous ammonium wet deposition ( $75 \%$ of the total decrease in $\mathrm{N}$ ) and dry deposition of ammonia gas (15\%), but also by near-source decreases in deposition of all forms of nitrate (10\%).

3. Hydrogen ion wet deposition increases (not shown). The increase in hydrogen ion deposition is spatially matched with the decreases in nitrogen deposition and is greatest over the regions of $\mathrm{NH}_{3}$ emissions.

\subsubsection{Annual critical load exceedances for sensitive ecosystems}

Annual critical-load exceedance fields for Canada were calculated for the base case and for the $30 \%$ emissions reduction scenario in two ways: for (a) sulphur (S) total deposition and for (b) sulphur + nitrogen $(\mathrm{S}+\mathrm{N})$ total deposition.

Annual critical-load exceedances for sulphur were not significantly changed between the base case and the $30 \%$
$\mathrm{NH}_{3}$ emissions reduction scenario (annual critical-load exceedances did decrease for the $\mathrm{NH}_{3}$ emissions reduction scenario, but significant reductions only occurred at two model gridpoints: not shown). This indicates that the impact of $\mathrm{NH}_{3}$ emissions reductions on sulphur acidification of ecosystems is expected to be small, in accord with the relatively small changes in total sulphur deposition (Fig. 18).

Figure 20a shows the predicted $\mathrm{S}+\mathrm{N}$ annual criticalload exceedances for the base case. Figure $20 \mathrm{~b}$ shows the corresponding reductions in $\mathrm{S}+\mathrm{N}$ annual critical-load exceedances in many parts of Canada that are predicted to result from a $30 \%$ reduction in agricultural $\mathrm{NH}_{3}$ emissions. These substantial decreases in $\mathrm{S}+\mathrm{N}$ annual critical-load exceedances are in contrast to the small decreases in S-only annual critical-load exceedances.

The implication of this finding is that if an ecosystem's ability to absorb $\mathrm{N}$ from atmospheric deposition is compromised at these locations in the future, i.e., $\mathrm{N}$ saturation (e.g., Aber and Magill, 2004), then the deposition of atmospheric nitrogen resulting from $\mathrm{NH}_{3}$ emissions will contribute to a degradation of these ecosystems. While recent streamwater-chemistry trend analyses in Europe suggest that many decades of elevated $\mathrm{N}$ deposition may be required for N saturation to occur (Wright et al., 2001), reduced N retention in soils and increased $\mathrm{N}$ leaching to streams and lakes can begin much sooner (e.g., Kaste et al., 2002; Jeffries and Ouimet, 2005). Reductions in $\mathrm{NH}_{3}$ emissions can thus reduce present or potential acidification due to inorganic $\mathrm{N}$ deposition

\subsubsection{A conceptual model}

The above analysis of AURAMS simulations may be used to provide a simple conceptual model to describe the effect of reductions in $\mathrm{NH}_{3}$ emissions on atmospheric chemistry. The following diagram (Figure 21) depicts the processes, on a hypothetical transect with $\mathrm{NH}_{3}$ emissions on the left, a source of $\mathrm{SO}_{2}$ and $\mathrm{NO}_{\mathrm{x}}$ in the centre, and a receptor region downwind on the right. This is similar to the situation on the eastern half of the North American continent, with the US midwest $\mathrm{NH}_{3}$ source on the left, the Ohio Valley and Great Lakes regions in the centre, and the Atlantic provinces and New England states on the right. The prevailing wind blows from left to right in this diagram. The upper half of the diagram shows the system in the absence of $\mathrm{NH}_{3}$ emission controls, the lower half the system including controls in $\mathrm{NH}_{3}$ emissions. Coloured text in the lower half of the diagram indicates terms that have changed; red for species that have decreased, blue for species that have increased, and green for species with a non-linear response that may be seasonally dependant.

In the absence of emissions controls (Figure 21, top), excess $\mathrm{NH}_{3}$ in the source region at left creates particle ammonium nitrate, in addition to particle ammonium sulphate. Winds blowing to the right then transport the particles and 


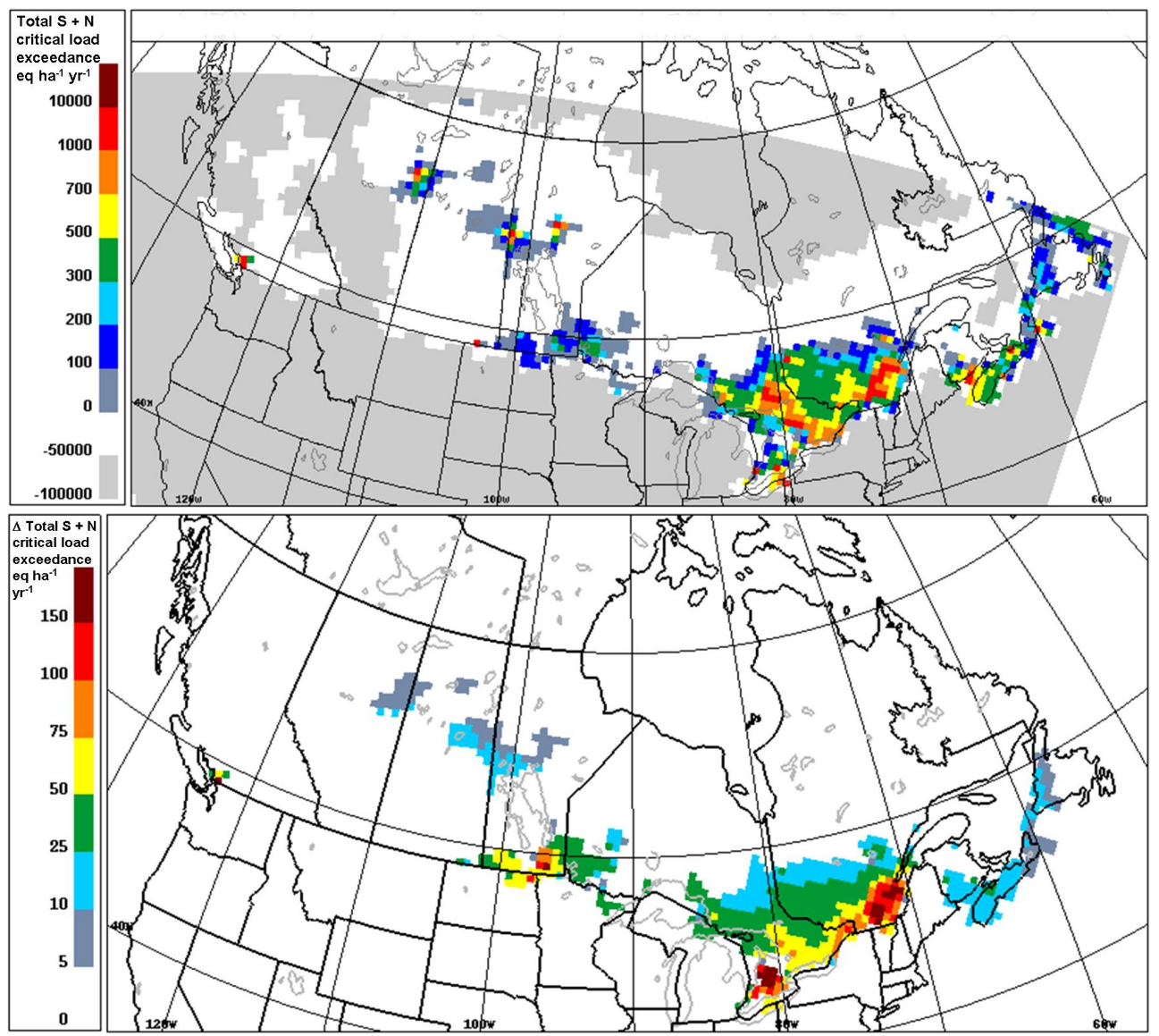

Fig. 20. AURAMS-predicted Canadian $(S+N)$ critical-load exceedances for 2002: (top) NAESI base case; and (bottom) (base case - 30\% $\mathrm{NH}_{3}$ emissions reduction scenario). Gray areas in the top panel indicate areas for which critical-load values were not available. Positive values in the bottom panel indicate areas where the critical load exceedance has decreased in response to decreasing $\mathrm{NH}_{3}$ emissions.

$\mathrm{NH}_{3}$ gas. En route, the $\mathrm{NH}_{3}$ gas is depleted due to wet and dry deposition, as are the particles by wet deposition. Nevertheless, significant amounts of particle ammonium and nitrate reach the $\mathrm{SO}_{2}$ and $\mathrm{NO}_{\mathrm{x}}$ emissions source region in the centre of the figure. The addition of fresh $\mathrm{SO}_{2}$ and nitric acid to the system cause the particles to locally become more acidic, with some transfer of the transported ammonium from particle nitrate to particle sulphate possible due to inorganic thermodynamics. With subsequent transport further downwind, the particles are deposited; relatively little $\mathrm{SO}_{2}$ reaches far downwind locations due to $\mathrm{NH}_{3}$-enhanced aqueous-phase conversion to sulphate closer to the source regions, particularly in colder seasons, when $\mathrm{HSO}_{3}^{-}(\mathrm{aq})$ oxidation is inhibited.

With the presence of $\mathrm{NH}_{3}$ controls (Figure 21, bottom, also Figs. 5, 6, 7, 8, 12, 13), less ammonium nitrate is created in the Midwest source region, and hence less is available for transport (e.g. Fig. 8, seasonal average $\mathrm{p}-\mathrm{NO}_{3}$ decreases of $>0.7 \mu \mathrm{g} / \mathrm{m}^{-3}$ in western Illinios, summer and fall). Smaller amounts of ammonium reach the central $\mathrm{SO}_{2}$ and $\mathrm{NO}_{\mathrm{x}}$ source region; this reduces the rate of further particle formation and allows more subsequent downwind transport and deposition of $\mathrm{SO}_{2}$. (see Fig. 6 , note $\mathrm{p}-\mathrm{NH}_{4}$ decreases in NW Illinios, NW Indiana of about $0.2 \mu \mathrm{g} / \mathrm{m}^{-3}$, also note Fig. 18b, c, sulphur deposition increasing fall and winter, when aqueous phase conversion to sulphate is less efficient; more transport of $\mathrm{SO}_{2}$ and less deposition close to sources). Depending on the season, the conversion of $\mathrm{HSO}_{3}^{-}(\mathrm{aq})$ to $\mathrm{SO}_{4}^{2-}(\mathrm{aq})$ in cloud water may increase with the drop in $\mathrm{H}^{+}(\mathrm{aq})$ associated with ammonia emissions increases. (see Fig. 7a, average summer increase in p- $\mathrm{SO}_{4}$ over the Eastern USA. on the order of $0.10 \mu \mathrm{g} / \mathrm{m}^{-3}$, due to cloud water oxidation of $\mathrm{SO}_{2}$ ).

A neutral charge balance ratio is maintained over the $\mathrm{NH}_{3}$ source region at the left regardless of the scenario; since this region remains $\mathrm{NH}_{3}$-saturated, reductions in $\mathrm{p}-\mathrm{NH}_{4}$ here are matched by reductions in $\mathrm{p}-\mathrm{NO}_{3}$ in the denominator (c.f. Figure 14, neutralization over Minnesota and Iowa is unchanged despite emissions reductions). In the $\mathrm{SO}_{2}$ and $\mathrm{NO}_{\mathrm{x}}$ source region in the centre, however, the upwind reductions in $\mathrm{NH}_{3}$ 


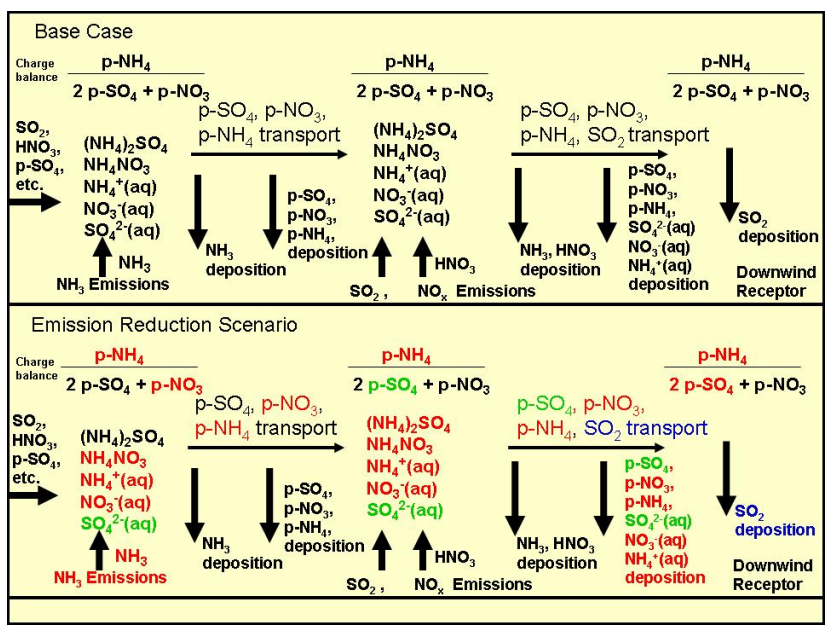

Fig. 21. Conceptual model of $\mathrm{NH}_{3}$ emissions, reaction and transport: (top) without $\mathrm{NH}_{3}$ emissions controls; (bottom) with $\mathrm{NH}_{3}$ emissions controls. Font colours: red: species that have decreased with $\mathrm{NH}_{3}$ emissions controls; blue: species that have increased; green: species with a non-linear response that may be seasonally dependant.

emissions result in a net decrease in charge balance and an increase in particle acidity that is then maintained during further downwind transport (c.f. Figure 14, Ohio river valley increased acidity).

While this conceptual model aids in understanding the AURAMS predictions, it is not intended as a quantitative analysis of a given region, or a specific time period.

\section{Uncertainty analysis of the $50 \%$ Canadian Beef Cattle emissions reduction scenario}

The main intent of this scenario was to serve as an uncertainty benchmark for the previous scenario. The sub-sector with the largest uncertainty in the Canadian agricultural $\mathrm{NH}_{3}$ emissions inventory is that of Beef Cattle, estimated to be as high as a factor of two; the $50 \%$ reduction considered in this scenario thus represents the lower range of the uncertainty envelope. Comparisons to the $30 \%$ all-sector scenario thus show the limitations to the above analysis, in locations where this sub-sector dominates $\mathrm{NH}_{3}$ emissions.

The model response for $\mathrm{PM}_{2.5}$ mass for this emissions scenario, relative to the base case, is shown below in Fig. 22. This combines the seasonal difference in $\mathrm{PM}_{2.5}$ due to a $30 \%$ agricultural ammonia reduction (left hand column of panels) with the seasonal difference due to a $50 \%$ reduction in ammonia emissions from Canadian Beef Cattle alone (righthand column of panels). The reduction of beef-cattle emissions by $50 \%$ has about the same impact in this region (about the same size as the US state of Texas) as the $30 \%$ overall reduction noted above. Smaller magnitude changes were also noted in the province of Ontario (not shown).
One important conclusion from this analysis is that for the Canadian Prairie provinces, the range of uncertainty in model predictions associated with the beef-cattle emissions factors may be as large as the impacts from an across-the-board 30\% reduction of $\mathrm{NH}_{3}$ emissions. While the best available information was used to compile the new $\mathrm{NH}_{3}$ emissions inventory, improvements in the beef-cattle subsector of the inventory are recommended for future work. Similar uncertainty analyses for US ammonia emissions are also recommended.

The other aspect to this sensitivity analysis is to demonstrate the extent to which sector-specific scenario simulations are possible with the updated $2002 \mathrm{NH}_{3}$ Canadian emissions inventory. An emissions reduction strategy may be "tailored" for the dominant emissions sources in a given region; very specific emissions reduction strategies may be tested in the future.

\section{Conclusions and recommendations for future re- search}

A unified regional air-quality modelling system (AURAMS) was used to investigate the effects of reductions in $\mathrm{NH}_{3}$ emissions on regional air quality, especially PM. Three simulations of one-year duration were performed for a North American domain for different sets of $\mathrm{NH}_{3}$ emissions. The simulation for a $30 \%$ continent-wide reduction in agricultural ammonia emissions predicted decreases in median hourly $\mathrm{PM}_{2.5}$ mass of $<1 \mu \mathrm{g} \mathrm{m}^{-3}$. However, the atmospheric response to these emission reductions has marked seasonal variations, and on even shorter time scales the impacts of the emissions reductions are highly episodic: for example, 95th-percentile hourly $\mathrm{PM}_{2.5}$ mass decreases may be a factor of six larger than the median values.

A key feature of the above simulations is the manner in which continental-scale long-range transport may play a role in defining the impacts of reductions in $\mathrm{NH}_{3}$ emissions. The emissions reductions affect local $\mathrm{NH}_{3}$ gas concentrations, but the largest impacts of these reductions may take place significantly downwind of the main $\mathrm{NH}_{3}$ emissions source in strongly or weakly $\mathrm{NH}_{3}$-limited areas. The interaction between transport and chemistry is complex: $\mathrm{NH}_{3}$ mass is transported from the source regions as aqueous and particle ammonium, and emissions of other particle precursors play a significant role in the subsequent chemistry. Reductions in $\mathrm{NH}_{3}$ emissions result in a small but significant decrease in the amount of $\mathrm{SO}_{2}$ gas converted to sulphate in the colder three seasons of the year. Small increases in aqueous sulphate formation and $\mathrm{SO}_{2}$ uptake are predicted in summer. Reductions in aqueous buffering capacity and decreases in particle size decrease local sulphur deposition in favour of $\mathrm{SO}_{2}$ deposition further downwind; a by-product of the $\mathrm{NH}_{3}$ emissions reduction is to increase the overall transport distance of emitted atmospheric sulphur. Ammonia emissions reductions result in a significant decrease in total ammonia 


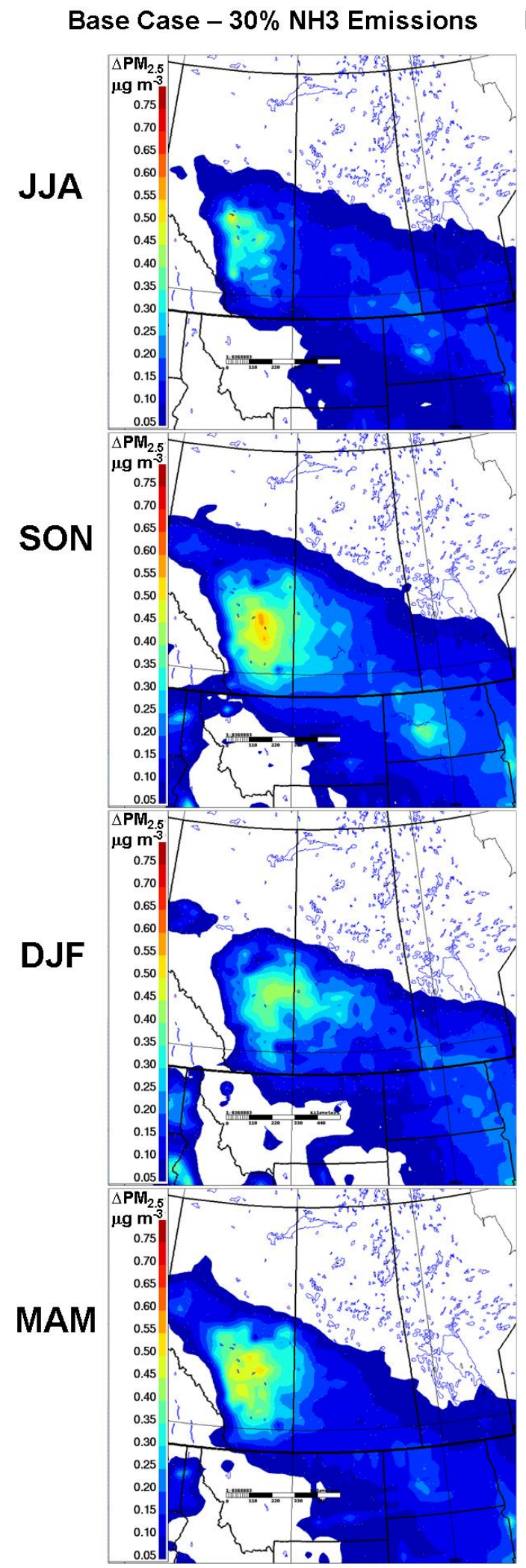

\section{Base Case - $\mathbf{5 0 \%}$ Cdn. Beef Emissi}
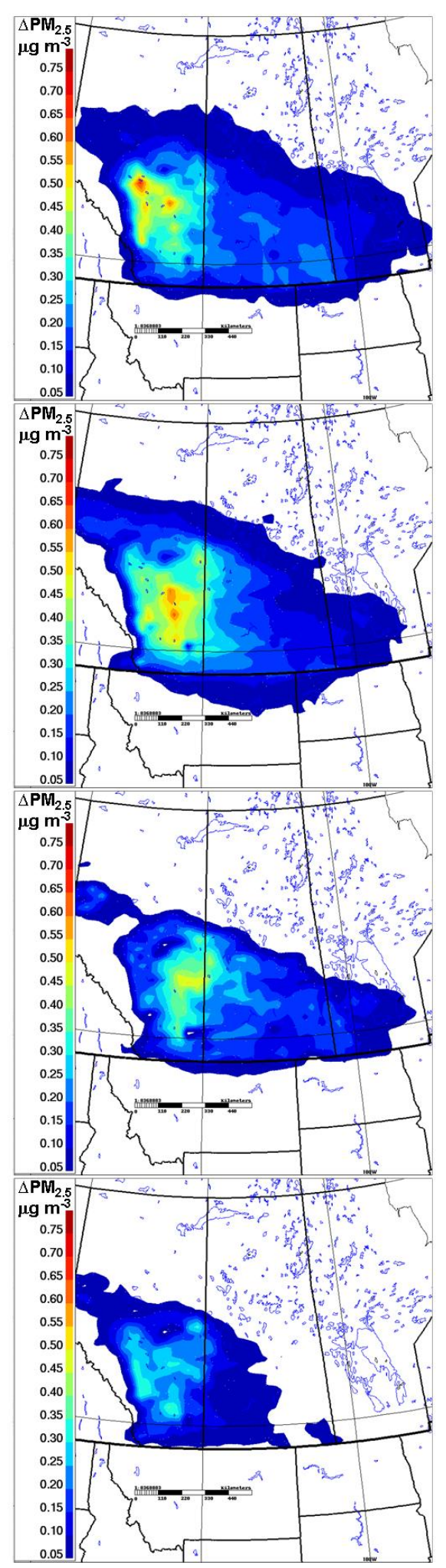

Fig. 22. Seasonal average change in $\mathrm{PM}_{2.5}$ mass $\left(\mu \mathrm{g} \mathrm{m}^{-3}\right)$ associated with a $50 \%$ reduction in Canadian beef-cattle emissions. Portion of model domain covering provinces of Alberta, Saskatchewan, and Manitoba. 
deposition and a smaller decrease in nitrate deposition, in regions of high ammonia emissions.

Figures 10 and 11 show that the impact of $\mathrm{NH}_{3}$ emissions reductions is highly episodic in nature. In both high and low resolution model runs, 95th percentile values of the differences between base case and scenarios are often much larger (up to a factor of 6) than the median differences of the distribution. This is in accord with the known chemistry of $\mathrm{p}-\mathrm{NH}_{4}$ formation, specifically ammonium nitrate, and our analysis suggests that $\mathrm{PM}_{2.5}$ mass decreases resulting from ammonia emissions reductions will result from decreases in particle ammonium and particle. Relatively small changes in local temperature, humidity, and precursor-gas concentrations can give rise to rapid particle formation and/or loss conditions (e.g., Yu et al., 2005). Decreases in $\mathrm{NH}_{3}$ emissions may have a modest or low impact on $\mathrm{PM}_{2.5}$ levels in median or average conditions, but a much larger impact when $\mathrm{PM}_{2.5}$ levels are high.

Reductions in $\mathrm{NH}_{3}$ emissions may result in decreases in acid deposition and in exceedance of $\mathrm{S}+\mathrm{N}$ critical loads for sensitive Canadian ecosystems. The predicted small changes to sulphur deposition, on the other hand, have little impact on sulphur critical-load exceedances, implying that $\mathrm{NH}_{3}$ emissions reductions at the current time will not reduce the sulphur acidification of sensitive ecosystems. However, if the ability of these ecosystems to absorb nitrogen becomes saturated, the role of $\mathrm{NH}_{3}$ on the exceedance of critical loads does become substantial. Ammonia emissions reductions hence may eventually be required to reduce acidification of Canadian ecosystems

The important linkages between transport and chemistry when $\mathrm{NH}_{3}$ reductions are considered suggests that crossborder transport may be an important factor when assessing the outcomes of $\mathrm{NH}_{3}$ emission reduction strategies. Ammonia and PM concentrations may be affected considerably downwind, and sulphur and nitrogen transport distances from sources of sulphur and nitrogen and associated deposition patterns are changed. Some future scenario runs should focus on trans-boundary transport.

The beef-cattle emissions scenario shows that the uncertainty associated with the updated 2002 Canadian agricultural $\mathrm{NH}_{3}$ emissions inventories for this source subsector is large. Future work on emissions inventories should attempt to reduce this uncertainty. This scenario also serves to show the potential for $\mathrm{NH}_{3}$ emissions reduction scenarios that assess the impacts of agricultural-subsector-specific changes in emitting practices. Scenarios examining the impacts of $\mathrm{NH}_{3}$ management practice changes should therefore be considered in future work.

A potentially significant source of uncertainty in all of the model results is the role of coarse-mode chemistry in the real atmosphere; the model neglects base cation chemistry (calcium, magnesium, sodium, potassium), and the model particle nitrate formation may therefore be more sensitive to changes in ammonia gas emissions than would occur in the ambient atmosphere. Coarse-mode particle chemistry may reduce the impact of ammonia emissions reductions by competing with the fine mode for the available nitric acid, as well as providing sites for condensation of nitric and sulphuric acid during intense dust storm events. For this reason, the changes depicted here should be considered upper limits. Inclusion of coarse-mode chemistry is recommended for future model simulations of ammonia emission scenarios.

Acknowledgements. The authors are grateful for the financial assistance of the Canadian federal National Agri-Environmental Standards Initiative (NAESI) for carrying out this work. The authors also wish to thank the two anonymous peer reviewers; their insightful comments resulted in a number of improvements to the original manuscript.

Edited by: S. Pandis

\section{References}

Aber, J. D. and Magill, A. H.: Chronic nitrogen additions at the Harvard Forest (USA): the first 15 years of a nitrogen saturation experiment, Forest Ecol. Manage., 196, 1-5, 2004.

Adema, E. H., Heeres, P., and Hulskotte, J.: On the dry deposition of $\mathrm{NH}_{3}, \mathrm{SO}_{2}$, and $\mathrm{NO}_{2}$ on wet surfaces in a small scale wind tunnel. edited by: Hartman, H. F., Proceedings of the Seventh World Clean Air Congress, Clean Air Society of Australia and New Zealand, 2, 1-8, 1986.

Anlauf, K. G., Lusis, M. A., and Wiebe, H. A.: Toronto Air Quality Study, Env Canada report ARQA-60-78, 1978.

Ansari, A. S. and Pandis, S. N.: Response of inorganic PM to precursor concentrations, Environmental Science and Technology, 32, 2706-2714, 1998.

Ansari, A. S. and Pandis, S. N. Prediction of multicomponent inorganic atmospheric aerosol behavior, Atmos. Environ., 33, 745757, 1999.

Ayres, J., Bittman, S., Girdhar, S., Sheppard, S., Niemi, D., Ratté, D., Smith, P.: Chapter 5: Sources of Ammonia Emissions. In Environment Canada. The 2008 Canadian Atmospheric Assessment of Agricultural Ammonia, Environment Canada, Gatineau, QC, Canada, in press, 2009.

Binkowski F. S. and Shankar U.: The Regional Particulate Matter Model. 1. Model description and preliminary results, J. Geophys. Res., 100, 26, 191-26, 1995.

Binkowski, F. S. and Roselle S. J.: Models-3 Community Multiscale Air Quality (CMAQ) model aerosol component 1. Model description, J. Geophys. Res. Atmos., 108, AAC 3-1-3-18, 2003.

Bittman, S., Ayres, J., Sheppard, S., and Girdhar, S.: Chapter 4: Emission Inventory Development. In Environment Canada, The 2008 Canadian Atmospheric Assessment of Agricultural Ammonia (in press), Environment Canada, Gatineau, QC, Canada, 2008.

Blanchard, C. L., Roth, P. M., Tanenbaum, S. J., Ziman, S. D., and Seinfeld, J. H.: The use of ambient measurements to identify which precursor species limit aerosol formation, J. Air Waste Manage. Assoc., 50, 2073-2084, 2000.

Brosset, C.: Water-soluble sulphur compounds in aerosols, Atmos. Environ., 12, 25-38, 1978. 
Carolina Environmental Program (CEP): Sparse Matrix Operator Kernel Emission (SMOKE) modelling system, University of North Carolina, Carolina Environmental Programs, Chapel Hill, $\mathrm{NC}$, online available at: http://www.smoke-model.org/index. cfm, 2003.

Chang, J. S., Brost, R. A., Isaksen, I. S. A., Madronich, S., Middleton, P., Stockwell, W. R., Walcek, C. J.: A three-dimensional Eulerian acid deposition model: Physical concepts and formulation, J. Geophys. Res., 92, 14681-14700, 2003.

Coste, J. H. and Courtier, G. B.: Sulphuric acid as a disperse phase in town air, T. Faraday Soc., 32, 1198-1202, 1936.

Côté, J., Gravel, S., Méthot, A., Patoine, A., Roch, M., and Staniforth, A.: The operational CMC-MRB Global Environmental Multiscale (GEM) model. Part 1: Design considerations and formulation, Mon. Weather Rev., 126, 1373-1395, 1998.

D'Ans, J.: Zur Kenntnis der Suaren Sulfate VII. Sulfate und Pyrosulfate des Natrium, Kalium und Ammonium. Z. Allg. Anorg, On the knowledge of acidic sulphate VII. Acid sulphate and pyro-sulphate of sodium, potassium and ammonium, Journal for Inorganic and General Chemistry Ch., 80, 235-245, 1913.

Denman, K. L., Brasseur, G., Chidthaisong, A., Ciais, P., Cox, P.M., Dickinson, R. E., Hauglustaine, D., Heinze, C., Holland, E., Jacob, D., Lohmann, U., Ramachandran, S., da Silva, P. L., Wofsy, S. C., and Zhang, X. Couplings Between Changes in the Climate System and Biogeochemistry, in: Climate Change 2007: The Physical Science Basis. Contribution of Working Group I to the Fourth Assessment Report of the Intergovernmental Panel on Climate Change edited by: Solomon, S., Qin, D., Manning, M., Chen, Z., Marquis, M., Averyt, K. B., Tignor, M., Miller, H. L., Cambridge University Press, Cambridge, UK and New York, USA, 499-587, 2007.

Dentener, F., Drevet, J., Lamarque, J. F., Bey, I., Eickhout, B., Fiore, A. M., Hauglustaine, D., Horowitz, L. W., Krol, M., Kulshrestha, U. C., Lawrence, M., Galy-Lacaux, C., Rast, S., Shindell, D., Stevenson, D., Van Noije, T., Atherton, C., Bell, N., Bergman, D., Butler, T., Cofala, J., Collins, B., Doherty, R., Ellingsen, K., Galloway, J., Gauss, M., Montanaro, V., Muller, J.-F., Pitari, G., Rodriguez, J., Sanderson, M., Solmon, F., Strahan, S., Schultz, M., Sudo, K., Szopa, S., and Wild, O. Nitrogen and sulfur deposition on regional and global scales: A multimodel evaluation, Global Biogeochem. Cy., 20, GB4003, doi:10.1029/2005GB002672, 2006.

Eder, B. and Yu, S.: A performance evaluation of the 2004 release of Models-3 CMAQ, Atmos. Environ., 40, 4811-4824, 2006.

Erisman, J. W., Vanelzakker, B. G., Mennen, M. G., Hogenkamp, H., Zwart, E., Van den Beld, L., Romer, F. G., Bobbink, R., Heil, G., Raessen, M., Duyzer, J. H., Verhage, H., Wyers, G. P., Otjes, R. P., and Möls, J. J.: The Elspeetsche Veldexperiment on surface exchange of trace gases: summary of results, Atmos. Environ., 28, 487-496, 1994a.

Erisman, J.W., Mennen, M., Hogenkamp, J., Kemkers, E., Godhart, D., van Pul, A., Draaijers, G., Duyzer, J., Wyers, P.: Dry deposition monitoring of $\mathrm{SO}_{2}, \mathrm{NH}_{3}$ and $\mathrm{NO}_{2}$ over a coniferous forest, in: Proceedings of EUROTRAC Symposium '94, edited by: Borrell, P. M., Borrell, P., Cvitas, T., and Seiler, W., The Hague, The Netherlands, 655-659, 1994b.

Fenn, R. W., Gerber, H. E., and Wasshuasen, D.. Measurements of the sulphur and ammonium component of the arctic aerosol of the Greenland icecap, J. Atmos. Sci., 20, 466-468, 1963.
Fenn, M. E., Jovan, S., Yuan, F., Geiser, L., Meixner, T., and Gimeno, B. S.: Empirical and simulated critical loads for nitrogen deposition in California mixed conifer forests, Environ. Poll., 155, 492-511, 2008.

Fowler, D., Cape, J. N., Coyle, M., Smith, R. I., Hjellbrekke, A.G., Simpson, D., Derwent, R. G., and Johnson, C. E.: Modelling photochemical oxidant formation, transport, deposition and exposure of terrestrial ecosystems, Environ. Poll., 100, 43 $55,1998$.

Fung, C. S., Misra, P. K., Bloxam, R., and Wong, S.: A numerical experiment on the relative importance of $\mathrm{H}_{2} \mathrm{O}_{2}$ and $\mathrm{O}_{3}$ in aqueous conversion of $\mathrm{SO}_{2}$ to $\mathrm{SO}_{4}$, Atmos. Environ., 25A, 411-423, 1991.

Gilliland, A. B., Appel, K. W., Pinder, R. W., and Dennis, R. L.: Seasonal $\mathrm{NH}_{3}$ emissions for the continental United States: inverse model estimation and evaluation, Atmos. Environ., 40, 4986-4998, 2006.

Gong, W., Dastoor, A. P. , Bouchet, V. S. , Gong, S. , Makar, P. A., Moran, M. D., Pabla, B. , Ménard, S. , Crevier, L.-P. , Cousineau, S., and Venkatesh, S.: Cloud processing of gases and aerosols in a regional air quality model (AURAMS), Atmos. Res., 82, 248275,2006

Gordon, R. J. and Bryan, R. J.: Ammonium nitrate in airborne particles in Los Angeles, Environmental Science and Technology, 7, 645-647, 1973.

Hall, J., Hornung, M., Kennedy, F., Langan, S., Reynolds, B., and Aherne, J.: Investigating the uncertainties in the simple mass balance equation for acidity critical loads for terrestrial ecosystems. Water Air Soil Pollut. Focus, 1, 43-56, 2001.

Heard, M. J. and Wiffen, R. D.: Electron microscopy of natural aerosols and the identification of particulate ammonium sulphate, Atmos. Environ., 3, 337-340, 1969.

Herrmann, H., Ervens, B., Jacobi, H.-W., Wolke, R., Nowack, P., and Zellner, R.: CAPRAM2.3: A Chemical Aqueous Phase Radical Chemistry for Tropospheric Chemistry, J. Atmos. Chem., 36, 231-284, 2000.

Herrmann, H., Tilgner, A., Barzaghi, P., Majdik, Z., Gligorovski, S., Poulain, L., and Monod, A.: Towards a more detailed description of tropospheric aqueous phase organic chemistry: CAPRAM 3.0., Atmos. Environ., 39, 4351-4363, 2005.

Houyoux, M. R., Vukovich, J. M., Coats, C. J. Jr., and Wheeler, N. J. M.: Emission inventory development and processing for the Seasonal Model for Regional Air Quality (SMRAQ) project, J. Geophys. Res., 105, 9079-9090, 2000.

Jeffries, D. S. and Ouimet, R.: Critical loads: are they being exceeded? [In] Chapter 8 of Canadian Acid Deposition Science Assessment 2004, Environment Canada, 4905 Dufferin Street, Downsview, Canada, 440 pp., online available at: http://www. msc-smc.ec.gc.ca/saib/acid/acid_e.html, 2005.

Jeffries, D. S., Lam, D. C. L., Moran, M. D., and Wong, I.: The effect of $\mathrm{SO}_{2}$ emission controls on critical load exceedances for lakes in southeastern Canada, Water Sci. Tech., 39, 165-171, 1999.

Junge, C. E. and Ryan, T. G.: Study of the SO2 oxidation in solution and its role in atmospheric chemistry, Q. J. Roy. Meteor. Soc., 84, 46-55, 1958.

Kaste, $\varnothing$, Henriksen, A., and Posch, M.: Present and potential nitrogen outputs from Norwegian soft water lakes - an assessment made by applying the steady-state First-order Acidity Balance 
(FAB) model, Hydrol. Earth Syst. Sci., 6, 101-112, 2002.

Kusik, C. L. and Meissner, H. P.: Electrolyte activity coefficients in inorganic processing, A.I.Ch.E. Symposium 173, 14-20, 1978.

Logan, J. A.: An analysis of ozonesonde data for the troposphere: Recommendations for testing 3-D models, and development of a gridded climatology for tropospheric ozone, J. Geophys. Res., 104, 16115-16149, 1998.

Luo, C., Zender, C. S., Bian, H., and Metzger, S.: Role of ammonia chemistry and coarse mode aerosols in global climatological inorganic aerosol distributions, Atmos. Environ., 41, 2510-2533, 2007.

MacDonald, A. M., Anlauf, K. G., Leaitch, W. R., and Liu, P. S.: Multi-year Chemistry of Particles and Selected Trace Gases at the Whistler High Elevation Site, EOS Trans., AGU 87(52), Fall Meet., Suppl., Abstract A53b-0179, 2006.

Makar, P. A., Bouchet, V. S., and Nenes, A.: Inorganic chemistry calculations using HETV - a vectorized solver for the $\mathrm{SO}_{4}^{2-}$ $\mathrm{NO}_{3}^{-}-\mathrm{NH}_{4}^{+}$system based on the ISORROPIA algorithms, Atmos. Environ., 37, 2279-2294, 2003.

Mathur, R. and Dennis, R. L.: Seasonal and annual modeling of reduced nitrogen compounds over the eastern United States: Emissions, ambient levels, and deposition amounts, J. Geophys. Res. Atmos., 108, ACH 22-1-ACH 22-19 2003.

McNulty, S. G., Cohen, E. C., Moore Myers, J. A., Sullivan, T. J., and Li, H.: Estimates of critical acid loads and exceedances for forest soils across the conterminous United States, Environ. Pollut., 149, 281-292, 2007.

Moran, M. D., Zheng, Q., Samaali, M., Narayan, J., Pavlovic, R., Cousineau, S., Bouchet, V. S., Sassi, M., Makar, P. A., Gong, W., Gong, S., Stroud, C., and Duhamel, A.: Comprehensive surface-based performance evaluation of a size-and compositionresolved regional particulate-matter model for a one-year simulation. Proc. 29th NATO/SPS ITM on Air Pollution Modelling and Its Application, Aveiro, Portugal, 24-28 Sept., 9 pp., published in Air Pollution Modeling and its Application XIX, 2008, edited by: Borrego, C. and Miranda, A. I., Springer, Dordrecht, The Netherlands, 434-442, 2007.

Moran, M. D., Zheng, Q., Pavlovic, R., Cousineau, S., Bouchet, V. S., Sassi, M., Makar, P. A., Gong, W., and Stroud, C.: Predicted acid deposition critical-load exceedances across Canada from a one-year simulation with a regional particulate-matter model. Proc. 15th Joint AMS/A\&WMA Conf. on Applications of Air Pollution Meteorology, 21-24 January, New Orleans, American Meteorological Society, Boston, 20 pp., online available at: http://ams.confex.com/ams/pdfpapers/132916.pdf, 2008.

Neirynck, J., Kowalski, A. S., Carrara, A., Ceulemans, R.: Driving forces for ammonia fluxes over mixed forest subjected to high deposition loads, Atmos. Environ., 39, 5013-5024, 2005.

Pinder, R. W., Adams, P. J., and Pandis, S. N.: Ammonia emission controls as a costeffective strategy for reducing atmospheric particulate matter in the eastern United States, Environ. Sci. Technol., 41, 380-386, 2007.

Phillips, S. B., Aneja, V. P., Kang, D., and Arya, S. P.: Modelling and analysis of the atmospheric nitrogen deposition in North Carolina, International Journal of Global Environmental Issues, 6, 231-252, 2006.

Pinder, R. W., Gilliland, A. B., and Dennis, R. L.: Environmental impact of atmospheric $\mathrm{NH} 3$ emissions under present and future conditions in the eastern United States, Geophys. Res. Lett., 35,
L12808, doi:10.1029/2008GL033732, 2008.

Quan, J. and Zhang, X.: Assessing the role of ammonia in sulfur transformation and deposition in China, Atmos. Res., 88, 78-88, 2008.

Robbins, R. C. and Cadle, R. D.: Kinetics of the reaction between gaseous ammonia and sulfuric acid droplets in an aerosol, J. Phys. Chem., 62, 469-471, 1958.

Schwarze, P. E., Orevik, J., Lag, M., Refsnes, M., Nafstad, P., Hetland, R. B., and Dybing, E.: Particulate matter properties and health effects: Consistency of epidemiological and toxicological studies, Human and Experimental Toxicology, 25, 559-579, 2006.

Scire, J. S., Lurmann, F. W., Karamchandani, P., Venkatram, A., Yamartino, R., Young, J., and Pleim, J.: ADOM/TADAP Model Development Program, Volume 9: User's Guide, Environmental Research and Technology, Inc., Newbury Park, California, USA, 1986.

Seinfeld, J. H. and Pandis, S. N.: Atmospheric chemistry and physics: from air pollution to climate change, John Wiley and Sons, Inc., New York, USA, 1326 pp., 1998.

Spranger, T., Hettelingh, J.-P., Slootweg, J., Posch, M.: Modelling and mapping long-term risks due to reactive nitrogen effects: An overview of LRTAP convention activities, Environ. Pollut., 154, 482-487, 2008.

Spurny, K. and Heard, M. J.: Discussions: Electron microscopy of natural aerosols and the identification of particulate ammonium sulphate. Atmos. Environ., 3, 483, 1969.

Stelson, A. W., Friedlander, S. K. and Seinfeld, J. H.: A note on the equilibrium relationship between ammonia and nitric acid and particulate ammonium nitrate, Atmos. Environ., 13, 369-371, 1979.

Stilg, M.: World-wide limits for toxic and hazardous chemicals Noyes Publications, NJ, USA, 792 pp., 1994.

Stockwell, W. R. and Calvert, J. G.: The mechanism of the $\mathrm{HO}-\mathrm{SO}_{2}$ reaction, Atmos. Environ., 17, 2231-2235, 1983.

Sutton, M. A., Asman, W. A. H., SchjoØrring, J. K.: Dry deposition of reduced nitrogen, Tellus 46, 255-273, 1994.

Tanner, R. L.: An ambient experimental study of phase equilibrium in the atmospheric system: aerosol $\mathrm{H}^{+}, \mathrm{NH}_{4}^{+}, \mathrm{SO}_{4}^{2-}, \mathrm{NO}_{3}^{-}$, $\mathrm{NH}_{3}(\mathrm{~g}), \mathrm{HNO}_{3}$ (g), Atmos. Environ., 16, 2935-2942, 1983.

Tsimpidi, A. P., Karydis, V. A., and Pandis, S. N.: Response of Inorganic Fine Particulate Matter to Emission Changes of Sulfur Dioxide and Ammonia: The Eastern United States as a Case Study, J. Air Waste Manage. Assoc., 57, 1489-1498, 2007.

Van Hove, L. W. A., Adema, E. H., Vredenberg, W. H., and Pieters, G. A.: A study of the adsorption of $\mathrm{NH}_{3}$ and $\mathrm{SO}_{2}$ on leaf surfaces. Atmos. Environ., 23, 1479-1486, 1989.

Venkatram, A. and Karamchandani, P. K.: Testing a comprehensive acid deposition model. Atmospheric Environment, 22, 737-747, 1988.

Wang, J., Deeter, M. N., Gille, J. C., and Bailey, P. L.: Retrieval of tropospheric carbon monoxide profiles from MOPITT: Algorithm description and retrieval simulation, Proc. SPIE - Int. Soc. Opt. Eng., 3756, 437-446, 1999.

Wang, Z., Xie, F., Sakurai, T., Ueda, H., Han, Z., Carmichael, G. R., Streets, D., Engardt, M., Holloway, T., Hayami, H., Kajino, M., Thongboonchoo, N., Bennet, C., Park, S. U., Fung, C., Chang, A., Sartelet, K., and Amann, M.: MICS-Asia II: Model intercomparison and evaluation of acid deposition, Atmos. Environ., 
42, 3528-3542, 2008.

West, J. J., Ansari, A. S., and Pandis, S. N.: Marginal PM 2.5 : Nonlinear aerosol mass response to sulfate reductions in the eastern United States, J. Air Waste Manage. Assoc., 49, 1415-1424, 1999.

Wright, R. F., Alewell, C., Cullen, J. M., Evans, C. D., Marchetto, A., Moldan, F., Prechtel, A., and Rogora, M.: Trends in nitrogen deposition and leaching in acid-sensitive streams in Europe, Hydrol. Earth Syst. Sci., 5, 299-310, 2001,

http://www.hydrol-earth-syst-sci.net/5/299/2001/.

Ying, Q. and Kleeman, M. J.: Source contributions to the regional distribution of secondary particulate matter in California. Atmos. Environ., 40, 736-752, 2006.
Yu, S., Dennis, R., Roselle, S., Nenes, A., Walker, J., Eder, B., Schere, K., Swall, J., and Robarge, W.: An assessment of the ability of three-dimensional air quality models with current thermodynamic equilibrium models to predict aerosol $\mathrm{NO}_{3}^{-}$. J. Geophys. Res., 110, doi:10.1029/2004JD004718, 22 pp., 2005.

Zhang, L., Gong, S., Padro, J., and Barrie, L.: A size-segregated particle dry deposition scheme for an atmospheric aerosol module. Atmos. Environ., 35, 549-560, 2001.

Zhang, L., Moran, M. D., Makar, P. A., Brook, J. R., and Gong, S.: Modelling gaseous dry deposition in AURAMS: a unified regional air-quality modelling system. Atmos. Environ., 36, 537560, 2002. 